\title{
Sisteınas de localização dinâmica de serviços em ambientes de computação móvel
}

Leonardo Marques Alves de Pinho

DisSERTAÇÃo APRESENTADA AO INSTITUTO DE MATEMÁtICA E

ESTATÍSTICA DA

Universidade de SÃo Paulo

COMO PARTE DOS REQUISITOS

PARA OBTENÇÃO DO GRAU DE

Mestre em Ciência da ComputaÇÃo

Área de Concentração: Computação Móvel

Orientador: Prof. Dr. Alfrero Goldman

- São Paulo - Novembro de 2003 - 


\title{
Sistemas de localização dinâmica de serviços em ambientes de computação móvel
}

\author{
Este exemplar corresponde à redação final \\ da tese de mestrado devidamente \\ corrigida e defendida por \\ Leonardo Marques Alves de Pinho \\ e aprovada pela comissão julgadora.
}

São Paulo, 14 de novembro de 2003.

Banca examinadora:

- Prof. Dr. Alfredo Goldman vel Lejbman (Orientador) - IME-USP

- Prof. Dr. Edmundo R. M. Madeira - IC-UNICAMP

- Prof. Dr. Fabio Kon - IME-USP

- Prof. Dr. Antonio A. F. Loureiro - UFMG

- Prof. Dr. Marco Dimas Gubitoso - IME-USP 
Aos meus pais Albino e Maria Angelina e meus irmãos Américo e Fernando 


\section{Agradecimentos}

Meus sinceros agradecimentos ao meu orientador, Alfredo Goldman, pela sua forma paciente e dedicada com que me orientou. Sempre disposto e participativo me ajudou muito durante todo o curso.

Agradeço também à professora Dilma M. Silva, que foi minha tutora durante a graduação, e me ajudou a obter com sucesso o título de bacharel em ciência da computação neste instituto.

Ao professor Carlos E. Ferreira pela sua conduta e ótima didática de suas aulas, com as quais aprendi muito, e pela sua paciência em ajudar os alunos.

Aos meus pais, Albino e Angelina, pela dedicação e carinho. Aos meus irmãos, Fernando e Américo, sempre presentes e prestativos.

À minha namorada, Guta, pelo seu apoio e dedicação.

Aos meus amigos, Alexandre Barbosa, Cynthia Cardoso, Luciano Kubo, Luis Endo, Marcelo Vinagreiro e Ricardo Oliveira, que me apoiaram e incentivaram durante todo o decorrer do curso. 


\section{Resumo}

Um dos desafios atuais, com o aumento do número de serviços em uma rede, é a localização dinâmica dos mesmos. Várias tecnologias de localização de serviços foram desenvolvidas para simplificar o seu uso, permitindo que eles sejam encontrados, configurados e usados com um mínimo de esforço.

Entretanto, não encontramos nenhum sistema que selecione o servidor mais conveniente ao cliente, como o mais próximo a ele. Apresentamos uma solução para estender os sistemas existentes, integrando-os com sistemas de localização física de unidades móveis, a fim de localizar o serviço mais próximo, segundo algum critério configurável, ao cliente.

Acreditamos que isso incentivará a criação de serviços sensíveis à localização (location-aware), como o de impressão, ou de um guia turístico virtual, entre outros.

Palavras-Chave: sistemas de descoberta de serviços, localização de unidades móveis, sistemas sensíveis à localização, computação ubíqua. 


\begin{abstract}
One of the current challenges, with the increasing number of services in a network, is the dynamic discovery of the services. Service location technologies have been developed to simplify their use, in such way that they can be found, configured, and used with a little effort.

However, to the best of our knowledge, there are no systems which select the most convenient server to the clients, such as the nearest one. We present a solution to extend existing systems, integrating them with physical location systems of mobile units; this is done to find the nearest service to the client.

We believe that this will stimulate the creation of location-aware services, such as printing services, virtual tourist guides, among others.
\end{abstract}

Keywords: service discovery, location systems, location-aware applications, pervasive computing. 


\section{Conteúdo}

Agradecimentos .................................. iv Resumo .......................... . . . . .

Abstract .................................

Lista de Figuras $\quad$ xi

Lista de Tabelas $\quad$ xiii

Lista de Códigos Fonte xiv

1 Introdução $\quad 15$

1.1 Motivação . . . . . . . . . . . . . . . . . . . . 16

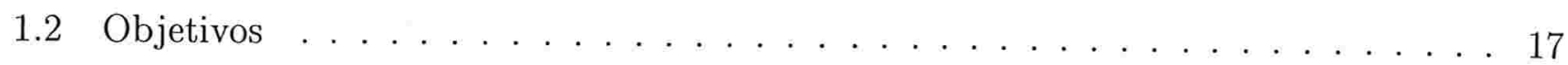

2 Tecnologias $\quad 19$

2.1 Visão Geral . . . . . . . . . . . . . . . . . . . . . . . . . . . . . . 19

2.2 Modelo com Gerenciador de Serviços . . . . . . . . . . . . . . . . . . 20

2.2 .1 Fase de Inicialização . . . . . . . . . . . . . . . . . . . . . . . 20

2.2 .2 Fase de Consulta . . . . . . . . . . . . . . . . . . . 22

2.2 .3 Fase de Seleção . . . . . . . . . . . . . . . . . . . . . . 22

2.2 .4 Fase de Configuração . . . . . . . . . . . . . . . . . . . 23

2.3 Modelo sem Gerenciador de Serviços . . . . . . . . . . . . . . . . . . . . 23

2.3 .1 Fase de Consulta . . . . . . . . . . . . . . . . . . 23

2.3 .2 Fase de Seleção . . . . . . . . . . . . . . . . . . . . . . . 23

2.3 .3 Fase de Configuração . . . . . . . . . . . . . . . . . . . . . 23

2.4 Análise . . . . . . . . . . . . . . . . . . . . . . . . . 24 
3 Principais Arquiteturas $\quad 25$

3.1 Service Location Protocol (SLP) . . . . . . . . . . . . . . . . . . 25

3.1 .1 Arquitetura . . . . . . . . . . . . . . . . . 26

3.1 .2 Modelos de Interação e Operações . . . . . . . . . . . . . . . . . . . 27

3.1 .3 Análise . . . . . . . . . . . . . . . . . . . . 31

3.2 Jini Network Technology . . . . . . . . . . . . . . . . . . . . . . 32

3.2 .1 Arquitetura . . . . . . . . . . . . . . . . . 32

3.2 .2 Funcionamento . . . . . . . . . . . . . . . . 33

3.2 .3 Análise . . . . . . . . . . . . . . . . . . . . . 38

4 Outras Arquiteturas $\quad 40$

4.1 Salutation . . . . . . . . . . . . . . . . . . . 40

4.1 .1 SLM - API . . . . . . . . . . . . . . . . . 41

4.1 .2 Análise . . . . . . . . . . . . . . . . . . 42

4.2 Microsoft Universal Plug and Play (UPnP) . . . . . . . . . . . . . . . . . . 42

4.2 .1 Arquitetura . . . . . . . . . . . . . . . . . . 43

4.2 .2 Análise . . . . . . . . . . . . . . . . . . 46

4.3 Bluetooth Service Discovery Protocol (SDP) . . . . . . . . . . . . . 46

4.3 .1 Rede Bluetooth . . . . . . . . . . . . . . . . . . 46

4.3 .2 Arquitetura . . . . . . . . . . . . . . . . 47

4.3 .3 Service Discovery Protocol . . . . . . . . . . . . . . . . 48

4.3 .4 Análise . . . . . . . . . . . . . . . . . . . . 49

4.4 Quadro Comparativo . . . . . . . . . . . . . . . . . . 50

5 Sistemas de Localização de Unidades Móveis $\quad 52$

5.1 Visão Geral . . . . . . . . . . . . . . . . . . . . . . . . . 5 52

5.2 Funcionamento . . . . . . . . . . . . . . . . . . . . 53

5.2 .1 Triangulação . . . . . . . . . . . . . . . . . . . 53

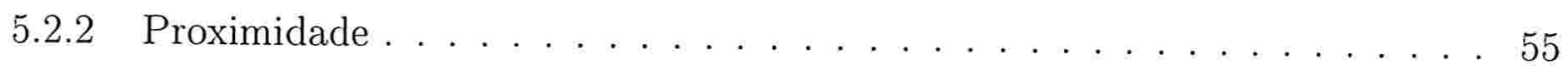

5.2 .3 Análise de Cenas . . . . . . . . . . . . . . . . . . 55

5.3 Propriedades . . . . . . . . . . . . . . . . . . . . 56

5.3 .1 Localização Física e Simbólica . . . . . . . . . . . . . . . . . . . 56 
5.3 .2 Posição Absoluta ou Relativa . . . . . . . . . . . . . . . . . . . 57

5.3 .3 Exatidão e Precisão . . . . . . . . . . . . . . . . . . . . . . . 57

5.3 .4 Ambientes Externos e Internos . . . . . . . . . . . . . . . . . . 57

5.3 .5 Cálculo Local da Localização . . . . . . . . . . . . . . . . . . . . 57

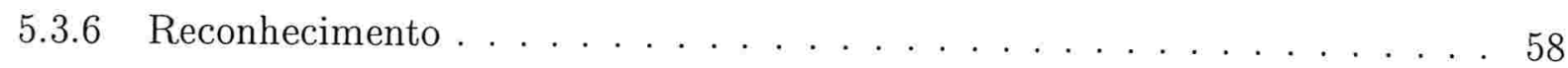

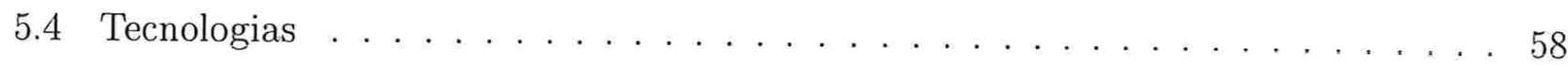

5.4 .1 Active Badge . . . . . . . . . . . . . . . . . . . 58

5.4 .2 Active Bat . . . . . . . . . . . . . . . . . . 59

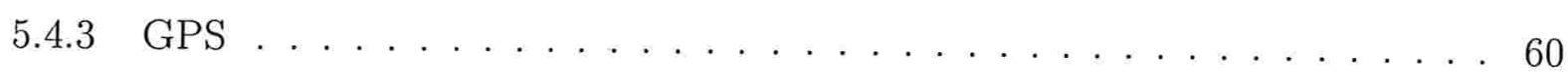

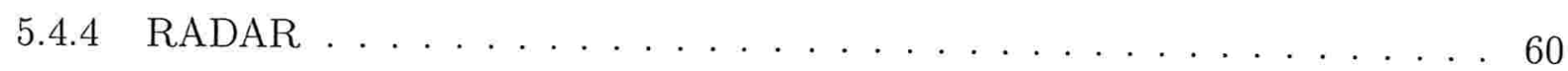

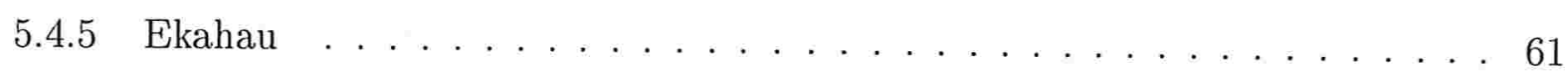

5.4 .6 Tecnologia Utilizada . . . . . . . . . . . . . . . . . . 61

5.5 Ekahau Positioning Engine . . . . . . . . . . . . . . . . . . 62

5.5 .1 Funcionamento . . . . . . . . . . . . . . . 63

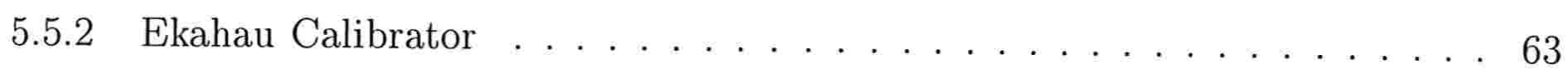

5.5 .3 Ekahau Manager ... . . . . . . . . . . . . . . . 65

5.5.4 Ekahau Positioning Engine . . . . . . . . . . . . . . . 66

5.5 .5 Ekahau Device Service . . . . . . . . . . . . . . . . . 68

5.6 Conclusão . . . . . . . . . . . . . . . . . . . . . . . 69

6 Implementação $\quad 70$

6.1 Protótipo . . . . . . . . . . . . . . . . . . . 70

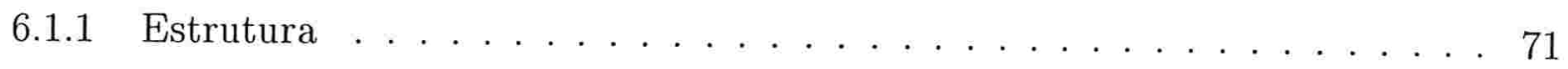

6.1 .2 Impressão . . . . . . . . . . . . . . . . . . . . . . 71

6.1 .3 Localização . . . . . . . . . . . . . . . . . . . . . . . . . 72

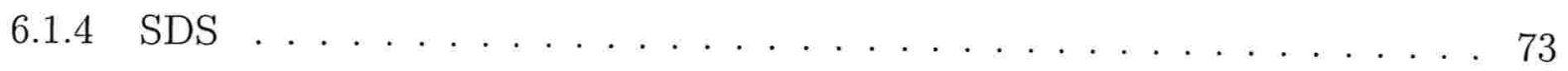

6.1 .5 Dispositivo Móvel . . . . . . . . . . . . . . . . . . . . . . 82

6.2 Exemplo de Uso . . . . . . . . . . . . . . . . . . . . . . 85

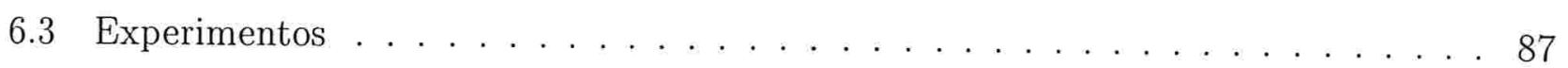

6.3 .1 Ambiente de Desenvolvimento . . . . . . . . . . . . . . . . 87

6.3 .2 Utilização do Sistema . . . . . . . . . . . . . . . . . . . . . . 87

6.3 .3 Experimentos Realizados . . . . . . . . . . . . . . . . . . 90 
7 Considerações Finais

7.1 Trabalho Futuro . . . . . . . . . . . . . . . . . . . . . . . 94

Glossário

Referências Bibliográficas 


\section{Lista de Figuras}

1.1 Empresas que desenvolvem sistemas de localização . . . . . . . . . . . . . . . 18

2.1 Operações no modelo com gerenciador de serviços . . . . . . . . . . . . . . . . 21

2.2 Operações no modelo sem gerenciador de serviços . . . . . . . . . . . . . 23

3.1 Cabeçalho binário de uma mensagem no SLP . . . . . . . . . . . . 26

3.2 Principais operações no SLP . . . . . . . . . . . . . . . . . . . . 29

3.3 Fase de consulta no SLP . . . . . . . . . . . . . . . . . 31

3.4 Representação da arquitetura do Jini . . . . . . . . . . . . . . . . . . 33

3.5 Operações no Jini . . . . . . . . . . . . . . . . . . . . . 37

4.1 Arquitetura do Salutation . . . . . . . . . . . . . . . . . . 41

4.2 Arquitetura do Bluetooth . . . . . . . . . . . . . . . . . 48

5.1 Técnica de localização baseada na lateração . . . . . . . . . . . . . . . . . 54

5.2 Técnica de localização baseada na angulação . . . . . . . . . . . . . . 55

5.3 Gráfico comparativo da precisão do Ekahau . . . . . . . . . . . . . . . . . . 62

5.4 Arquitetura do Ekahau Positioning Engine . . . . . . . . . . . . . . . . 64

5.5 Mapa contendo as áreas lógicas lidas pelo Ekahau . . . . . . . . . . . . . . . 64

6.1 Estrutura da mensagem SrvRqstWithLocation . . . . . . . . . . . . . 75

6.2 Diagrama de atividades do protótipo . . . . . . . . . . . . 86 
6.3 Coleta de pontos de amostra no Ekahau . . . . . . . . . . . . . . . . . . 91

6.4 Localizando uma unidade móvel no Ekahau . . . . . . . . . . . . . . . . . 92 


\section{Lista de Tabelas}

3.1 Campos do cabeçalho de uma mensagem no SLP . . . . . . . . . . . . . 27

3.2 Mensagens do SLP e suas descrições . . . . . . . . . . . . . . . . . . 27

4.1 Métodos do API Salutation . . . . . . . . . . . . . . . . . . 42

4.2 Representação dos dados de um serviço no SDP . . . . . . . . . . . . . . . . 49

4.3 Quadro comparativos dos SDSs . . . . . . . . . . . . . . . . 50

5.1 Tecnologias de localização de unidades móveis . . . . . . . . . . . . . . . . 61

5.2 Módulos do Ekahau . . . . . . . . . . . . . . . . . . . . 63

6.1 Divisão de pacotes do sistema . . . . . . . . . . . . . . . . . 71

6.2 Classes do serviço de impressão . . . . . . . . . . . . . . . . . . 72

6.3 Classes do módulo de localização . . . . . . . . . . . . . . . . 73

6.4 Divisão de pacotes no subsistema SLP . . . . . . . . . . . . . . . . . 74

6.5 Principais classes do subsistema SLP . . . . . . . . . . . . . . 78

6.6 Divisão de pacotes no subsistema Jini . . . . . . . . . . . . . . . 78

6.7 Principais classes do subsistema Jini . . . . . . . . . . . . . . . . . . . . . 82

6.8 Divisão de pacotes do cliente Palm . . . . . . . . . . . . . . . . . 84

6.9 Principais classes do cliente Palm . . . . . . . . . . . . . . . . . 85

6.10 Ambiente utilizado . . . . . . . . . . . . . . . . . . 88 


\section{Lista de Códigos Fonte}

3.1 Localização do Lookup Service . . . . . . . . . . . . . . . . . . . . . . 34

3.2 Registro do Service Provider . . . . . . . . . . . . . . . . . 36

3.3 Consulta um Service Provider . . . . . . . . . . . . . . . . . . 38

4.1 Mensagem HTTP do anúncio de um serviço no UPnP . . . . . . . . . . . . . 43

4.2 Mensagem HTTP de uma consulta no UPnP . . . . . . . . . . . . . . . . 44

4.3 Descrição XML de um serviço no UPnP . . . . . . . . . . . . . . . . . . . 44

4.4 Exemplo do acesso a um serviço no UPnP . . . . . . . . . . . . . . 45

5.1 Cliente do Ekahau Positioning Engine . . . . . . . . . . . . . . . 67

5.2 Cliente do Ekahau com áreas lógicas . . . . . . . . . . . . . . 68

6.1 Implementação do Service Agent . . . . . . . . . . . . . . . 76

6.2 Implementação do User Agent . . . . . . . . . . . . . . . . . . 77

6.3 Implementação da AttrServiceLocation . . . . . . . . . . . . . . . . 79

6.4 Implementação do proxy do serviço . . . . . . . . . . . . . . . . 80

6.5 Implementação do cliente no Jini . . . . . . . . . . . . . . . . . 81

6.6 Interface de dados do Palm . . . . . . . . . . . . . . . . . 84 


\section{Capítulo 1}

\section{Introdução}

Uma rede de computadores, em particular a Internet, é um conjunto de subredes e computadores interligados. Ela oferece aos seus usuários um enorme potencial para o compartilhamento de recursos, tais como documentos, programas, dados e, principalmente, serviços. No contexto deste texto, definiremos serviço como uma coleção de componentes distribuídos colaborando entre si, a fim de disponibilizar um recurso ao cliente, seja ele físico, como uma impressora, ou lógico, como um envio de e-mail. Além desses serviços básicos, estão surgindo novos serviços a cada dia.

Nesse ambiente, mecanismos para descoberta de serviços tornam-se extremamente importantes. Sem eles, os usuários utilizam uma fração muito pequena dos recursos de uma rede, por falta de conhecimento dos seus serviços.

Outro fator importante para a utilização dos serviços de uma rede é a forma de acesso a estes. Idealmente, os usuários gostariam de acessar os serviços automaticamente, sem a necessidade de reconfigurar o seu sistema, como instalar drivers manualmente, ou procurä o endereço (por exemplo: IP) do servidor. Assim, é importante que os serviços sejam acessados com o mínimo de esforço, ou seja, com a menor reconfiguração possível no dispositivo do cliente que deseja utilizar o serviço.

Esse cenário se torna mais problemático quando analisamos as redes sem fio e suas respectivas unidades móveis ${ }^{1}$ (UMs). Nesse tipo de rede, muito comum ultimamente, os clientes mudam freqüentemente e por isso não tem conhecimento dos serviços disponíveis na rede e nem de que

\footnotetext{
${ }^{1}$ Denotaremos unidade móvel um usuário portando um dispositivo conectado a uma rede sem fio.
} 
forma acessá-los.

Isso aumenta a quantidade de tarefas do administrador da rede, que precisa reconfigurar cada novo elemento, para que este tenha acesso aos recursos da mesma. Além disso, como as unidades são móveis, em cada local (subrede) que o usuário estiver, será necessário realizar novamente esse trabalho de configuração.

\subsection{Motivação}

Imagine um usuário que deseja imprimir um arquivo do seu dispositivo móvel (Palm, IPaq, etc.) conectado a uma rede sem fio de um prédio comercial. Na maioria das vezes, o usuário precisa contactar o administrador da rede para descobrir o endereço da impressora mais próxima, suas características e a respectiva forma de acesso.

Seria interessante, se existisse um sistema em que o usuário simplesmente informasse o interesse pelo serviço de impressão, e o sistema automaticamente encontrasse a impressora mais próxima a ele de acordo com a sua localização, e ainda, reconfigurasse o seu dispositivo para que fosse possível a utilização da mesma. Existem outros aspectos do problema, tais como a permissão de acesso aos serviços, eventuais formas de pagamento pela sua utilização, mas que fogem do escopo dessa dissertação.

Um outro exemplo interessante é uma sala de conferência em que o palestrante possui a sua apresentação em um dispositivo móvel e deseja enviá-la, através da rede sem fio existente, para o projetor da sala, que está conectado à rede física do auditório. Gostaríamos que o usuário acessasse um sistema informando o seu interesse de utilizar o serviço de projeção, e a sua unidade móvel fosse automaticamente reconfigurada para ter acesso transparente ao projetor, sem nenhuma intervenção administrativa manual. Além disso, seria possível disponibilizar em tempo real o arquivo da apresentação para os outros presentes na palestra portadores de dispositivos móveis.

Assim, o cenário ideal é uma rede que se auto gerencie, onde novos dispositivos e serviços sejam adicionados e recursos sejam utilizados, sem nenhuma intervenção administrativa, de forma análoga à tecnologia plug and play [9]. Para isso, é necessário que as aplicações sejam sensíveis ao contexto (context-aware), reconfigurando-se automaticamente conforme o local em que se 
encontram.

\subsection{Objetivos}

Apresentaremos um sistema sensível à localização (location-aware) em que o usuário simplesmente informa o interesse por um determinado serviço da rede e a aplicação automaticamente encontra o servidor mais próximo a ele. Ademais, o sistema reconfigurará a unidade móvel para que esta acesse o serviço sem nenhuma intervenção administrativa.

Utilizaremos uma rede sem fio no padrão IEEE 802.11b [32] e para testar a solução apresentada, utilizaremos como exemplo a implementação de um serviço de impressão. No entanto a solução aqui apresentada se adequa a qualquer tipo de serviço. Com isso, esperamos criar uma arquitetura para redes sem fio em que novos serviços sensíveis a localização possam ser criados e disponibilizados na rede rapidamente, sem que o desenvolvedor tenha que se preocupar em como o serviço será encontrado e acessado pelo cliente ou em como obter a localização da unidade móvel.

Assim, para desenvolver o sistema foi necessário solucionar dois problemas principais: a) como prover um mecanismo de busca e acesso transparente aos serviços; b) como obter a localização das unidades móveis em uma rede sem fio.

Atualmente existem no mercado várias tecnologias que visam resolver o problema a), são os chamados sistemas de descoberta de serviços (SDS), como mostra a figura 1.1. Eles permitem a localização dinâmica dos serviços disponíveis em uma rede e o acesso transparente a eles, sem nenhuma intervenção manual.

O Jini [26] é uma tecnologia desenvolvida pela Sun Microsystems, utilizando a linguagem Java e, fortemente, a sua camada para objetos distribuídos, RMI - Remote Method Invocation; o Service Location Protocol (SLP) [40] foi desenvolvido pelo IETF SrvLoc working group e foi projetado para ser executado em redes locais TCP/IP; o Universal Plug and Play [4] é uma arquitetura proprietária que está sendo desenvolvida pela Microsoft; o Salutation [38], por sua vez, está sendo desenvolvido por um consórcio aberto, chamado Salutation Consortium; assim como o Bluetooth Service Discovery Protocol [44], que foi criado por um consórcio de empresas de telecomunicações. 
No próximo capítulo descrevemos de forma genérica o funcionamento de um sistema para localização dinâmica de serviços. Nos capítulos 3 e 4, detalhamos algumas das principais tecnologias existentes, citadas acima. No capítulo 5 , explicamos a solução encontrada para o problema b), de localização das unidades móveis. No capítulo 6, por sua vez, descrevemos o protótipo construído, integrando as soluções apresentadas e apresentamos as modificações realizadas nas mesmas. Finalmente, no último capítulo, apresentamos algumas considerações finais e idéias para trabalhos futuros.

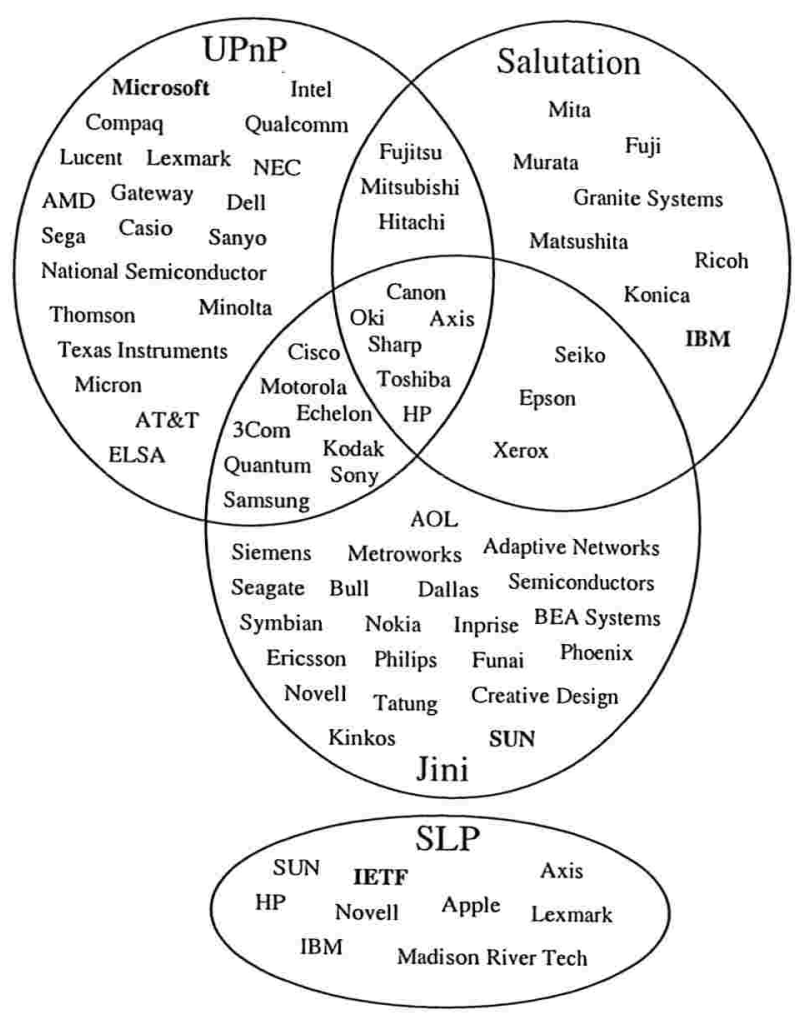

Figura 1.1: Empresas que participam do desenvolvimento do Jini, SLP, UPnP e Salutation. 


\section{Capítulo 2}

\section{Tecnologias}

Neste capítulo descreveremos modelos genéricos para protocolos de localização de serviços, que abrangem algumas características comuns dos sistemas existentes. Estes modelos contém dois ou três elementos: cliente, fornecedor do serviço e, opcionalmente, um gerenciador de serviços.

No modelo sem gerenciador de serviços toda comunicação é feita diretamente entre os clientes e os provedores de serviços. No modelo com três elementos, por sua vez, o gerenciador de serviços é responsável por intermediar o acesso aos provedores.

\subsection{Visão Geral}

As tecnologias para descoberta de serviços foram desenvolvidas visando reduzir a complexidade da utilização dos serviços, e assim, simplificar o uso de dispositivos móveis em uma rede.

Para isso, essas tecnologias provêem localização dinâmica (on the fly) dos serviços disponíveis. Alguns sistemas também oferecerem mecanismos de divulgação de novos serviços e acesso transparente aos mesmos, atuando como uma "ponte" (middleware) entre o usuário e o provedor do serviço. Sistemas mais avançados fornecem ainda um "esqueleto" para a implementação de serviços, servindo como um arcabouço para a criação dos mesmos.

Todas as tecnologias de descoberta de serviços possuem um sistema de catálogo, equivalente a uma lista de classificados ou "páginas amarelas", para que o cliente tenha conhecimento dos serviços disponíveis na rede ou procure por algum serviço específico, através do seu tipo ou 
propriedade $^{1}$. Essa forma centralizada de armazenar referências aos serviços estimula a integração dos mesmos, criando comunidades espontâneas. Por exemplo, uma câmera ligada à rede envia uma foto para uma impressora.

Por segurança, os sistemas oferecem mecanismos de tolerância a falhas e exclusão automática de serviços inacessíveis, mantendo a sua lista de serviços disponíveis relativamente atualizada.

Em todos os cenários descritos existem pelo menos dois elementos: o usuário do serviço e o provedor do serviço. Em alguns sistemas, há um elemento intermediário entre as requisições dos clientes e as respostas dos provedores, geralmente chamado de gerenciador de serviços. Para referenciar esses elementos utilizaremos a seguinte abreviação: C - Cliente, SP - Provedor de Serviço e SM - Gerenciador de Serviços.

Conforme o número de participantes, com ou sem SM, teremos que considerar duas arquiteturas ou modelos de interação. Para cada caso, teremos diferentes fases do protocolo, que descrevemos a seguir:

- Fase de Inicialização ${ }^{2}$;

- Fase de Consulta;

- Fase de Seleção;

- Fase de Configuração.

\subsection{Modelo com SM}

Como foi dito anteriormente, a principal função do SM é atender às requisições do cliente e encontrar os serviços disponíveis de acordo com o tipo requisitado ou através das características do serviço descritas pelo cliente (modo opcional). Um esquema resumido do seu funcionamento é mostrado na figura 2.1.

\subsubsection{Fase de Inicialização}

- Localização do SM

\footnotetext{
${ }^{1}$ Esse tipo de busca só está disponível em alguns sistemas.

${ }^{2}$ Essa fase existe apenas no modelo com SM.
} 
Inicialmente é necessário que o cliente, de alguma forma, tenha a informação (endereço) de como acessar um SM da rede em que ele está conectado. Para isso existem quatro possibilidades:

- static: o endereço de um SM é atribuído manualmente;

- active: os clientes e SPs requisitam a localização de um SM (por exemplo, através de multi/broadcast);

- passive: o SM anuncia periodicamente sua localização (por exemplo, através de multi/broadcast);

- dhcp: pode-se adaptar o DHCP [39], para que este forneça um SM responsável por aquela rede.

Uma observação importante: o modo passive pode aumentar bastante o tráfego na rede, dependendo do período escolhido, assim como o modo active, considerando-se o número de elementos no sistema. Assim, os três últimos modos são recomendados para redes locais (LAN) e o primeiro para redes globais (WAN), como a Internet.

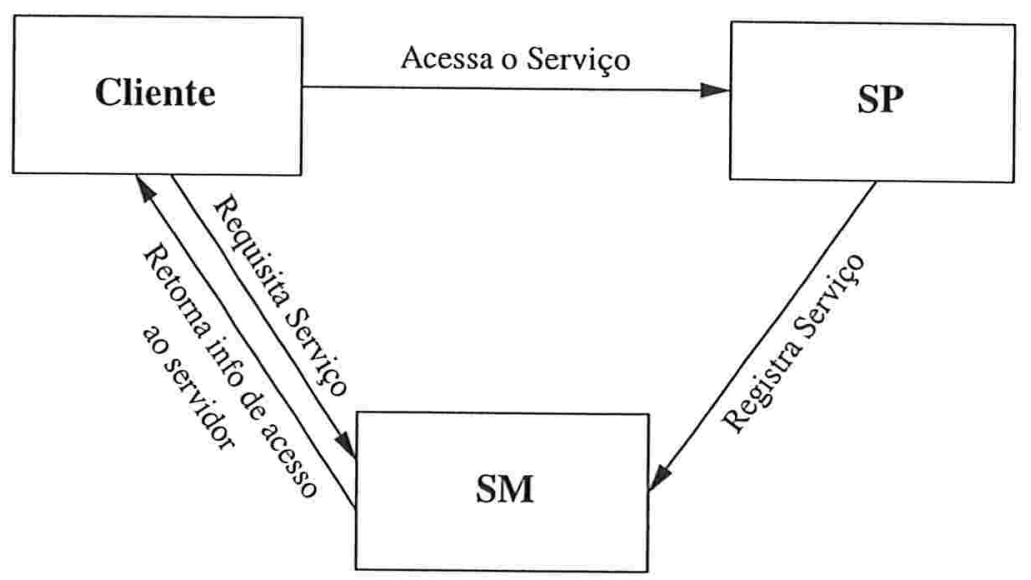

Figura 2.1: Operações no modelo com SM.

\section{- Registro dos SPs}

Cada provedor de serviço, após localizar um SM, deve registrar-se no mesmo, fornecendo as informações necessárias para o seu acesso, e em alguns casos, a lista de atributos (características) que descrevem o serviço. Geralmente existe um mecanismo para a atualização das propriedades do serviço do SP, após o seu registro. 
Os registros podem ser persistentes, ou seja, o SM armazena em memória estável (por exemplo disco rígido) as informações dos SPs disponíveis. Caso ocorra uma interrupção no funcionamento do mesmo, os servidores não precisarão se registrar novamente, mas isso provoca um custo adicional no processo de registro.

\subsubsection{Fase de Consulta}

O cliente informa ao SM sobre o interesse por algum tipo de serviço. Alguns protocolos também permitem a requisição por um serviço com certas características, por exemplo: um serviço de impressão colorida.

\subsubsection{Fase de Seleção}

Nesta fase desejamos selecionar o SP correspondente ao pedido do cliente (C). Vamos dividí-la em duas subfases:

\section{- Subfase de comparação}

Desejamos encontrar o subconjunto de SPs da lista de serviços disponíveis (registrados no SM) que atendem a requisição do cliente.

\section{- Subfase de decisão}

Depois de encontrado o subconjunto, o SM decide como será dada a resposta ao cliente, se irá simplesmente devolver a lista de todos os SPs que atendem o pedido, se escolherá aleatoriamente um SP, ou, o mais apropriado, se utilizará algum critério para a decisão, por exemplo, o SP mais próximo ao cliente.

Infelizmente, nenhum dos sistemas estudados provê a funcionalidade de seleção do servidor mais conveniente ao cliente. A maioria dos sistemas permite apenas que o cliente especifique se deseja receber a lista de todos os servidores ou apenas um servidor que atenda o seu pedido. 


\subsubsection{Fase de Configuração}

Nesta última fase, é modificada a configuração do cliente, para que este possa acessar o serviço encontrado.

\subsection{Modelo sem SM}

Nessa arquitetura temos apenas dois participantes: clientes (C) e provedores de serviços (SP), como mostra a figura 2.2. Por isso, o processo é um pouco mais simples nesta arquitetura, com apenas três fases. Como não existe SM, não temos a fase de inicialização.

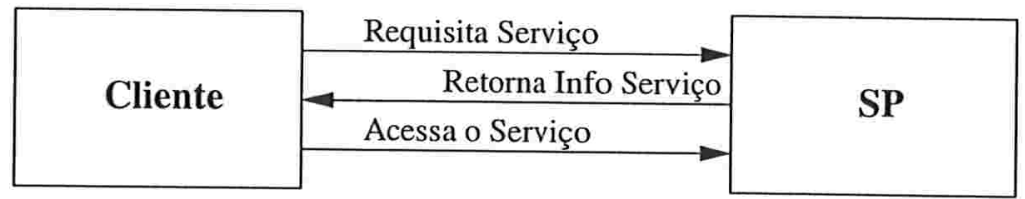

Figura 2.2: Operações no modelo sem SM.

\subsubsection{Fase de Consulta}

O cliente, ao invés de se comunicar diretamente com o SM, se comunica com os SPs indiretamente utilizando a rede (por exemplo, por UDP multicast), enviando a sua requisição. Todos os provedores de serviços que estiverem disponíveis irão processar a requisição.

\subsubsection{Fase de Seleção}

Nesse modelo temos apenas a subfase de comparação, que será executada localmente por cada agente de serviço. Caso ele atenda o pedido do cliente, o SP se comunica diretamente com o cliente (por exemplo, via unicast) fornecendo-lhe as informações de como acessá-lo.

\subsubsection{Fase de Configuração}

Idêntica à fase do modelo com SM, a configuração do cliente é modificada para que este possa acessar o serviço encontrado. 


\subsection{Análise}

A arquitetura sem SM é mais simples, não contempla um repositório de serviços, toda comunicação é feita diretamente entre o cliente e os provedores de serviços. Devido a isso, o tráfego de mensagens de multicast aumenta consideravelmente na rede, prejudicando o desempenho do sistema.

Além disso, devido à falta de um gerenciador de serviços, perdem-se algumas funcionalidades do sistema: não existirá uma lista de serviços disponível na rede, buscas avançadas de serviços não poderão ser utilizadas, qualquer modificação no protocolo em relação à fase de seleção deverá ser realizada em todos os SPs pois essa fase é executada localmente em cada SP da rede.

Assim, o modelo sem SM é indicado para redes pequenas, onde o desempenho não é tão importante e as funcionalidades mais complexas de busca de serviços não serão utilizadas. A arquitetura com SM, por sua vez, é indicada para redes maiores, nas quais o desempenho é essencial e onde o aumento do número de trocas de mensagens poderia ser prejudicial ao funcionamento da rede. 


\section{Capítulo 3}

\section{Principais Arquiteturas}

Neste capítulo apresentaremos os principais sistemas de localização de serviços encontrados na literatura. Primeiramente, explicaremos o funcionamento do Service Location Protocol e em seguida descreveremos as principais características do Jini Network Technology.

O SLP é um sistema simples, desenvolvido pelo IETF sobre TCP/IP para ser utilizado em redes pequenas. O protocolo permite a busca e o registro de serviços, porém a forma de acesso aos mesmos não é contemplada. O Jini, por sua vez, é um sistema mais completo. Desenvolvido pela Sun utilizando a plataforma Java, ele permite ao cliente acessar de forma transparente o serviço desejado.

\subsection{Service Location Protocol (SLP)}

Service Location Protocol foi desenvolvido pelo IETF (Internet Engineering Task Force) para possibilitar que uma aplicação descubra automaticamente a localização de um serviço, incluindo o seu endereço (ou domínio) e outras informações de acesso. Como todos os protocolos do IETF, o SLP é especificado detalhadamente em documentos denominados Request For Comments (RFC) $[12]$.

Em 1997, o Srvloc working group do IETF publicou um RFC [31] com a primeira versão do SLP, que continha algumas inconsistências. Entretanto, em junho de 1999, o Internet Engineering Task Force anunciou a segunda versão do protocolo, adicionando novas funcionalidades, aumentando a segurança e eliminando as inconsistências. 


\subsubsection{Arquitetura}

Sua arquitetura é composta por três agentes, que interagem entre si:

- User Agent (UA), o usuário do serviço, que procura pela localização de um serviço;

- Service Agente (SA), o provedor do serviço, responsável por oferecer um serviço à rede;

- Directory Agent (DA) ${ }^{1}$, o repositório de serviços, que atua como uma central de informação sobre a localização dos serviços existentes na rede.

A comunicação entre os agentes é feita utilizando 11 tipos de mensagens (ver a tabela 3.2) enviadas através do protocolo de comunicação TCP/IP ou do protocolo UDP. A mensagem pode ser enviada para um agente específico (unicast) ou para todos os agentes interessados (multicast). Devemos esclarecer que multicast não é o mesmo que broadcast, pois mensagens de broadcast teoricamente são recebidas por todos os nós da rede, enquanto que mensagens de multicast são recebidas apenas pelos nós interessados nelas, que fazem parte do grupo do multicast.

Além disso, a maioria dos roteadores filtra mensagens de broadcast a fim de reduzir o tráfego na rede. Assim, mensagens desse tipo que forem geradas em uma subrede não serão redirecionadas para outras subredes conectadas ao roteador. Mensagens de multicast, por sua vez, são redirecionadas pelos roteadores se a subrede de destino tem pelo menos um nó interessado na mensagem. Por esses motivos, o SLP foi especificado para utilizar mensagens unicast e multicast.

Todas as mensagens transmitidas são alfa-numéricas precedidas de um cabeçalho binário, como mostra a figura 3.1. O conteúdo da mensagem é composto por strings UTF-8 precedidos de um campo informando o tamanho da série de caracteres.

\begin{tabular}{|c|c|c|c|}
\hline 00 & Version & Func. ID & Length \\
\hline 04 & Length cont. & Flags & Next extension \\
\hline 08 & \multicolumn{2}{|c|}{ Next extension continued } & XID \\
\hline$O C$ & \multicolumn{2}{|c|}{ Language tag length } & Language tag \\
\hline
\end{tabular}

Figura 3.1: Cabeçalho binário de uma mensagem no SLP.

\footnotetext{
${ }^{1}$ Para melhorar o desempenho do sistema, poderá existir mais de um DA na rede. Para simplificar o texto, descreveremos uma rede em que existe apenas um DA. Uma descrição completa pode ser encontrada em [40].
} 
A tabela 3.1 contém a descrição de cada campo do cabeçalho. Para identificar cada requisição realizada é enviado no campo XID um número (identificador) único para cada requisição. No campo (Language Tag) é informada a linguagem utilizada no conteúdo da mensagem.

\begin{tabular}{|l|l|}
\hline Campo do cabeçalho & Descrição \\
\hline \hline Version & Versão do protocolo SLP: 1 ou 2. \\
\hline Length & Tamanho total da mensagem. \\
\hline Function ID & Tipo da mensagem enviada (ver tabela 3.2). \\
\hline Flags & Indica forma de envio da mensagem: uni/multicast. \\
\hline Next extension offset & Offset, em bytes, da primeira extensão SLP. \\
\hline XID & Identificador único para cada requisição. \\
\hline Language tag & Indica a linguagem das strings incluídas na mensagem. \\
\hline Language tag length & Tamanho da string de linguagem. \\
\hline
\end{tabular}

Tabela 3.1: Campos do cabeçalho de uma mensagem no SLP.

Como podemos ver na tabela 3.2, a comunicação entre os componentes do sistema é feita através de pares de mensagens, por exemplo: Service Request (SrvRqst) - Service Reply (SrvRply), Attribute Request (AtrReq) - Attribute Reply (AtrRply), entre outros.

\begin{tabular}{|l|r|l|}
\hline \multicolumn{1}{|c|}{ Mensagem SLP } & ID & \multicolumn{1}{c|}{ Descrição } \\
\hline \hline Service Request (SrvRqst) & 1 & UAs requisitam um serviço \\
\hline Service Reply (SrvRply) & 2 & DA (ou SA) retorna sua URL para o cliente. \\
\hline Service Register (SrvReg) & 3 & SA registra URL e atributos. \\
\hline Service Deregister (SrvDeReg) & 4 & SA pede ao DA a exclusão do seu registro. \\
\hline Service Acknowledgment (SrvAck) & 5 & DA confirma o registro ou exclusão de um serviço. \\
\hline Attribute Request (AttrRqst) & 6 & UAs requisitam a lista de atributos de um serviço. \\
\hline Attribute Reply (AttrRply) & 7 & DA (ou SA) retorna a lista dos atributos pedida. \\
\hline Directory Advertisement (DAAdvert) & 8 & DA envia sua localização (URL). \\
\hline Service Type Request (SrvTypeRqst) & 9 & UAs pedem a lista dos tipos de serviço. \\
\hline Service Type Reply (SrvTypeRply) & 10 & DA (ou SA) retornam a lista de tipos cadastrados. \\
\hline Service Advertisement (SAAdvert) & 11 & SA envia sua URL e atributos para o UA. \\
\hline
\end{tabular}

Tabela 3.2: Tipos de Mensagens do SLP e suas descrições.

\subsubsection{Modelos de Interação e Operações}

O sistema oferece dois modos de operação: quando o DA está presente, ele é responsável por registrar os serviços de um SA e atender as requisições de um UA; no segundo modo, em que o 
DA não está presente, não há registro do serviço e as requisições do UA são feitas diretamente aos SAs da rede, através de mensagens multicast.

\section{Localização do DA}

Inicialmente, para que seja feita qualquer ação neste modelo, por parte do SA ou do UA, é necessário descobrir quem é o DA da rede. A figura 3.2 ilustra os dois diferentes métodos para a localização de um DA: ativo ou passivo.

No modo ativo, os agentes UAs e SAs solicitam a localização de um DA através do envio (via multicast) de uma mensagem de requisição do serviço (SrvRqst), procurando por um tipo especial de serviço: service:directory-agent (pré-definido pelo protocolo). Quando um DA recebe esta mensagem, ele envia (via unicast) para o UA, ou SA, uma mensagem DAAdvert com o seu endereço (IP) atual.

No modo passivo, por sua vez, o DA envia periodicamente uma mensagem DAAdvert (multicast) informando sua localização a todos. Existem outros dois modos que não são muito utilizados: dhcp [39], em que o serviço de DHCP é configurado para informar a localização do DA e o estático, utilizado quando o agente já tem conhecimento prévio do endereço do DA.

\section{Registro de um SA}

No SLP, a localização de um serviço é descrita através de uma Service $U R L^{2}$, que é composta por: endereço IP, número da porta e, dependendo do tipo do serviço, o caminho (path). Os clientes (UAs) recebem essa URL, também chamada de SAP (Service Access Point), e obtém toda informação necessária para se conectar a este serviço.

As características do serviço, por sua vez, são descritas através de uma lista de atributos, definidos pelo par nome/valor. Para os tipos de serviços conhecidos existe um documento chamado Service Templates [5], registrado na IANA (Internet Assigned Numbers Authority), que especifica os atributos e seus valores-padrão para um determinado tipo de serviço. Os SAs utilizam os atributos especificados para descrever o seu serviço, e os UAs os utilizam para procurar um serviço com determinadas características. Isso assegura que os agentes utilizarão o mesmo "vocabulário" durante essas operações.

\footnotetext{
${ }^{2}$ URL é abreviação de Universal Resource Locator.
} 
Como podemos ver na figura 3.2, para que um SA publique o seu serviço, após conhecer o endereço de um DA (executando o protocolo descrito na seção anterior), ele envia uma mensagem SrvReg com as informações descritas anteriormente: tipo de serviço, URL e lista de atributos.

Além dessas informações, o SA também fornece o tempo (lifetime) que deve durar o cadastro, cujo valor não pode ultrapassar 18 horas. Assim, para o SA estar sempre disponível, ele deve se registrar novamente antes que esse tempo expire. Esse procedimento estabelece um mecanismo de tolerância a falhas a fim de assegurar que os serviços publicados estejam acessíveis, pois se um SA tem uma falha, o seu cadastro não será renovado, logo, seu registro será excluído quando o lifetime expirar. Esse mecanismo será mais eficiente quanto menor for o lifetime. Mas aqui temos um compromisso, quanto menor for o tempo, maior será o tráfego de mensagens na rede.

A operação termina quando o DA recebe a mensagem SrvReg íntegra e envia ao SA uma mensagem de confirmação SrvAck do registro do serviço. O SA tem a possibilidade de pedir a exclusão do seu registro a qualquer momento através da mensagem SrvDeReg.

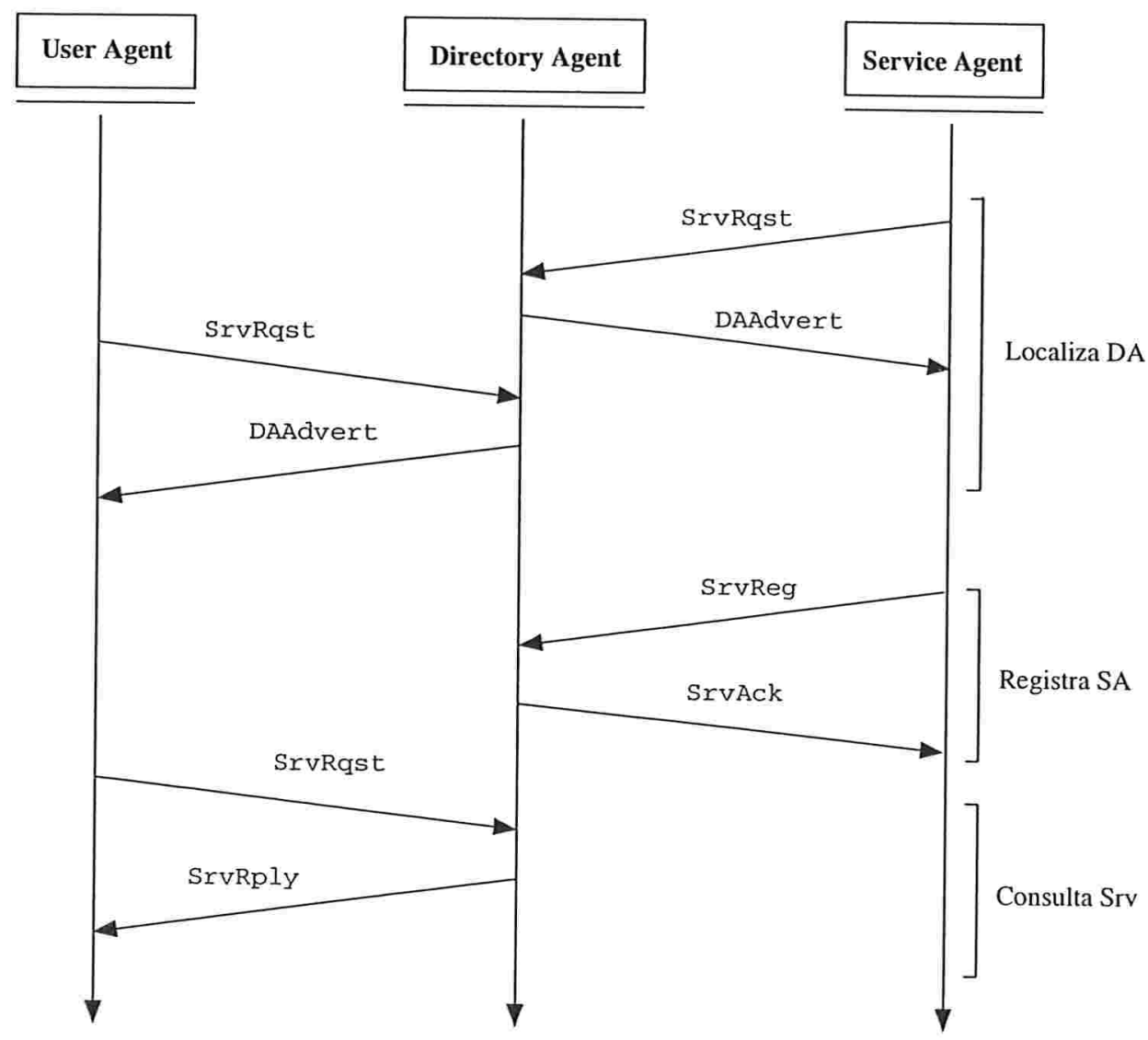

Figura 3.2: Exemplo de troca de mensagens das principais operações. 


\section{Consultas}

No SLP, o usuário não precisa conhecer os nomes ou endereços dos agentes de serviço, ele apenas precisa informar a descrição do serviço em que ele está interessado e, baseado nessa descrição, o SLP retornará o SAP que contém todas as informações de acesso ao respectivo serviço.

Nesta operação, nós teremos diferentes ações de acordo com o modelo adotado: com ou sem DA (ver figura 3.3). No modelo com DA, o cliente (UA), que já obteve o endereço do DA na fase de inicialização, envia a este uma mensagem (unicast) SrvRqst, informando o tipo de serviço procurado e, opcionalmente, as características (atributos) que o serviço deve ter.

Quando o DA recebe uma mensagem de SrvRqst, que não seja do tipo especial especificado service:directory-agent (ver seção 3.2.1), ele realiza uma busca no seu repositório por serviços que atendam à requisição. Em seguida, o DA envia uma mensagem (unicast) SrvRply contendo todas as URLs dos SAs que atendem ao pedido, ou uma mensagem com conteúdo vazio, caso não encontre nenhum SA para a requisição realizada.

No modelo sem DA, por sua vez, um UA envia a mensagem SrvRqst (multicast) para os SPs da rede, que analisam a requisição. Caso satisfaça o pedido, o SP responderá enviando uma mensagem (unicast) SAAdvert contendo a sua URL de acesso. No momento em que o UA recebe as URLs dos SAs, ele obtém a informação necessária para se conectar ao servidor. Entretanto, o protocolo utilizado entre o cliente e o servidor está fora do escopo da especificação do SLP.

Além dessa operação principal de consulta, o cliente ainda pode realizar duas consultas secundárias: tipos de serviços ou atributos de um serviço. A consulta dos tipos de serviços é bem simples: o UA envia uma mensagem de SrvTypeRqst para o DA, que responde através de uma mensagem SrvTypeRply contendo a lista dos tipos de serviços disponíveis. Na consulta de atributos, por sua vez, o cliente especifica qual serviço ou tipo de serviço de seu interesse, enviando uma mensagem AttrRqst ao DA, que atenderá a solicitação através do envio de uma mensagem AttrRply contendo a lista de atributos encontrados. 


\subsubsection{Análise}

O SLP é um protocolo leve, totalmente baseado na troca de mensagens via TCP/IP ou UDP. Ele oferece um sistema de localização de serviços bem completo em relação ao registro e consulta de serviços, provê uma descrição detalhada do serviço e diferentes tipos de busca.

Sua principal limitação é não especificar uma forma de acesso do cliente ao serviço, preocupandose apenas em como encontrar o serviço, mas não contemplando a forma de utilização do mesmo.

Outro problema, que existe na maioria dos protocolos, é a falta de seleção do SA mais conveniente para o cliente. Por exemplo, o mais próximo, pois um cliente que deseja imprimir um texto, com certeza não gostaria que seu texto fosse impresso em uma impressora muito longe de onde ele se encontra.

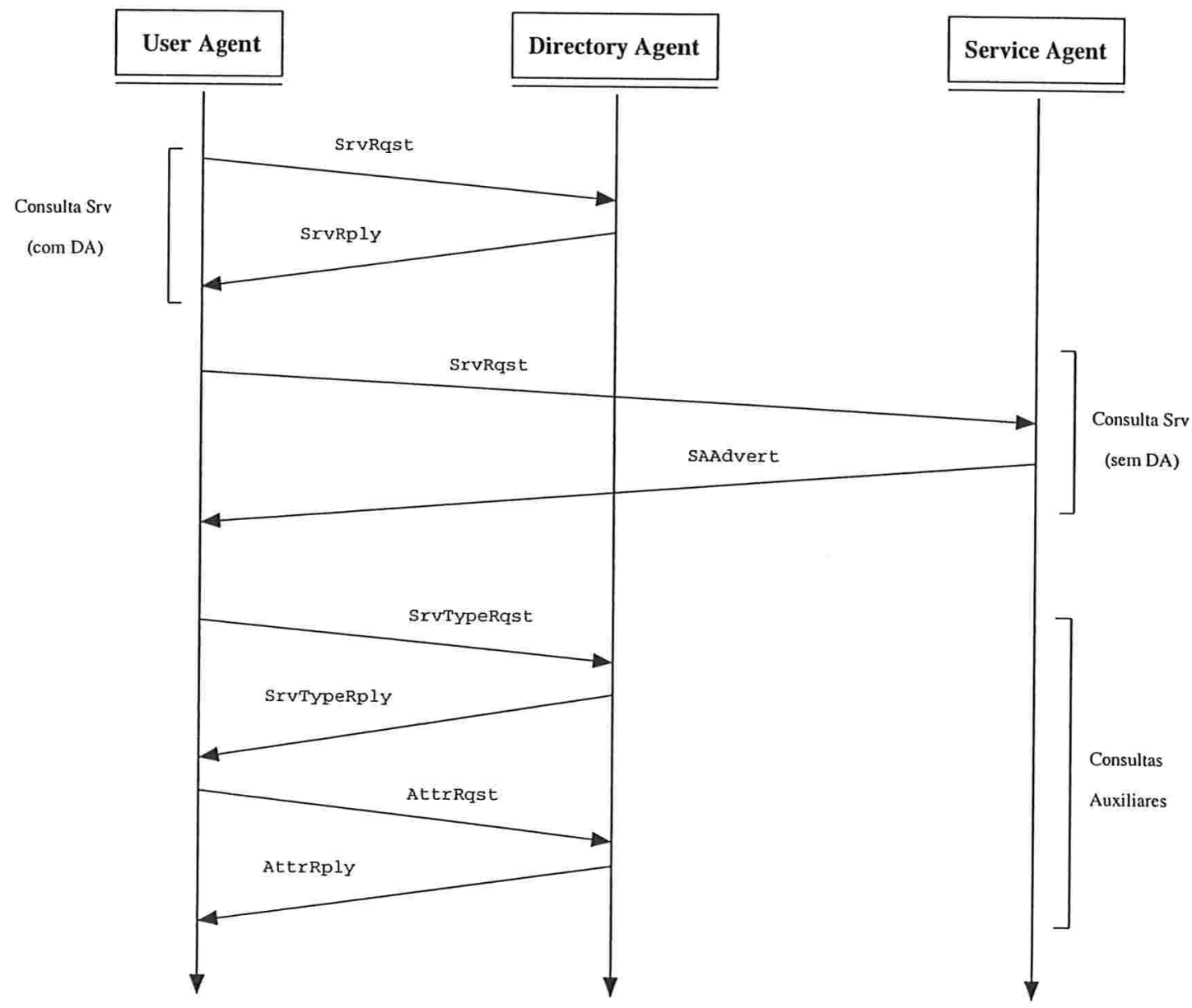

Figura 3.3: Exemplo de troca de mensagens na fase de consulta. 


\subsection{Jini Network Technology}

O Jini [25] foi desenvolvido pela Sun Microsystems Inc. com o objetivo de possibilitar a criação de um centro de serviços em uma rede. Através dele, os usuários podem descobrir facilmente os serviços existentes na rede.

Para permitir a descoberta dinâmica dos serviços, o Jini armazena uma lista dos serviços da rede, e por isso, inicialmente ele pode ser comparado ao DNS (Domain Name Server), mas veremos que ele tem muitas outras vantagens, não sendo apenas um servidor de nomes. Além de localizar o serviço, o Jini também fornece uma forma de acesso transparente ao recurso desejado. Baseado na mobilidade de código do serviço, ele substitui a necessidade de pré-instalação de drivers no cliente, automatizando o processo de configuração do dispositivo para acesso a um serviço.

Ademais, no processo de consulta de serviços, a arquitetura fornece a busca pelo nome (ou tipo) do serviço e/ou através dos atributos do mesmo. Por exemplo, um usuário que deseja encontrar uma impressora na rede, mas necessita de impressora colorida ou laser.

O Jini também provê um mecanismo para notificação de eventos, logo, se o serviço não é encontrado, o sistema oferece a possibilidade ao cliente interessado no recurso de ser avisado automaticamente quando este estiver disponível.

O sistema tolera ainda falhas dos servidores, reajustando-se automaticamente a um novo cenário e desabilitando o serviço oferecido por eles, evitando que o cliente tente acessar um servidor indisponível em um dado momento.

\subsubsection{Arquitetura}

O Jini foi desenvolvido sobre a linguagem Java, utilizando sua tecnologia para objetos distribuídos: RMI - Remote Method Invocation na comunicação entre os elementos do sistema, por isso ele depende também da camada de rede e obviamente, do sistema operacional, como mostra a figura 3.4. Sua implementação atual é baseada nos protocolos de comunicação TCP/IP e UDP, mas implementações baseadas em outros protocolos são possíveis.

O Jini é composto por três elementos: Lookup Service (LS), Service Provider (SP), Client (C). O primeiro elemento é o agente principal do sistema e os dois últimos são os usuários finais 
do sistema.

O Service Provider é o elemento que disponibiliza o serviço e o Client é o elemento que deseja utilizá-los. O Lookup Service é um elemento intermediário entre as requisições dos clientes e os provedores, geralmente chamado de localizador de serviços, ou gerenciador de serviços. Ele é o elemento principal do sistema, responsável pelas funcionalidades principais do Jini: mantêm a lista dos serviços registrados, gerencia acesso a um serviço, notifica clientes sobre novos serviços, etc.

\begin{tabular}{|c|c|}
\hline Cliente & Servidor \\
\hline \multicolumn{2}{|c|}{ Jini Network Technology } \\
\hline \multicolumn{2}{|c|}{ Java - RMI } \\
\hline \multicolumn{2}{|c|}{ Sistema Operacional } \\
\hline Tran & e rede \\
\hline
\end{tabular}

Figura 3.4: Camadas presentes na arquitetura do Jini.

\subsubsection{Funcionamento}

O seu funcionamento é baseado em micro-protocolos, que serão explicados abaixo:

\section{Localização do LS}

No Jini, as principais operações são realizadas através do LS. Para isso os elementos da rede precisam inicialmente ter acesso a algum LS da rede em que estão conectados. A API do Jini disponibiliza três modos para a localização do lookup service da rede:

- Multicast Request: SPs e clientes realizam multicast, requisitando a localização do LS;

- Multicast Announcement: o LS realiza multicast periódicos com a sua localização;

- Unicast Discovery: Clientes e SPs se comunicam diretamente com um LS específico. 
A localização é feita através da classe LookupDiscovery disponibilizada pela API do Jini. O processo de descoberta do LS culmina com a transferência de um objeto remoto (stub RMI) referente ao LS específico. O objeto é uma instância da classe ServiceRegistrar que possibilita todas as operações sobre o LS encontrado, como a consulta e o registro de serviços. Todas as interações entre o LS e os outros elementos são feitas através do RMI.

No quadro 3.1, mostramos um trecho de código correspondente à execução do Multicast Request Protocol. A classe exemplificada implementa os métodos discovered e discarded da interface DiscoveryListener chamados quando um ou mais LS são encontrados na rede e algum LS é finalizado, respectivamente. Quando existe mais de um Lookup Service na rede, todos os objetos ServiceRegistrar, correspondentes aos LSs da rede, são devolvidos (veja a linha 16 do quadro 3.1).

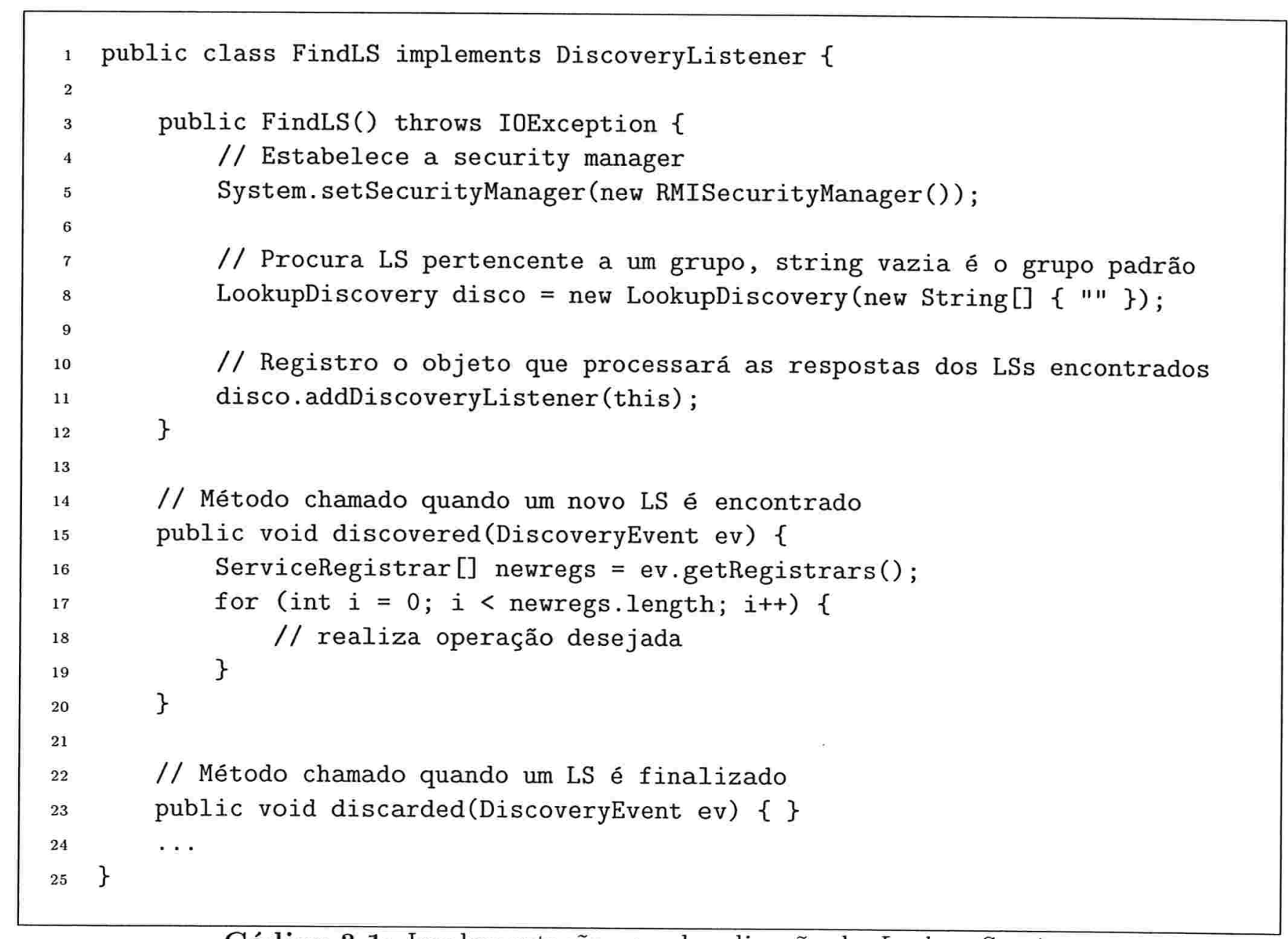

Código 3.1: Implementação para localização do Lookup Service. 


\section{Publicação do Serviço}

Cada provedor de serviço, depois de localizar o LS, deve registrar-se com o mesmo com as informações relevantes à sua descrição, como o tipo de serviço oferecido e, opcionalmente, a lista de atributos que descrevem o serviço; além das informações necessárias para o seu acesso.

No Jini, todas essas informações de acesso ao serviço ficam armazenadas em um objeto denominado service proxy, que encapsula a localização do serviço e o protocolo necessário para operá-lo, permitindo um acesso transparente ao mesmo. A definição desse objeto é bem flexível, pode ser um proxy que contém a informação de conexão ao servidor, como o IP, porta de acesso e protocolo utilizado; ou um objeto remoto, por exemplo, um stub RMI. A única exigência é que esse objeto seja seriável para permitir o seu envio ao cliente, que poderá executá-lo localmente e acessar assim o serviço procurado.

Para o registro efetivo do serviço é utilizado um objeto da classe ServiceItem, que é instanciado recebendo três argumentos: o $i d$ do serviço (opcional, pode ser null), utilizado somente quando o serviço já foi registrado uma vez; service proxy, a implementação da forma de acesso ao serviço; e o último argumento, um vetor de atributos (características) que descrevem o serviço a ser registrado.

Por último, é preciso definir a política de tempo de validade do registro, pois ao registrar o serviço, este será válido somente pelo período de tempo especificado durante o registro. Após esse período, o registro precisa ser renovado para que o servidor continue disponível. Portanto, para servidores permanentes é necessário ter uma thread, que mantenha sempre o registro válido, renovando-o periodicamente. Através desse mecanismo, é possível ao Jini identificar os servidores inacessíveis, retirando-os da lista dos servidores disponíveis, atuando assim, como um mecanismo de tolerância a falhas dos SPs.

O serviço é publicado através do método register() do objeto ServiceRegistrar, que recebe como parâmetro uma instância da classe ServiceItem e o tempo de expiração desse registro (leasing time), como mostra o quadro 3.2. O resultado da publicação será armazenado no objeto de retorno ServiceRegistration, que contém um id identificando o seu registro, e podendo ser mais tarde utilizado para atualizar os atributos do serviço ou o código do service proxy, não sendo necessário reinstalar em cada cliente a nova versão da implementação de acesso ao serviço. Um esquema da operação de registro de serviços no Jini pode ser visualizado na 
figura 3.5.

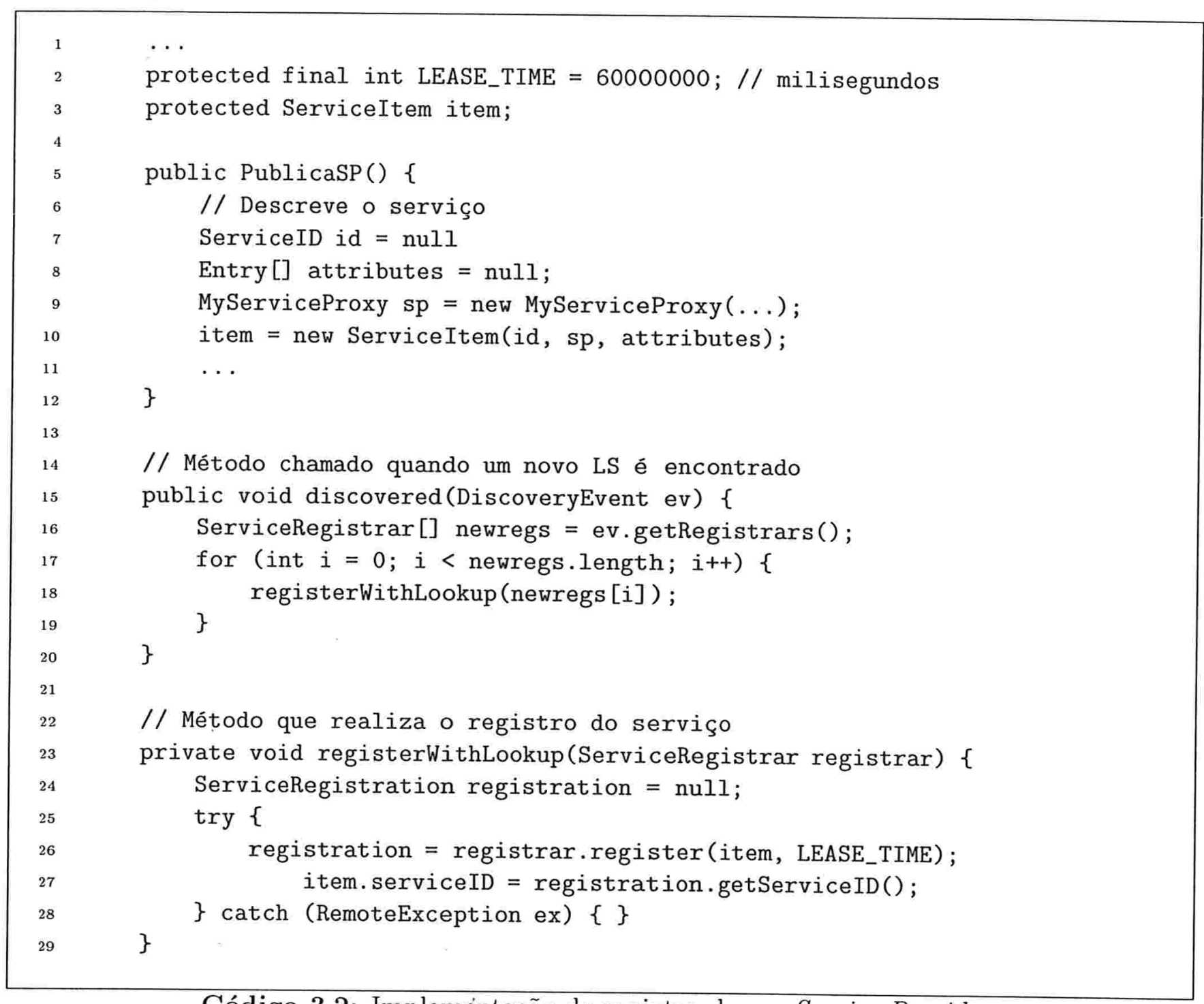

Código 3.2: Impleméntação do registro de um Service Provider.

\section{Consultas}

Nesta fase o cliente informa ao LS o interesse por um tipo de serviço enviando uma requisição de busca por tipo ou características de um serviço, por exemplo um serviço de impressão laser.

Inicialmente é necessário instanciar o objeto que representará a consulta, no caso do Jini implementado através da classe ServiceTemplate. Este objeto é instanciado recebendo três argumentos: $i d$, o identificador do serviço, que é opcional e pode ser null; o vetor de atributos desejados, e o último argumento, que representa o tipo do serviço, identificado pelo nome de 
uma interface Java. Assim, o LS buscará em seu catálogo por um servidor cujo service proxy implemente esta interface.

Para efetuar a busca, os clientes utilizam o método lookup() de uma instância do Lookup Service (ServiceRegistrar), como mostra o quadro 3.3. Esse método recebe um objeto da classe ServiceTemplate como parâmetro. O retorno do método, que representa o resultado da consulta, será um objeto ServiceMatches, que contém um vetor de instâncias ServiceItem, representando os servidores encontrados.

Quando o cliente obtém o objeto ServiceItem, ele recupera a implementação do proxy do serviço (service proxy) através da propriedade service, e utiliza os métodos disponíveis para ter acesso ao mesmo, como mostra o quadro 3.3 .

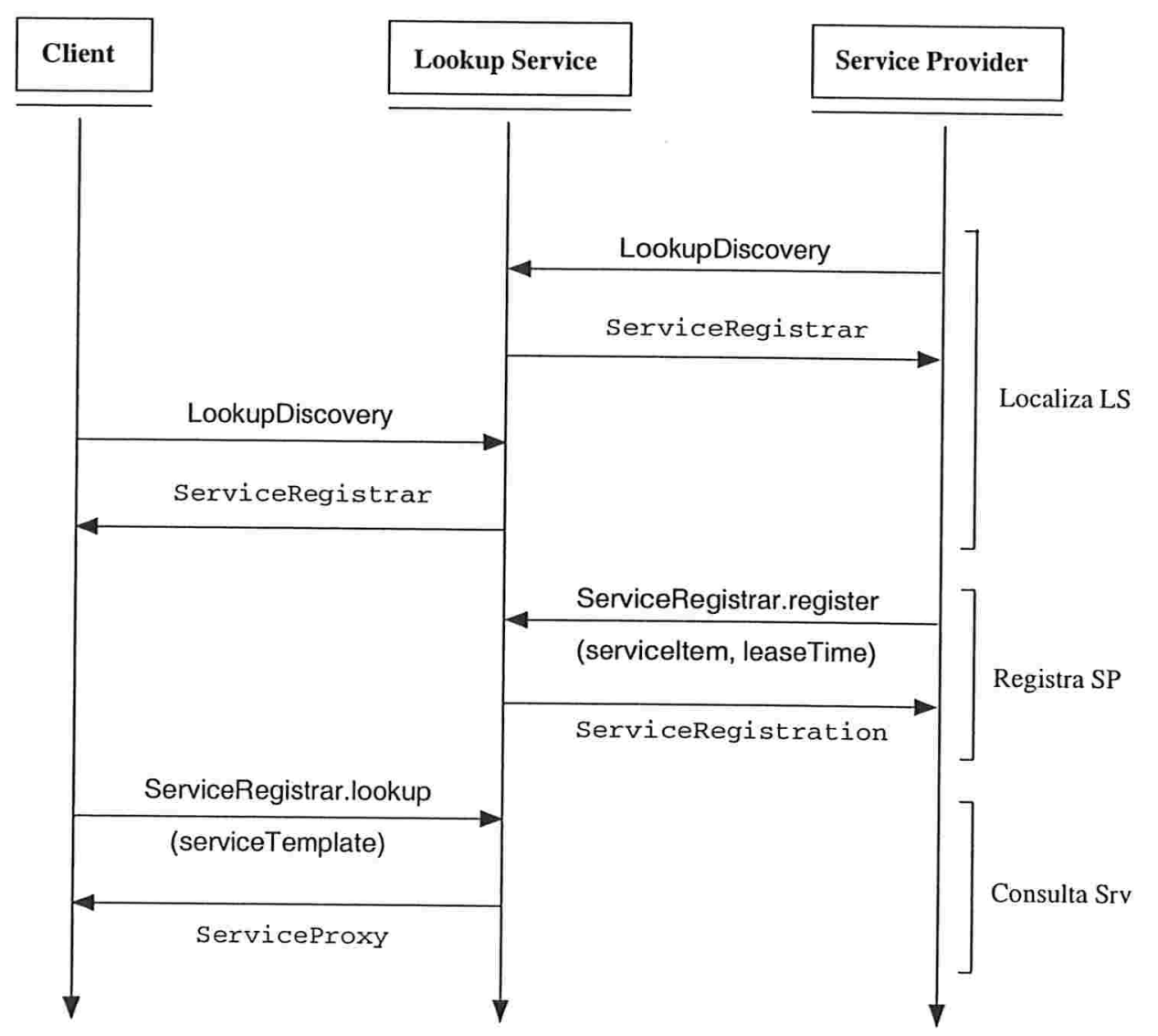

Figura 3.5: Operações na arquitetura do Jini.

Se nenhum SP foi encontrado, o cliente pode registrar o seu interesse pelos eventos de um LS da rede e ser notificado posteriomente do registro de um SP que implemente o serviço procurado. 
Para isso o cliente deve implementar a interface RemoteEventListener e se registrar no serviço de notificação do LS através do método notify do ServiceRegistrar informando como parâmetro o objeto ServiceTemplate.

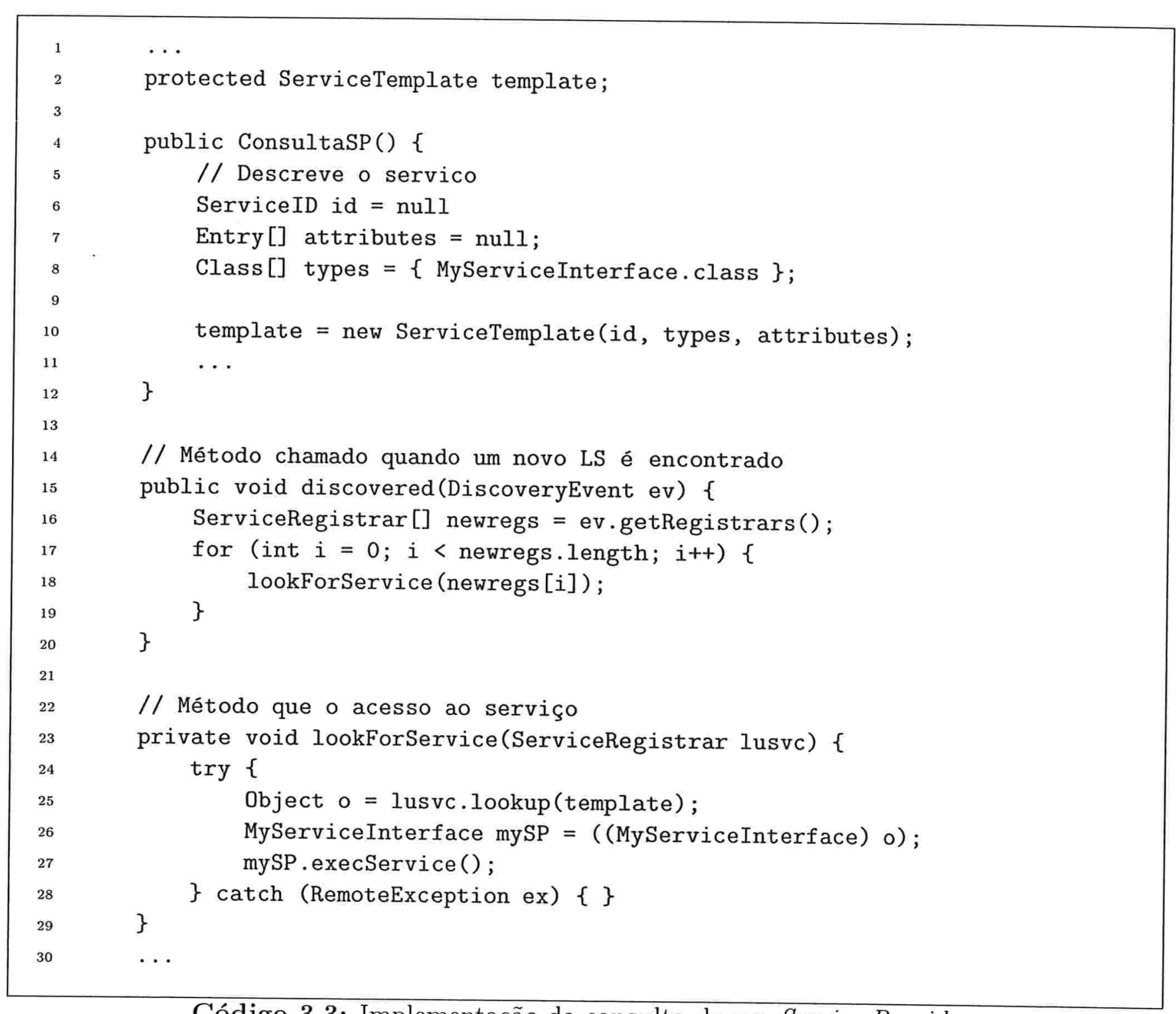

Código 3.3: Implementação da consulta de um Service Provider.

\subsubsection{Análise}

O Jini é um sistema mais complexo e com maiores recursos que o SLP. Sua principal vantagem é disponibilizar ao cliente uma forma de acesso transparente aos serviços, pois em sua lista de cadastro é armazenada também a implementação de uma forma de acesso ao serviço, e não 
apenas o endereço do servidor.

Um dos principais problemas do Jini é a obrigatoriedade do cliente conhecer a interface do serviço em que ele está interessado, os seus métodos e nome, para ser possível o acesso e a busca por tipo, respectivamente. Existem formas de contornar o problema, as assinaturas dos métodos disponíveis no service proxy podem ser obtidas através da API de reflexão (java.lang.reflect) [16] disponibilizada pelo Java. Entretanto, esta não é a soluç̧ão ideal, pois o cliente pode ter dúvidas em relação aos parâmetros de um método ou sua forma de retorno. Para amenizar esse problema, a Sun está propondo uma padronização de interfaces para os serviços mais conhecidos, como de impressão, envio de e-mails, etc. A partir dessa interface, cada fabricante implementará o seu próprio serviço.

Assim como o SLP, o Jini não provê um método para seleção de serviços, depois de encontrado o conjunto de servidores que atendem a requisição. O ideal seria que o sistema automaticamente escolhesse o servidor mais apropriado para aquele cliente, como o serviço mais próximo, ou o com menos demanda, podendo ser implementado, por exemplo, um mecanismo de balanceamento de carga. 


\title{
Capítulo 4
}

\section{Outras Arquiteturas}

\begin{abstract}
Nesse capítulo descreveremos sistemas menos conhecidos, alguns ainda em fase de desenvolvimento, e que não tem muitas referências na literatura ${ }^{1}$. Por esse motivo, faremos uma breve descrição de cada um deles. Veremos os sistemas Salutation [38], Microsoft Universal Plug and Play [8] e o Bluetooth Service Discovery Procotol [44].
\end{abstract}

\subsection{Salutation}

Essa arquitetura está sendo desenvolvida por um consórcio aberto [38]. Sua principal vantagem é disponibilizar uma especificação que não depende de uma linguagem, de um sistema operacional ou de um protocolo de rede específico.

A especificação define um elemento principal, o Salutation Manager (SLM), também chamado de service broker, pois é responsável por todas operações do sistema, inclusive intermediar o acesso do cliente ao serviço.

Sua arquitetura é mostrada na figura 4.1. A primeira camada é a de transporte de rede (Transport Manager), que, como foi dito anteriormente, é independente, permitindo a utilização de vários protocolos de transporte de rede, tais como TCP/IP, IrDA [1], etc. Entretanto, no momento só existe uma implementação disponibilizada pelo consórcio sobre IrDA.

O SLM disponibiliza uma API (Salutation Manager Application Program Interface) para os clientes e provedores de serviços (denominados Functional Unit) se comunicarem com o SLM.

\footnotetext{
${ }^{1}$ No CiteSeer encontramos em média 20 ocorrências para cada um dos sistemas. Para o Jini e o SLP, no entanto, são encontradas 492 e 306 ocorrências, respectivamente. (data da pesquisa: set/2003)
} 

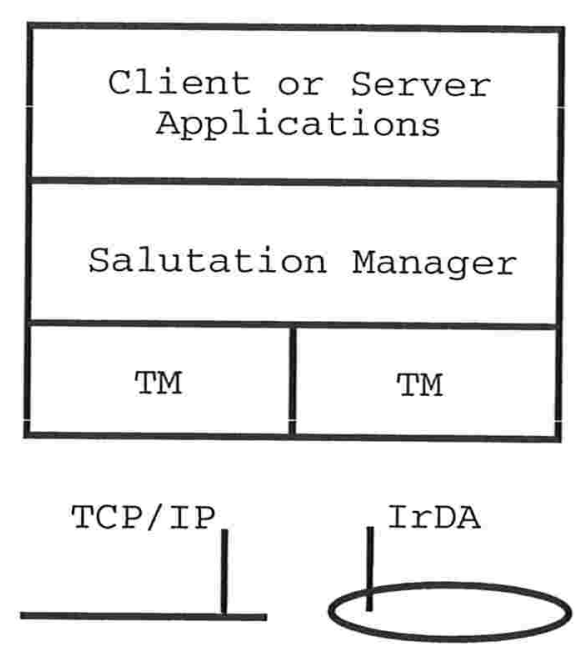

Figura 4.1: Arquitetura do Salutation.

\subsubsection{SLM - API}

A SLM-API oferece quatro operações básicas:

- Service Registry: permite o registro de serviços;

- Service Discovery: procura por um serviço através do seu tipo ou de suas características;

- Service Availability: verifica se um serviço continua disponível;

- Service Session Management: permite o gerenciamento do serviço registrado.

O servidor descreve o seu serviço através da estrutura Function Unit Description Record, que descreve as características e o tipo do serviço a ser registrado. Essa estrutura é passada como parâmetro para o método slmRegisterCapability da SLM - API (ver quadro 4.1). O Salutation Manager retorna o Function Unit Handle, que contém um identificador único para o registro publicado.

Após a publicação, o serviço pode ser consultado pelo método slmSearchCapability, informando o tipo e as características do serviço através da estrutura Service Description Record.

Como nos outros protocolos, os servidores utilizam o SLM para registrar os serviços, e os clientes para requisitar um determinado serviço. Quando o serviço desejado é localizado, o acesso ao mesmo é feito inteiramente através do SLM. 


\begin{tabular}{|l|l|}
\hline SLM-API Métodos & Descrição \\
\hline \hline slmRegisterCapability() & $\begin{array}{l}\text { Publica um serviço. Recebe como parâmetro um } \\
\text { Function Unit Description Record e devolve o } \\
\text { Function Unit Handle }\end{array}$ \\
\hline slmUnregisterCapability() & $\begin{array}{l}\text { Utilizado para cancelar um serviço. Recebe como parâmetro } \\
\text { o Function Unit Handle que identifica o registro }\end{array}$ \\
\hline slmSearchCapability() & $\begin{array}{l}\text { Consulta um serviço. Recebe como parâmetro um Service } \\
\text { Description Record e retorna uma lista de SLM-IDs }\end{array}$ \\
\hline slmQueryCapability() & $\begin{array}{l}\text { Obtém as características de um tipo de serviço. Recebe } \\
\text { como parâmetro um Service Description Record contendo } \\
\text { o tipo do serviço e retorna um Service Description Record } \\
\text { correspondente }\end{array}$ \\
\hline
\end{tabular}

Tabela 4.1: Métodos da SLM-API.

Além do SLM, o sistema contém um outro elemento, o Transport Manager, em uma camada abaixo do SLM. Ele é responsável por informar os clientes e servidores a localização do SLM, e também pela abstração da camada de transporte. Dessa forma, o Salutation se torna independente do protocolo de transporte.

\subsubsection{Análise}

No Salutation a localização dos serviços é definida em uma camada mais alta. Sua especificação não define a camada de transporte de rede e não depende de uma linguagem específica para a sua implementação.

Entretanto, o Salutation Consortium ainda não disponibilizou nenhuma implementação para o protocolo de rede TCP/IP, apenas para redes IrDA, o que impossibilita o seu uso na resolução do problema abordado (descrito no capítulo 1).

\subsection{Microsoft Universal Plug and Play (UPnP)}

A arquitetura Universal Plug and Play é um conjunto de protocolos para descoberta de serviços. Ela foi desenvolvida pelo Universal Plug and Play Forum [8], um consórcio de empresas liderado pela Microsoft.

Sua especificação utiliza alguns protocolos na comunicação entre os clientes (chamados de 
control points no UPnP), tais como SOAP (Simple Object Access Protocol) [10], GENA (General Event Notification Architecture) [30], entre outros.

Toda comunicação é baseada em troca de mensagens HTTP e é feita diretamente entre o cliente e o servidor. As mensagens podem ser do tipo multicast, para isso é utilizado o protocolo HTTPMU (HTTP over multicast) [14] ou unicast utilizando o HTTPU (HTTP over unicast). Devido a isso, o UPnP depende do protocolo de transporte TCP/IP.

\subsubsection{Arquitetura}

Como foi dito, não existe um elemento central no sistema. Para utilizar um serviço, o dispositivo cliente precisa inicialmente obter um endereço IP na rede. Para isso, o UPnP recomenda a utilização de um servidor DHCP [11] ou do protocolo AutoIP [11].

Os procedimentos de publicação e consulta dos serviços da rede são especificados no SSDP (Simple Service Discovery Protocol) proposto pelo IETF. Um provedor de serviço pode anunciar o serviço prestado enviando uma mensagem multicast ANNOUNCE (ver quadro 4.1).

O campo HOST contém o endereço IP e porta reservada para mensagens multicast do protocolo. A duração do fornecimento do serviço é expressa no campo CACHE-CONTROL e o seu tipo é indicado no Notification Type (NT). Por último, temos o campo USN, que contém o identificador único do servidor.

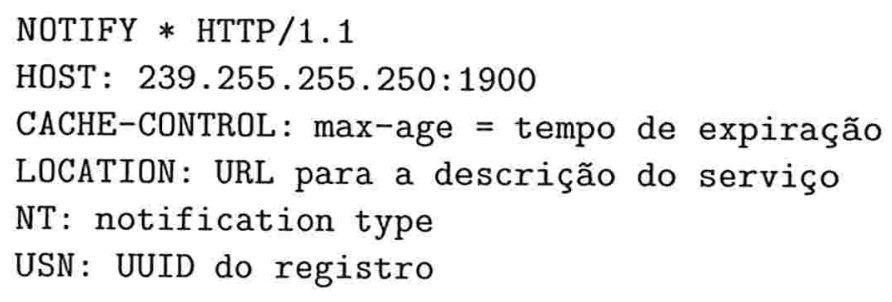

Código 4.1: Mensagem HTTP do anúncio de um serviço.

O cliente pode explicitamente requisitar um serviço específico. Isso é feito através de uma mensagem multicast SEARCH, em que o cliente, através do campo Search Target (ST), informa o tipo ou ID do serviço procurado (ver quadro 4.2). Não existe busca pelas características do serviço. 
SEARCH $*$ HTTP $/ 1.1$

HOST: $239.255 .255 .250: 1900$

MAN: "ssdp:discover"

MX: timeout de espera

ST: search target

Código 4.2: Mensagem HTTP de uma consulta.

Os servidores que atendem a requisição, respondem com uma mensagem unicast com o seu identificador no campo USN e a URL que contém a descrição do serviço.

No UPnP os serviços são descritos em documentos XML que informam as características do serviço, como mostra o quadro abaixo:

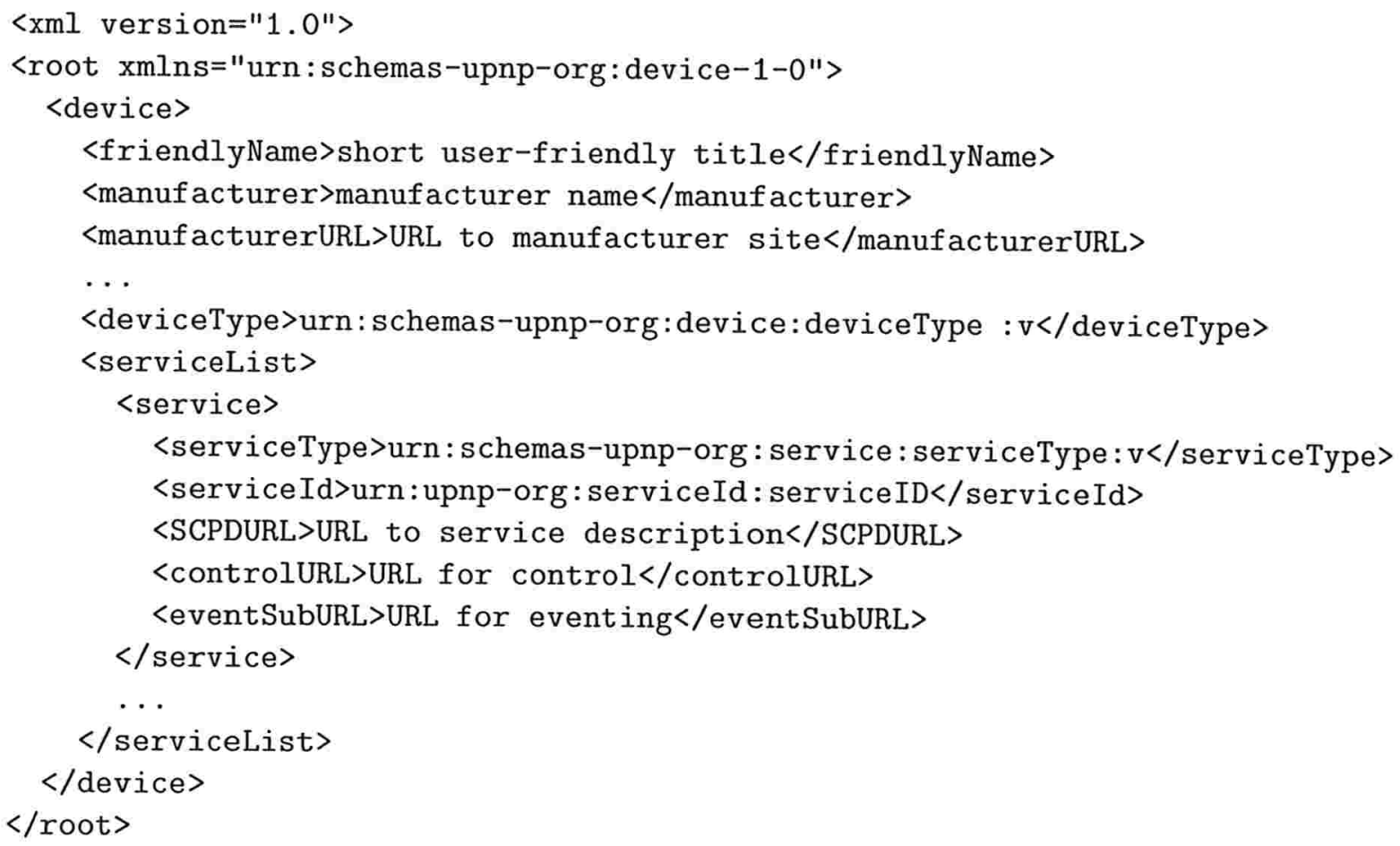

Código 4.3: Descrição XML de um serviço.

Finalmente, na última fase do processo o cliente acessa propriamente o serviço encontrado. O acesso é feito através do protocolo SOAP, o cliente envia uma mensagem XML no padrão SOAP para a URL informada no campo controlURL do XML de descrição do serviço. No envelope SOAP é informada a operação desejada e os parâmetros da mesma. O servidor executa 
o procedimento e retorna o resultado da operação em um envelope SOAP. Um exemplo dessa troca de mensagens é mostrada abaixo:

-- Requisição SOAP de uma operação --

POST caminho control URL HTTP/1.1

HOST: IP da control URL:porta da control URL

CONTENT-TYPE : text/xml; charset="utf-8"

SOAPACTION: "urn:schemas-upnp-org:service: serviceType:v\#actionName"

<s:Envelope xmlns:s="http://schemas.xmlsoap.org/soap/envelope/"

$\mathrm{s}$ : encodingStyle="http://schemas.xmlsoap.org/soap/encoding/">

$\langle\mathrm{s}:$ Body $>$

$<u$ :actionName xmlns:u="urn:schemas-upnp-org:service:serviceType:v">

<argumentName>in arg value</argumentName>

...

$</$ u:actionName $>$

$\langle/ \mathrm{s}$ : Body $>$

$\langle/ \mathrm{s}:$ Envelope $>$

-- Resposta a uma requisição SOAP --

HTTP/1. 1200 OK

CONTENT-TYPE: text/xml; charset="utf-8"

<s:Envelope xmlns:s="http://schemas.xmlsoap.org/soap/envelope/"

$\mathrm{s}$ : encodingStyle="http://schemas. xmlsoap.org/soap/encoding/">

$\langle\mathrm{s}:$ Body $>$

<u:actionNameResponse xmlns:u="urn:schemas-upnp-org:service:serviceType:v"> <argumentName>out arg value</argumentName>

...

$</$ u:actionNameResponse $>$

$\langle/ \mathrm{s}:$ Body $>$

$\langle/ \mathrm{s}:$ Envelope $>$

Código 4.4: Exemplo do acesso a um serviço via SOAP.

Além das operações mostradas, o UPnP disponibiliza um mecanismo de notificação de eventos, em que o cliente pode se registrar para receber eventos de um determinado serviço utilizando o protocolo GENA (General Event Notification Architecture) [30]. O cliente envia uma mensagem unicast SUBSCRIBE para o servidor informando o evento desejado e o tempo de validade do registro. 


\subsubsection{Análise}

O Universal Plug and Play é a arquitetura mais recente entre as apresentadas. Sua principal vantagem é utilizar protocolos simples e conhecidos no mercado, tais como HTTP, SOAP e GENA, na comunicação entre os seus elementos. Entretanto, devido a utilização desses protocolos, o UPnP só pode ser utilizado em redes TCP/IP.

A sua principal desvantagem é não utilizar um elemento central para intermediar as requisições dos clientes e, principalmente, armazenar os serviços disponíveis na rede. Isso, além de gerar um tráfego grande de dados na rede devido ao envio de mensagens multicast, impossibilita a seleção do servidor mais conveniente ao cliente, como o servidor próximo. Outra desvantagem é o acesso aos códigos fontes do sistema, restrito a membros da equipe de desenvolvimento. Por esses motivos, não foi possível utilizá-lo na resolução do problema estudado.

\subsection{Bluetooth Service Discovery Protocol (SDP)}

O Bluetooth [44] foi lançado em 1999 como um protocolo padrão para redes sem fio de curtas distâncias. Seu desenvolvimento foi financiado por um consórcio de grandes empresas de telecomunicações, pois uma aplicação imediata para este protocolo são os acessórios de celulares, como fones de ouvidos, microfones, etc. A utilização do Bluetooth eliminaria a necessidade de fios conectando o celular aos acessórios.

Assim, com o lançamento do protocolo, surgiram aplicações para esse tipo de rede, como serviços de fax, impressoras, etc. Para manter a interação e autoconfiguração dos dispositivos que utilizariam essas aplicações foi acrescentado à especificação do Bluetooth um módulo chamado Service Discovery Protocol (SDP), responsável por prover essas funcionalidades.

\subsubsection{Rede Bluetooth}

Cada elemento da rede Bluetooth pode iniciar conexões com outros dispositivos na rede. Inicialmente, o dispositivo precisa obter um identificador único, que representará o seu endereço na rede. Isso é realizado através de um procedimento chamado Inquiry Procedure, em que o elemento se comunica com os outros elementos da rede a fim de obter o seu ID. 
Após a obtenção do identificador único, o dispositivo poderá se conectar a qualquer outro elemento da rede. Toda a comunicacação é realizada via rádio utilizando a faixa de freqüência de 2,4 GHz. A conexão pode ser ponto-a-ponto ou ponto-a-multiponto.

No procedimento de conexão (Page Procedure), um dos participantes se torna o elemento mestre (master) do canal de comunicação e determina alguns parâmetros da rede iniciada (também chamada de piconet). Conseqüentemente, os outros elementos da piconet são denominados escravos (slaves).

O principal parâmetro definido pela unidade master é o frequency hop do canal de comunicação. Frequency-hopping (FH) é uma técnica utilizada em redes sem fio para evitar interferências em comunicações simultâneas em uma mesma faixa de freqüência. A faixa de freqüência é dividida em um número de canais de hop. Cada canal é somente um fração da banda. No Bluetooth, cada canal é utilizado por 625 us (um slot de tempo) seguido por um salto em uma ordem pseudo-aleatória para outro canal por outros 625 us e assim por diante, repetindo-se constantemente (625us x $1600=1$ segundo). Dessa maneira, o tráfego se espalha por toda a banda ISM e obtém-se um sistema com boa proteção contra interferência. Se uma das transmissões sofrer interferência de um forno de microondas, por exemplo, a probabilidade de interferência no próximo salto $(h o p)$ de freqüência é muito baixa. São utilizados algoritmos de correção de erro nas transmissões que sofreram interferências.

Outro vantagem da rede Bluetooth é a possibilidade de um dispositivo ser membro de várias piconets ao mesmo tempo, sendo mestre em uma e escravo em outras. O conjunto dessas piconets é chamado Scatternet na especificação do Bluetooth. Sendo assim, não é necessário um elemento central administrando a rede, há uma organização automática e própria entre os dispositivos da rede, de forma análoga as redes Ad Hoc [3].

\subsubsection{Arquitetura}

A arquitetura do protocolo é mostrada na figura 4.2. Ela contempla seis camadas, sendo que as camadas Baseband, Link Manager Protocol (LMP) e Host Controller Interface (HCI) estão geralmente integradas no módulo de hardware do Bluetooth. Essas camadas são responsáveis pela conexão física entre os dispositivos da rede.

Estabelecida a conexão, a camada Local Link Control and Adaptation Protocol (L2CAP) 
disponibiliza a forma de envio de dados para as camadas acima, como a RFCOMM, que emula uma linha serial e assim, pode ser utilizada como protocolo de transporte para outros protocolos, como o TCP/IP over PPP, entre outros.

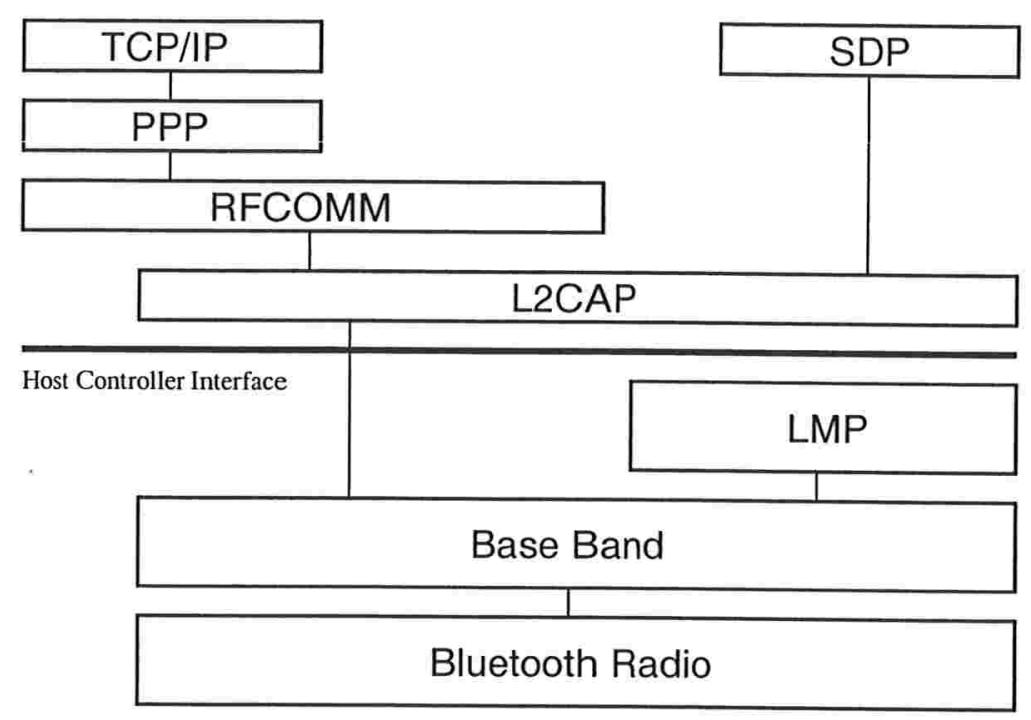

Figura 4.2: Arquitetura do Bluetooth.

\subsubsection{Service Discovery Protocol}

O SDP oferece a possibilidade de um dispositivo consultar os serviços da rede e suas características. Mas após o serviço ser encontrado, ele não provê o acesso ao serviço, que deve ser feito através de um outro mecanismo.

O protocolo é baseado em trocas de mensagens entre o cliente (SDP Client) e os provedores de serviços (SDP Server), não existe um elemento central que armazene os serviços da rede. As mensagens são denominadas protocol data unit (PDU) e existe sempre uma mensagem $P D U$ request com a respectiva $P D U$ response.

O servidor descreve o seu serviço através de uma estrutura de dados chamada Service Record, cujos campos são mostrados na tabela 4.2 .

A lista de campos contém dois atributos obrigatórios: ServiceRecordHandle, o identificador único do dispositivo e a ServiceClassIDList que contém o UUID (Universal Unique IDentifier) do tipo do serviço oferecido. 
O cliente pode requisitar um serviço através do tipo ou atributos do serviço. Isso é feito através do envio de uma mensagem SDP_ServiceSearchRequest para a rede com o respectivo tipo de serviço procurado. Os servidores que oferecerem o serviço procurado respondem ao cliente com uma mensagem SDP_ServiceSearchResponse contendo a estrutura Service Record do mesmo.

\begin{tabular}{|l|l|}
\hline \multicolumn{2}{|c|}{ Service Record } \\
\hline \hline attribute ID & attribute value \\
\hline ServiceRecordHandle & $<$ int $>$ \\
\hline ServiceClassIDList & $<$ UUID $(\mathrm{s})>$ \\
\hline ServiceID & $<$ UUID $>$ \\
\hline ProtocolDescriptorList & $<$ sequence $>$ \\
\hline BrowseGroupList & $<$ UUID $($ s $)>$ \\
\hline DocumentationURL & $<$ URL $>$ \\
\hline
\end{tabular}

Tabela 4.2: Representação dos dados de um serviço.

Além disso, é possível requisitar as características de um servidor específico através do envio da mensagem SDP_ServiceAttributeRequest.

\subsubsection{Análise}

O SDP faz parte da especificação do protocolo Bluetooth, que possibilita a comunicação sem fio em curtas distâncias entre os agentes da rede, sem a necessidade de um elemento central para intermediar a comunicação.

Sua especificação permite a publicação e consulta de serviços. Entretanto a forma de acesso não é contemplada, infelizmente. Por esse motivo, ele pode ser usado em conjunto com outros protocolos de localização de serviços, que contém essa funcionalidade, como o SLP ou o Salutation, sendo o SDP apenas responsável por localizar os serviços disponíveis, de acordo com a requisição.

Outra desvantagem do sistema é a obrigatoriedade da utilização do Bluetooth como camada de transporte de rede, impossibilitando assim a sua utilização em redes sem fio no padrão IEEE 802.11, por exemplo. Devido a isso, não utilizaremos o Service Discovery Protocol na resolução do problema abordado. 


\subsection{Quadro Comparativo}

Embora a maioria dos SDSs utilize a mesma arquitetura (cliente, SP e SM), existem muitas diferenças entre eles. O quadro comparativo 4.3 reflete algumas das diferenças entre os sistemas apresentados.

O SLP é o protocolo mais antigo e mais simples entre os apresentados. Desenvolvidos para redes locais TCP/IP, ele deve se utilizado na implementação de serviços simples, em que o acesso ao mesmo não seja complexo. O Jini, por sua vez, é um sistema mais completo, tem como principal vantagem a mobilidade de código e portabilidade disponibilizada pela arquitetura Java, escolhida para o seu desenvolvimento. Com isso, ele provê um acesso transparente aos serviços publicados.

\begin{tabular}{|l|l|l|l|l|l|}
\hline & \multicolumn{1}{|c|}{ SLP } & \multicolumn{1}{|c|}{ Jini } & \multicolumn{1}{c|}{ Salutation } & \multicolumn{1}{|c|}{ UPnP } & \multicolumn{1}{|c|}{ SDP } \\
\hline \hline Empresa & IETF & Sun & $\begin{array}{l}\text { Salutation } \\
\text { Consortium }\end{array}$ & Microsoft & $\begin{array}{l}\text { Telecom } \\
\text { Consortium }\end{array}$ \\
\hline Licença & Open Source & Open License & Open Source & Members & Members \\
\hline $\begin{array}{l}\text { Protocolo } \\
\text { de Rede }\end{array}$ & TCP/IP & Independente & IrDA & TCP/IP & Bluetooth \\
\hline Linguagem & Independente & Java & Independente & Independente & Independente \\
\hline Plataforma & Dependente & Independente & Dependente & Dependente & Dependente \\
\hline $\begin{array}{l}\text { Mobilidade } \\
\text { de Código }\end{array}$ & Não & Sim (RMI) & Não & Não & Não \\
\hline $\begin{array}{l}\text { Central de } \\
\text { Serviços }\end{array}$ & Sim & Sim & Sim & Não & Sim \\
\hline $\begin{array}{l}\text { Validade } \\
\text { do Serviço }\end{array}$ & Sim & Sim & Não & Sim & Não \\
\hline $\begin{array}{l}\text { Procura por } \\
\text { Atributos }\end{array}$ & Sim & Sim & Sim & Não & Sim \\
\hline $\begin{array}{l}\text { Seleção de } \\
\text { Serviços }\end{array}$ & Não & Não & Não & - & Não \\
\hline Segurança & Firewall & Java (policy) & Autenticação & Firewall & Rede PAN \\
\hline
\end{tabular}

Tabela 4.3: Quadro comparativos dos SDSs.

No Bluetooth SDP, infelizmente, a forma de acesso ao serviço não é contemplada. Entretanto, pelo fato do sistema ter sido desenvolvido para redes Bluetooth, em que ainda não existem outros SDSs, ele deve ser muito utilizado no futuro. Assim como o Salutation e o UPnP, que são arquiteturas mais recentes e ainda em fase de desenvolvimento, mas que contém características 
interessantes, como a independência do protocolo de rede no Salutation e o protocolo de comunicação HTTP utilizado no UPnP. 


\section{Capítulo 5}

\section{Sistemas de Localização de UMs}

Para que o cliente possa informar a sua localização ao SDS é necessário algum mecanismo que calcule automaticamente a localização da unidade móvel. No final da década de 80 surgiram sistemas com esse objetivo, denominados sistemas de localização de unidades móveis.

Neste capítulo apresentaremos as principais técnicas de localização utilizadas nesses sistemas, suas características e limitações. Ademais, justificaremos a escolha do sistema utilizado.

\subsection{Visão Geral}

Com o aumento do número de redes sem fio e de dispositivos móveis (notebooks, PDAs, etc.) surgiu a necessidade de desenvolver aplicativos que reagissem à localização do usuário, comportando-se de forma diferente conforme o contexto em que a unidade móvel se encontra.

Isto é chamado computação sensível ao contexto pois, as aplicações assim denominadas, adaptam-se (são sensíveis) às alterações nas condições do ambiente de execução. Definimos contexto, como qualquer informação que possa ser usada para caracterizar a situação de uma entidade, no nosso caso, a localidade.

Quando o contexto é baseado na localidade, as aplicações móveis também são chamadas aplicações sensíveis à localização (location-aware applications). Elas fornecem informações baseadas na localização da UM, como o restaurante mais próximo, hospitais na vizinhança, etc. 
Um exemplo típico desse tipo de aplicação é um guia turístico virtual. Existem museus [18] cujo sistema permite que o visitante, portando um dispositivo móvel e conectado a rede sem fio do local, obtenha informações sobre a obra visitada em tempo real. Além disso, poderia ser utilizada uma tecnologia push, em que o usuário não precisaria nem requisitar a informação, conforme o seu deslocamento, as informações exibidas na tela seriam atualizadas de acordo com a obra mais próxima a este. Há inúmeras outras funcionalidades que podem ser feitas, como a exibição dinâmica de mapas do museu, controle de obras mais visitadas, trajetos mais comuns na visita ao museu, entre outras.

Esse tipo de aplicação também é utilizada em supermercados cujo carrinho contém um visor e na medida que o mesmo muda de corredor, o visor do carrinho fornece informações específicas sobre os produtos do corredor atual. O sistema também pode ser instalado em outros tipos de estabelecimentos públicos, como shoppings, feiras de convenções, entre outros.

Entretanto, para que seja possível o desenvolvimento de aplicações sensíveis à localização, é necessário um sistema que consiga rastrear e fornecer a localização de uma unidade móvel. A partir da década de 90, começaram a surgir sistemas com essa finalidade.

\subsection{Funcionamento}

Existem basicamente três técnicas [19] que são utilizados pelos sistemas de localização existentes: triangulação, proximidade e análise de cena. As heurísticas podem ser utilizadas isoladamente ou combinadas entre si.

\subsubsection{Triangulação}

A técnica de triangulação utiliza propriedades geométricas de triângulos para calcular a localização de um objeto ou pessoa. Essa pode ser dividida em duas categorias: lateração, que utiliza medidas de distância e a angulação, que utiliza medidas de ângulos.

\section{Lateração}

A lateração calcula a posição de um objeto através da sua distância a alguns pontos de referência. Para o cálculo da posição do objeto em duas dimensões (2D) são necessárias as 
medidas de distância a três pontos de referência não-colineares, como mostra a figura 5.1. Em três dimensões (3D), por sua vez, são necessárias medidas a quatro pontos não-coplanares.

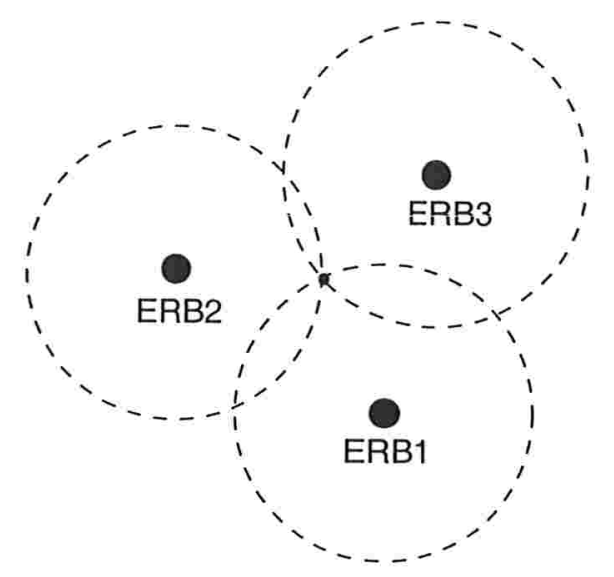

Figura 5.1: A interserção dos círculos corresponde à localização da UM.

Para a medição das distâncias existem três mecanismos: direta, time-of-flight e atenuação. A medida direta é a técnica mais básica, utiliza uma ação física ou movimento, como por exemplo, um robô que calcula as distâncias com uma fita métrica. É uma abordagem fácil de entender, mas difícil de implementar de forma automatizada.

O time-of-fight, como o seu próprio nome diz, utiliza-se do tempo médio gasto por um sinal enviado pelo objeto para ir do ponto em que o objeto está a um ponto $\mathrm{P}$ específico, a uma velocidade conhecida. Por exemplo, as ondas de som têm uma velocidade aproximada de $344 \mathrm{~m} / \mathrm{s}$. Portanto, um pulso ultra-sônico enviado por um objeto e chegando no ponto P (receptor do sinal) em 14, 5 milisegundos, permite concluir que o objeto está a 5 metros do ponto $\mathrm{P}$.

Por último, temos a abordagem de atenuação, que se baseia na intensidade do sinal emitido pela unidade móvel, pois o mesmo diminui quando a distância entre a fonte de emissão e o receptor aumenta. A atenuação é a diminuição relativa à intensidade original. Obtida a função que relaciona a atenuação e a distância entre o emissor e o receptor, é possível estimar a distância do objeto, em um ponto $\mathrm{P}$, ao emissor através da intensidade de emissão que ele possui em $\mathrm{P}$.

Obtida a distância aos pontos de referências, a técnica de lateração consegue estimar a localização do objeto, que corresponderá ao baricentro dos pontos. 


\section{Angulação}

A angulação, por sua vez, utiliza o ângulo de recebimento do sinal emitido para determinar a localização do objeto, mas o princípio é o mesmo da lateração. Em ambientes de duas dimensões são necessárias a medida de dois ângulos e a medida de comprimento (distância entre os dois pontos de referência), como mostra a figura 5.2. Em 3D, são necessários dois ângulos, uma medida (azimuth) e o comprimento para estimar a localização da unidade.

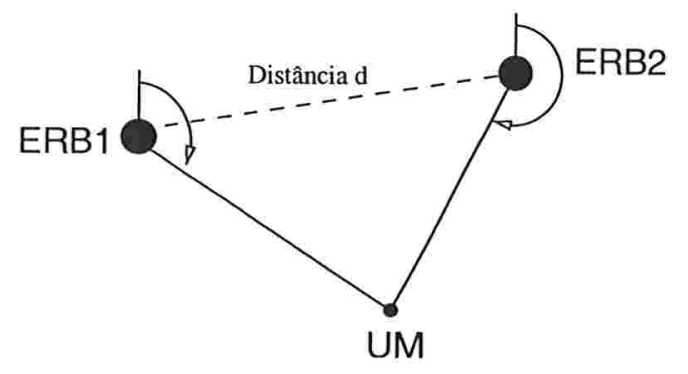

Figura 5.2: Técnica de localização baseada na angulação.

\subsubsection{Proximidade}

A técnica de proximidade determina quando um objeto está dentro de uma área com localização conhecida. Existem três enfoques para esta técnica:

- Contato físico: é a abordagem mais básica, detecta o contato físico com um objeto conhecido, tais como sensores de pressão, de toques, entre outros;

- Pontos de acesso sem fio: monitora quando a unidade móvel está na faixa de um ou mais pontos de acesso (receptores) do sinal emitido por ela;

- Sistema de identificação automática: obtém a localização do objeto ou pessoa através da utilização de terminais que identificam o mesmo e, obviamente, possuem localização conhecida. Por exemplo, terminais de cartão de crédito, login do computador, etc.

\subsubsection{Análise de Cenas}

A heurística de análise de cenas utiliza características de uma cena observada de uma posição estratégica para estimar a localização do observador ou dos objetos da cena. 
O sistema analisa a cena e verifica as suas características, comparando-as com a uma base de dados que indica para determinada localização, quais devem ser as características da cena, estimando assim, a posição do objeto.

As cenas podem consistir de imagens concretas, visuais, capturadas por uma câmera, ou qualquer outro fenômeno físico mensurável, tais como a intensidade de sinal naquele ambiente (cena), ou a variação do mesmo, entre outros.

\subsection{Propriedades}

Além da técnica utilizada, os sistemas de localização também se diferenciam em relação ao tipo de localização que fornecem, física ou simbólica, absoluta ou relativa, precisão, exatidão, entre outros. Explicaremos a seguir algumas dessas propriedades.

\subsubsection{Localização Física e Simbólica}

Um sistema de localização pode oferecer dois tipos de informação sobre a posição de uma unidade móvel: física e simbólica. Podemos dizer que um sistema oferece a localização física de um objeto quando ele é capaz de fornecer a posição "exata" do mesmo em relação a um ou mais pontos de referências. O GPS [48], por exemplo, pode fornecer a informação "o seu dispositivo está localizado em $47^{\circ} 39^{\prime} 17^{\prime \prime} \mathrm{N}$, a uma altitude de 20,5 metros". Esta informação está baseada no sistema de coordenadas geográficas.

A localização simbólica, por sua vez, nos fornece apenas uma informação abstrata da localização da unidade, menos precisa, por exemplo: na cozinha, no quarto, etc. Para obter esse tipo de informação geralmente o sistema utiliza uma rede de sensores no ambiente a ser rastreado.

Geralmente é possível transformar um sistema de localização física em simbólica. Isto é feito através de uma base de dados que delimita as regiões (símbolos) conhecidas. O sistema compara a localização absoluta com a base de dados e consegue inferir a região correspondente à informação obtida. 


\subsubsection{Posição Absoluta ou Relativa}

A informação de localização ainda pode ser classificada como absoluta ou relativa. Em um sistema de localização absoluta utiliza uma grade de referência compartilhada com todas as unidades do sistema. Por exemplo, todos dispositivos GPS utilizam a latitude, longitude e altitude para informar o seu posicionamento.

Em um sistema que fornece a posição relativa, cada objeto possui os seus próprios pontos de referência. A localização é calculada em relação aos mesmos. Esse tipo de sistema pode se utilizado para fornecer a posição absoluta se a localização absoluta dos pontos de referência é conhecida. De forma análoga, um sistema de localização absoluta pode fornecer uma informação relativa utilizando um segundo ponto como referência.

\subsubsection{Exatidão e Precisão}

Os sistemas de localização informam a posição de uma unidade móvel com o respectivo erro. Alguns receptores GPS, por exemplo, podem localizar um dispositivo com erros de, no máximo, 10 metros em $95 \%$ das medições. O primeiro valor é chamado precisão do sistema e o segundo a exatidão do mesmo.

\subsubsection{Ambientes Externos e Internos}

Um outro fator que caracteriza um sistema de localização é o seu ambiente de funcionamento. Dependendo da sua infra-estrutura, ele pode funcionar apenas em ambientes internos ou externos.

Um exemplo de sistema para ambientes interno é o Active Badge [47], que é baseado em uma rede de sensores, geralmente instalados no teto de cada área do ambiente. O GPS, por sua vez, necessita de comunicação com satélites, o que impossibilita a sua utilização em um prédio comercial (mais detalhes serão dados na subseção 5.4.3).

\subsubsection{Cálculo Local da Localização}

Alguns sistemas disponibilizam um mecanismo para o próprio dispositivo calcular a sua localização. Este modelo, Localized location computation (LLC), tem a vantagem de manter a 
informação da posição do objeto encapsulada. Se o objeto não publicar esta informação somente ele terá conhecimento da sua localização.

Entretanto, na maioria dos sistemas existe um elemento central responsável por fazer o cálculo da localização de um objeto. Para isto ser possível, a unidade móvel envia periodicamente ou sob demanda um sinal para este elemento, que pode assim, rastreá-la utilizando alguma técnica específica.

\subsubsection{Reconhecimento}

Em algumas situações, é importante que o sistema de localização disponibilize algum tipo de identificação (GUID - Globally-unique identifier) automática das unidades localizadas, de forma que outras aplicações possam utilizar essa informação, como por exemplo, para acessar um banco de dados que disponibiliza mais informações sobre a unidade móvel.

\subsection{Tecnologias}

As principais tecnologias foram desenvolvidas para ambientes internos, tais como ParcTab [20], Active Badge [47], Ekahau [7], Microsoft Radar [37], entre outras. Posteriormente surgiram sistemas para ambientes externos como o GPS [48]. A seguir descreveremos brevemente os principais sistemas.

\subsubsection{Active Badge}

O sistema de localização Active Badge foi desenvolvido pela Olivetti Research Laboratory no final da década de 80 . O objetivo inicial do projeto era simples, rotear chamadas telefônicas de um PABX para a extensão mais próxima à pessoa destinatária da ligação. Para isso, o ambiente a ser rastreado é coberto por uma rede de sensores (beacons), geralmente instalados no teto de cada área (quarto, sala, etc) do ambiente.

Além disso, cada pessoa a ser localizada carrega um pequeno crachá (badge) com um dispositivo infravermelho que emite um sinal único periodicamente, de 10 em 10 segundos, ou sob demanda do sistema. Um servidor central coleta os dados dos receptores IR (beacons) e provê uma API para utilização desses dados. 
É curioso notar que os primeiros badges continham apenas um botão, para verificar se o mesmo estava emitindo sinal. Mas posteriormente, o grupo de desenvolvedores percebeu que poderiam projetar um dispositivo que enviasse comandos (requisições) para o sistema de localização, e o sistema responderia de acordo com a localização da unidade, surgindo assim, o protótipo da primeira aplicação baseada em localização (location-based application).

Como podemos notar, a localização fornecida pelo sistema é simbólica, absoluta, baseada na técnica de proximidade, sem computação local e com reconhecimento das unidades. Sua precisão depende da quantidade de receptores e do tamanho de cada célula do ambiente.

Sua principal desvantagem é utilizar como meio de comunicação sinais infravermelhos que, como sabemos, sofrem interferência sob luz fluorescente e solar, o que acaba confundindo os receptores. Além disso, ele necessita de uma infra-estrutura própria (redes de sensores, dispositivos acoplados a UMs), o que aumenta o seu custo de implantação.

\subsubsection{Active Bat}

Posteriormente, os laboratórios da $A T B T$ desenvolveram um sistema mais preciso que o Active Badge, chamado Active Bat, que utiliza a técnica de triangulação através de sinais ultra-sônicos emitidos pelo Active Bat Tag, um pequeno dispositivo acoplado à UM.

Cada sensor de teto (controlador local) está conectado em rede serial cabeada ao controlador central. Para obter a localização de uma UM, o controlador central envia ao mesmo tempo um pacote de requisição via onda de rádio, e um sinal de sincronização aos sensores de teto através da rede serial. Cada sensor de teto mede o intervalo de tempo do sincronismo até o pulso ultra-sônico recebido e calcula a distância até o equipamento Bat. O controlador central recebe as distâncias calculadas pelos receptores locais e faz o cálculo da triangulação, obtendo a localização da UM.

Portanto, para fornecer a localização, o sistema utiliza a técnica de lateração, calculando a distância entre os pontos de referência através da abordagem time-of-flight. Isso possibilita um sistema muito preciso, estima-se que esse sistema tenha uma precisão de $9 \mathrm{~cm}$ em $95 \%$ das medições. 


\subsubsection{GPS}

Esse sistema surgiu no fim da década de 80 como um dos primeiros sistemas de localização para ambientes externos. Ele utiliza um conjunto de 24 satélites para encontrar a posição do usuário. Os satélites transmitem continuamente informações codificadas para os receptores portáteis, que conseguem identificar localizações na Terra, usando a medida de distância dos satélites.

O GPS, ou NAVSTAR, consiste de três segmentos: espaço (satélites), usuário (receptor GPS) e controle (estações terrestres). O segmento controle é responsável por prover a informação de relógio e órbita aos satélites. Existem cinco estações no mundo: quatro de monitoramento e uma estação mestre. As estações de monitoramento recebem constantemente dados dos satélites e reenviam a estação mestre. A estação mestre, por sua vez, corrige os dados do satélite e através de duas antenas, envia as informações aos satélites (uplink).

O GPS funciona da seguinte maneira. Inicialmente o receptor GPS precisa conhecer onde está e a que distância está dos satélites. Assim, o receptor GPS busca dois tipos de informação codificada. Uma das informações é conhecida como almanac e contém as posições aproximadas dos satélites. Este dado é continuamente transmitido e é armazenado em memória pelo receptor GPS. Com isso, ele conhece a órbita e a posição onde teoricamente o satélite está. Como foi dito, as estações terrestres enviam dados da órbita à estação mestre, que envia os dados corrigidos aos satélites. Este tipo de dado, que contém a posição corrigida, é chamado de ephemeris e é válido durante 4 a 6 horas, sendo transmitido como informação codificada ao receptor GPS. Assim, após ter recebido o almanac e ephemeris, o receptor GPS consegue calcular sua posição utilizando algumas leis básicas da física.

O sistema de posicionamento global fornece a localização física, absoluta, em termos de latitude, longitude e altitude, com uma precisão de 10 metros em $95 \%$ das medições. Devido à necessidade de comunicação com os satélites, os receptores GPS não funcionam em ambientes internos.

\subsubsection{RADAR}

A Microsoft desenvolveu um sistema de localização denominado RADAR [2], baseado no padrão de rede sem fio IEEE 802.11 [32]. Ele mede a intensidade do sinal do aparelho sem fio e compara com uma base de dados que contém a intensidade de sinal em cada área do ambiente. 
Assim, o sistema utiliza a técnica de análise de cena, obtendo uma precisão de 3 metros em $50 \%$ das medições. Sua principal vantagem é utilizar a mesma infra-estrutura da rede sem fio, não sendo necessário uma rede específica para o sistema de localização.

Infelizmente, o sistema ainda está sendo desenvolvido, no momento é apenas um protótipo (referenciado em [43]), não existe uma aplicação final disponibilizada aos usuários.

\subsubsection{Ekahau}

O sistema de localização Ekahau [23] foi desenvolvido por uma empresa da Finlândia e suas características são muito parecidas com o Microsoft Radar. Na próxima seção explicaremos em detalhes o seu funcionamento.

\subsubsection{Tecnologia Utilizada}

Para solucionar o problema proposto, gostaríamos que a tecnologia de localização não utilizasse nenhum hardware adicional, apenas a rede sem fio para localizar a unidade móvel. Por esse motivo, as opções se restringiram ao Ekahau e ao Microsoft Radar, como mostra o quadro 5.1 .

O sistema foi desenvolvido utilizando o Ekahau. Entretanto, a implementação foi feita de forma a tornar o sistema flexível quanto à tecnologia de localização utilizada. Criamos uma interface que define o esqueleto das classes que fornecem a localização do dispositivo móvel. Para utilizar outro sistema de localização, basta criar uma classe que implemente esta interface.

A seguir descreveremos detalhadamente o sistema utilizado Ekahau Positioning Engine.

\begin{tabular}{|c|c|c|c|c|c|c|}
\hline Tecnologia & Localização & Técnica & Precisão & Ambiente & LLC & GUID \\
\hline \hline Active Bagde & simbólica & proximidade & tamanho célula & interno & não & sim \\
\hline Active Bat & física & triangulação & $9 \mathrm{~cm}-95 \%$ & interno & não & sim \\
\hline GPS & física & triangulação & $10 m-95 \%$ & externo & sim & não \\
\hline Radar & física & an. cenas & $3-5 m-50 \%$ & interno & não & sim \\
\hline Ekahau & física & an. cenas & $1-5 m-75 \%$ & interno & não & sim \\
\hline
\end{tabular}

Tabela 5.1: Tecnologias de localização de UMs. 


\subsection{Ekahau Positioning Engine}

O sistema de localização Ekahau é um aplicativo comercial desenvolvido por uma empresa da Finlândia e é muito utilizado na Europa. Algumas universidades, como a de Copenhague (Dinamarca) [7], mantêm laboratórios para o desenvolvimento de aplicativos sensíveis à localização (location-aware) utilizando o Ekahau.

A principal razão para o sucesso desse sistema é o seu processo de localização, que é feito totalmente via software. Diferente de outros sistemas, ele não requer nenhum hardware proprietário adicional, pois o mesmo utiliza apenas a infra-estrutura da rede sem fio, obrigatoriamente do padrão IEEE 802.11b, para efetuar a localização de um dispositivo conectado à rede. O Ekahau é um sistema de localização para ambiente interno.

A localização pode ser fornecida de forma simbólica e/ou absoluta. Os tipos de retorno na forma simbólica são definidos pelo cliente através de áreas lógicas em um mapa, posteriormente mostraremos como criá-las. A precisão da localização fornecida é variável de acordo com alguns parâmetros: número e disposição das estações rádio-base (ERBs), configuração do Ekahau, etc., mas estima-se que o sistema tem em média 3 metros de precisão em $75 \%$ das medições. O gráfico 5.3 mostra uma média da precisão de acordo com o número de ERBs do ambiente interno.

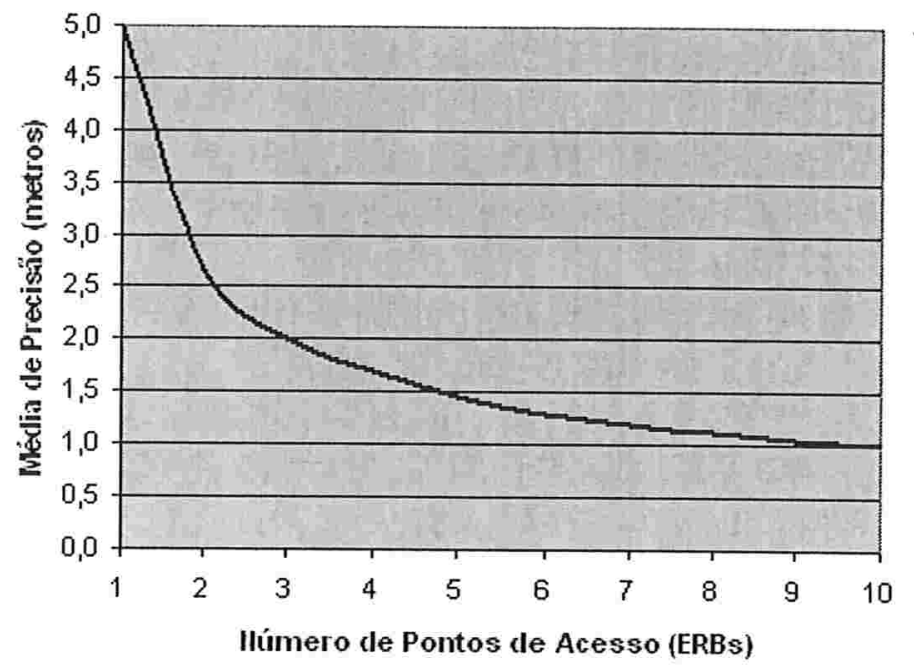

Figura 5.3: Gráfico comparando a precisão e o número de pontos de acesso [23]. 


\subsubsection{Funcionamento}

Seu mecanismo principal basea-se na diferença da intensidade de sinal (Received Signal Strength Intensity - RSSI) [32] entre locais físicos diferentes. No processo de instalação do Ekahau é realizado um processo de calibragem do sistema (explicado na próxima seção) em que é armazenada a intensidade do sinal em alguns pontos do ambiente coberto pela ERBs. Esses pontos são chamados de pontos de amostra (sample points). Baseado nos pontos de amostra armazenados, o Ekahau consegue comparar a intensidade de sinal da UM com os pontos armazenados e inferir a localização do dispositivo.

O módulo responsável por realizar esse processo é chamado Ekahau Positioning Engine, ele foi implementado em Java e pode ser acessado através de uma API Java disponibilizaḑa pelo sistema. Além deste módulo, a arquitetura é composta por outros quatro módulos (veja tabela 5.2 e a figura 5.4).

\begin{tabular}{lll}
\hline \hline Módulo & Descrição & Ambiente \\
\hline \hline Ekahau Positioning Engine & Aplicativo Java, disponibiliza a localização & Windows NT, \\
& e rastreamento de UMs aos clientes. & 2000, XP \\
\hline Ekahau Manager & Analisa a precisão do sistema, áreas & Windows NT, \\
& cobertas e gerencia áreas lógicas. & 2000, XP \\
\hline Ekahau Calibrator & Aplicação responsável por gravar os dados & Windows NT, \\
& da calibragem da área para a Positioning & 2000, XP, \\
& Engine. & CE, Pocket PC \\
\hline Ekahau Device Service & Serviço executado nas UMs a serem & Windows NT, \\
& rastreadas. & 2000, XP, \\
& & CE, Pocket PC \\
\hline
\end{tabular}

Tabela 5.2: Módulos do Ekahau.

Nas próximas seções descreveremos, em detalhes, o funcionamento de cada um dos módulos do Ekahau.

\subsubsection{Ekahau Calibrator}

O processo de calibragem do sistema é feito através do Ekahau Calibrator. Através dele, o usuário poderá armazenar os pontos de amostras em um arquivo de dados (.ecd) para posteriormente serem lidos pela Positioning Engine. 


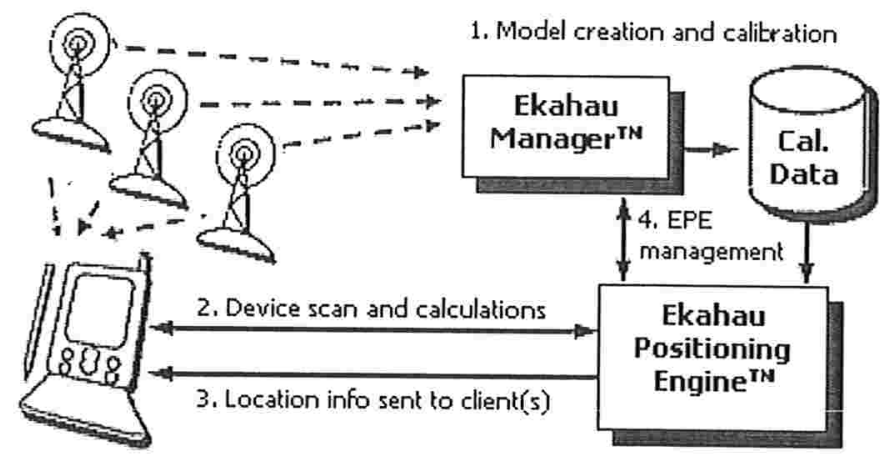

Figura 5.4: Arquitetura do Ekahau Positioning Engine.

Nesse aplicativo é feito o cadastro de um mapa (.bmp ou .png) com a visualização do ambiente a ser rastreado com a sua respectiva escala. Isso permite a visualização no mapa dos pontos de amostra (ver figura 5.5).

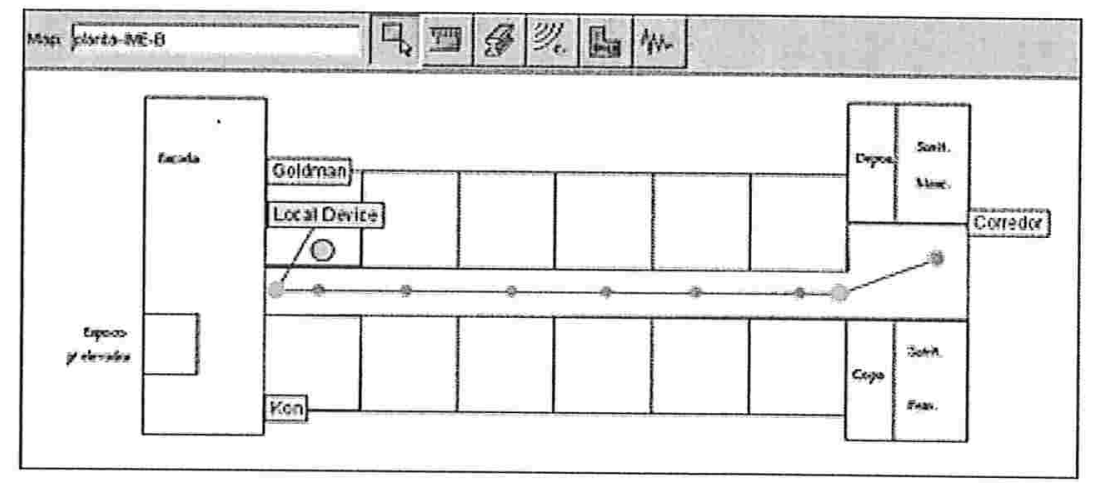

Figura 5.5: Exemplo de mapa contendo as áreas lógicas lidas pelo Ekahau.

Há dois métodos para criar os pontos de amostras: ponto e linha. No método do ponto, o usuário precisa se fixar em um ponto do ambiente, tentando não se mover, e girar lentamente $360^{\circ}$ em volta do seu próprio eixo, simulando a rotação do dispositivo. Esse procedimento deve ser repetido para cada ponto de amostra a ser armazenado.

No método da linha o usuário consegue gravar pontos de amostra na mesma sessão. O usuário marca um ponto de origem e um de destino e anda lentamente, tentando manter a mesma velocidade e direção, até o ponto de destino. Assim, o aplicativo, consegue inferir a intensidade de sinal em alguns pontos do trajeto.

O primeiro método é mais preciso, e deve ser usado para a calibragem final do sistema. O método da linha, embora seja mais rápido, somente deve ser utilizado para a coleta de dados de 
teste.

Para melhorar ainda mais a precisão do sistema, existe uma técnica para a escolha dos pontos de amostras. Os pontos devem ser escolhidos a cada $5-20 \mathrm{~m}^{2}$, dependendo do tamanho do ambiente. Os pontos também não devem estar próximos a paredes ou outros objetos que possam interferir no sinal da ERB.

Além disso, para cada tipo de local, o Ekahau disponibiliza um modelo de escolha dos pontos de amostra, recomendando como deve ser feita a escolha de acordo com o tipo de ambiente. Em cada ponto de amostra, o Ekahau Calibrator armazena a intensidade de sinal (RSSI) em decibéis $(\mathrm{dBm})$ de cada canal da ERB.

Para áreas problemáticas, com pouco sinal ou com muita variação de sinal, é recomendado gravar mais pontos de amostra. A identificação dessas áreas pode ser feita pelo Ekahau Manager como mostraremos a seguir.

\subsubsection{Ekahau Manager}

A principal funcionalidade deste módulo é diagnosticar problemas com o sistema de localização. Ele analisa a precisão do sistema, a coleta dos pontos de amostra, entre outros dados.

Através deste aplicativo, é possível abrir um arquivo de dados (.ecd) e verificar, em cada ponto de amostra, a disposição da intensidade de sinal (em cada canal). Além disso, é possível calcular a média (mínimo ou máximo) da intensidade em cada ponto da amostragem.

Baseado nesse cálculo o Ekahau Manager pode gerar um mapa de intensidades de sinais, mostrando as áreas cobertas pela ERB com a respectiva intensidade do sinal em cada área. Sendo possível assim, identificar áreas que estão parcialmente cobertas, indicando ao usuário uma má localização das ERBs ou uma subestimação do número das mesmas.

Além disso, o aplicativo permite a criação ou edição de áreas lógicas. O usuário define cada uma das áreas lógicas através de um editor de mapa. As coordenadas das áreas são armazenadas em um arquivo de dados (.txt) que posteriormente pode ser lido pelo Positioning Engine. O módulo permite ainda realizar o rastreamento de um dispositivo, através do fornecimento do seu endereço IP e o período de tempo de atualização da localidade do mesmo. 


\subsubsection{Ekahau Positioning Engine}

O Ekahau Positioning Engine é um servidor, desenvolvido em Java, que fornece a localização de um dispositivo móvel. Além disso, ele provê uma biblioteca em Java para disponibilizar um mecanismo de requisição ao mesmo.

As aplicações podem utilizar a Positioning Engine API para rastrear usuários ou recursos conectados à rede sem fio. A engine retornará para o cliente um objeto TrackedDevice que contém as informações de localização do mesmo, coordenadas, áreas lógicas, indicador de qualidade da informação de localização, etc. Para iniciar o módulo é necessário fornecer a porta de requisição que será utilizada, o respectivo arquivo de dados (.ecd) e o arquivo de log.

Com o aplicativo iniciado é possível implementar um cliente que se comunique com a aplicação e requisite a localização de um dispositivo especificado. Isso é feito através da instanciação da classe PositioningEngineClient fornecida pela API, cujo construtor recebe como parâmetro um arquivo de propriedades especificando a porta e endereço IP do servidor a ser utilizado.

Para requisitar a localização de um dispositivo é necessário criar um objeto TrackedDevice através do método createTrackedDevice, que recebe o endereço IP da UM como parâmetro (veja quadro 5.1). Com o objeto criado, é possível associar uma classe receptora da informação da localização. Esta deve implementar a interface LocationHandler para que a Positioning Engine chame o método handleLocation informando a localização do dispositivo especificado. 


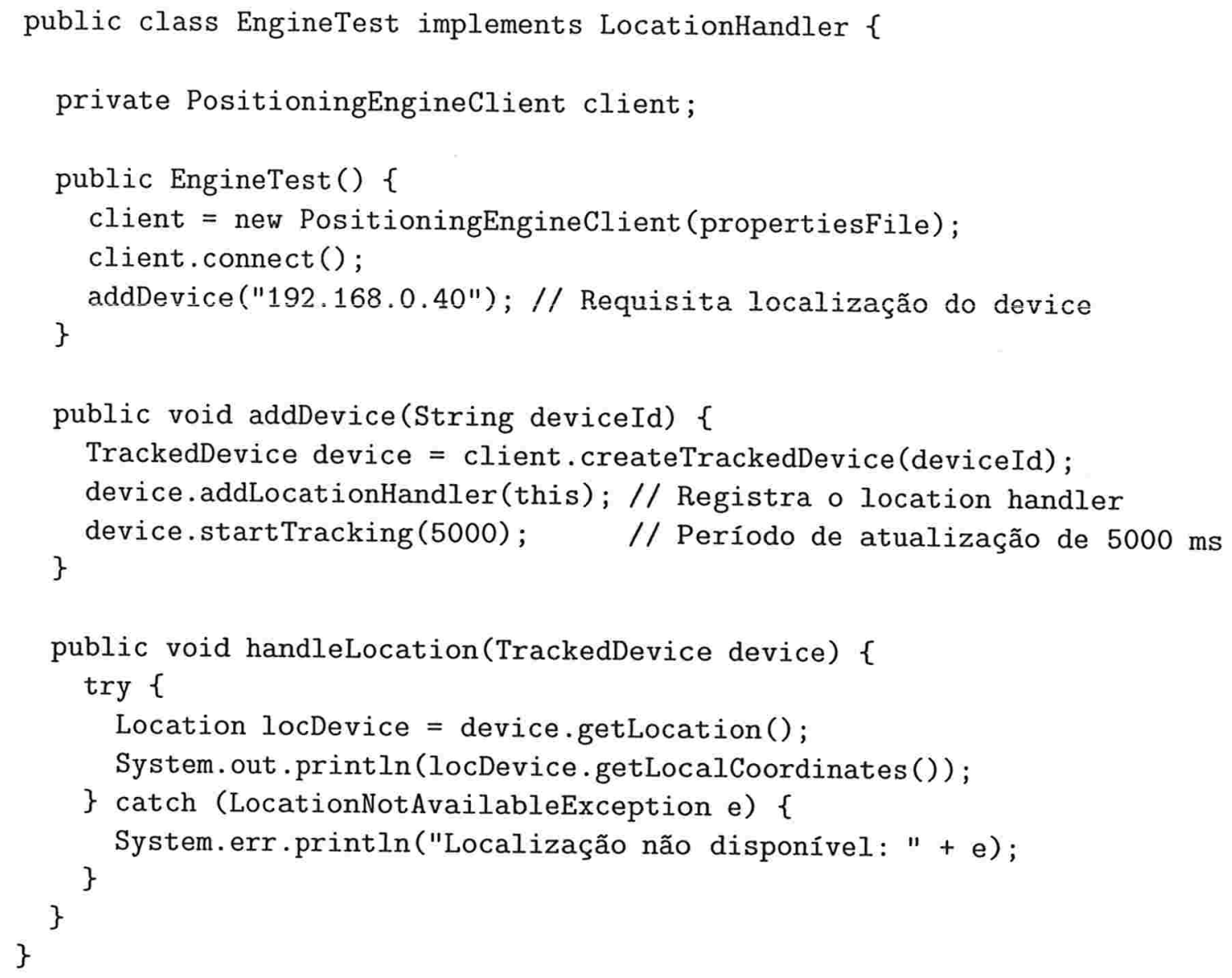

Código 5.1: Cliente requisita a localização da UM.

Se o cliente quiser a localização de forma simbólica, utilizando áreas lógicas, ele deve fornecer o arquivo de dados (.txt) que delimita as mesmas (veja quadro 5.2). Com isso a engine consegue analisar a localização da UM encontrada, comparar com as coordenadas das áreas lógicas fornecidas e devolver para o cliente, através do método getAreaProbabilities, uma ou mais áreas lógicas em que a UM possa estar, com a respectiva probabilidade. 


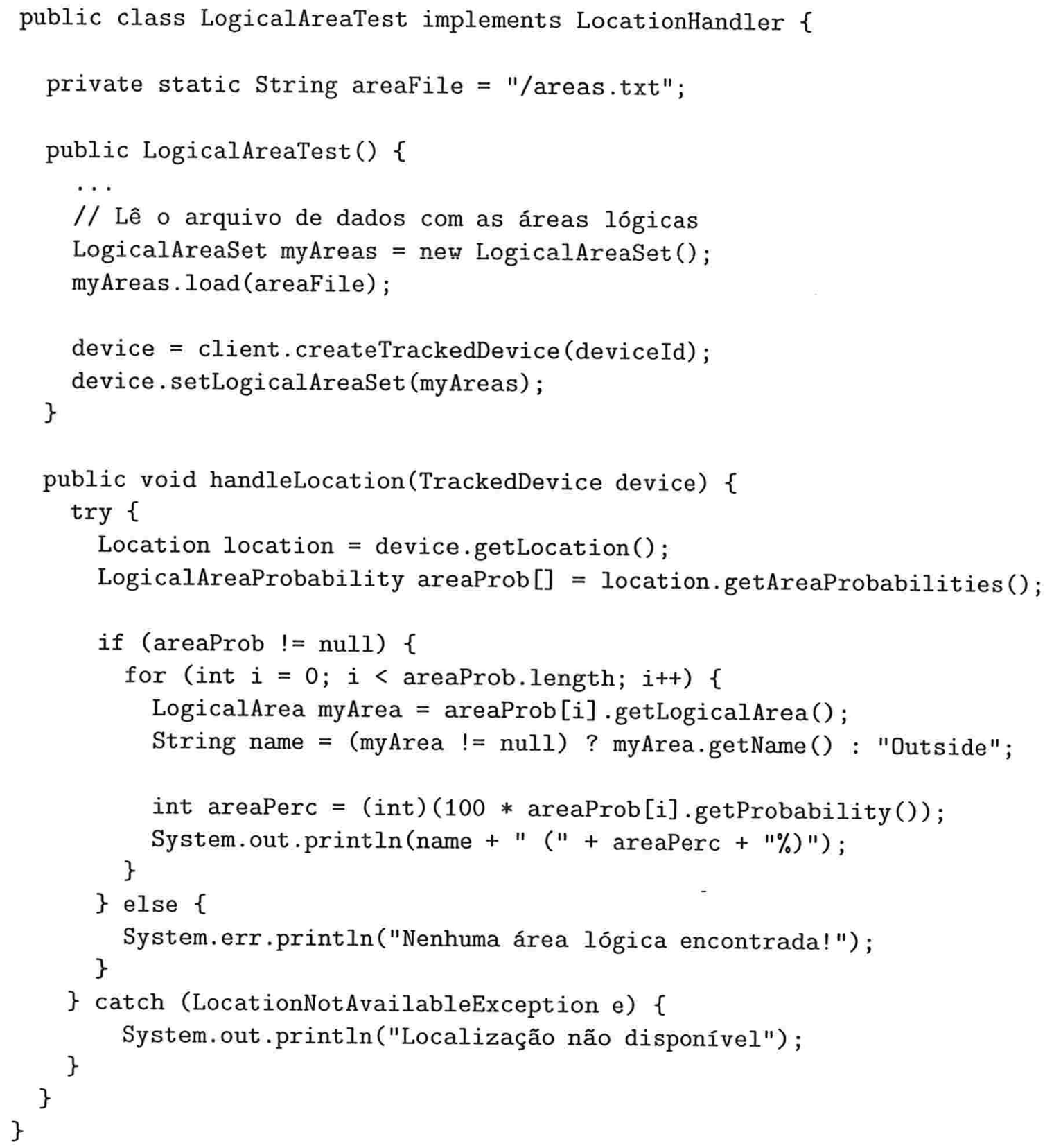

Código 5.2: Cliente requisita a localização simbólica da UM.

\subsubsection{Ekahau Device Service}

Este aplicativo é o único que não tem intervenção do usuário. É um serviço que deve ser executado em cada unidade móvel que pode ser rastreada. Depois de iniciado o serviço a UM poderá ser encontrada pelo módulo Positioning Engine. 
Ele é responsável por informar à Positioning Engine a intensidade de sinal atual da unidade móvel. Por isso, depende da placa sem fio utilizada. Atualmente, o ekahau contempla cinco modelos diferentes de placas sem fio: Compaq WL110, Nokia, Enterasys RoamAbout, Avaya World Card e Orinoco Gold/Silver.

\subsection{Conclusão}

O problema da localização de unidades móveis em uma rede tem grande importância atualmente devido ao aumento do número de redes sem fio e pequenos dispositivos nos últimos anos.

Várias tecnologias foram desenvolvidas para prover a localização dinâmica das unidades móveis. Entretanto, a maioria dos sistemas desenvolvidos necessitam de uma infra-estrutura de rede própria e, em alguns casos, é necessário acoplar um pequeno dispositivo à unidade móvel para que o sistema funcione.

Para resolver o problema proposto e obter a localização do cliente móvel, gostariamos de utilizar uma tecnologia cuja solução utilizasse somente a rede sem fio no padrão IEEE 802.11 e não necessitasse de hardware adicional. Devido a isso, escolhemos o Ekahau Positioning Engine para validar o protótipo.

A principal vantagem do Ekahau é disponibilizar um sistema que não necessita de nenhum recurso físico adicional, apenas da infra-estrutura da rede sem fio. Entretanto, por esse motivo ele depende da placa sem fio a ser utilizada e atualmente só contempla poucos modelos, o que pode ser um fator limitante na sua utilização.

Além disso, como o seu servidor (Positioning Engine) foi implementado em Java, ele pode ser acessado, através da API, por qualquer aplicação feita nessa linguagem e portanto, potencialmente rodando em qualquer plataforma. Entretanto, os outros três módulos do sistema: Manager, Calibrator e Service só podem ser utilizados na plataforma Windows, o que limita a utilização do Ekahau em outras plataformas. 


\section{Capítulo 6}

\section{Implementação}

Como foi mencionado nos capítulos anteriores, nenhum sistema apresentado possui a funcionalidade de escolher o serviço mais conveniente ao usuário, como por exemplo o servidor mais próximo a ele. No serviço de impressão, essa funcionalidade seria extremamente útil, pois, por razões óbvias, o cliente gostaria de utilizar a impressora mais próxima a ele. Isso é ainda mais importante em ambientes grandes de rede sem fio, como o prédio do IME-USP, em que uma UM pode estar em qualquer andar ou bloco.

Neste capítulo apresentaremos em detalhes o protótipo desenvolvido, as modificações realizadas no Jini e no SLP, a integração dos SDSs com o Ekahau Positioning Engine e a implementação de um módulo para pequenos dispositivos. Descreveremos ainda, uma simulação do seu funcionamento, o ambiente dos testes realizados no sistema e um breve procedimento para a sua utilização.

\subsection{Protótipo}

Decidimos implementar um protótipo que agregasse essas novas funcionalidades aos sistemas estudados, integrando os sistemas de descoberta de serviços às tecnologias de localização física de UMs. Mas para isso, foi necessário solucionar algumas questões. Como obter a localização de uma UM? Como adaptar os sistemas existentes para considerar a localização do cliente? O sistema funcionará em pequenos dispositivos com recursos (processamento, memória, etc.) limitados? Essas questões serão respondidas ao longo deste capítulo. 


\subsubsection{Estrutura}

O protótipo foi feito totalmente em Java a fim de facilitar a comparação entre os SDSs e incentivar a reutilização de código. Seu desenvolvimento foi dividido em módulos independentes entre si. Cada um dos módulos ficou responsável pela implementação de algumas tarefas:

- Impressão: Implementação do serviço de impressão;

- Localização: Construção do módulo que fornece a localização da UM;

- SDS: Desenvolver cliente e servidor no respectivo SDS e modificar SM para considerar a localização do cliente na busca ao serviço;

- Dispositivo Móvel: Migrar o sistema para as arquiteturas utilizadas em pequenos dispositivos (por exemplo: Palm, Ipaq).

O módulo de SDS foi desenvolvido em duas versões: uma utilizando a tecnologia SLP e outra utilizando a tecnologia Jini. A implementação dos módulos deu origem aos seguintes pacotes em Java:

\begin{tabular}{|l|l|}
\hline Pacote & Descrição \\
\hline \hline ime.print & Pacote responsável pelo serviço de impressão \\
\hline ime.loc & Disponibiliza subsistemas de localização da unidade móvel \\
\hline ime.slp & Implementa os agentes do SLP \\
\hline ime.jini & Implementa os elementos do Jini \\
\hline ime.palm & Fornece o cliente do sistema feito para o Palm \\
\hline
\end{tabular}

Tabela 6.1: Divisão de pacotes do sistema.

A seguir explicaremos detalhadamente a implementação de cada um dos módulos.

\subsubsection{Impressão}

O servidor de impressão é o módulo mais simples do sistema. Ele é responsável por disponibilizar o canal de comunicação final com a impressora. Por esse motivo, o computador em que ele estiver sendo executado deve conter todo o software necessário (drivers, clientes, etc) e hardware (acesso físico: cabo paralelo ou rede) para a comunicação com a mesma. 
O servidor é inicializado fornecendo uma porta e um nome para a impressora. Com esses dados, o sistema abre um canal de comunicação na porta especificada. A partir desse momento, o cliente pode enviar, via socket, o arquivo a ser impresso e o servidor chama o serviço local de impressão fornecendo o caminho do arquivo, que finalmente envia o arquivo para a impressora. Para que isto fosse possível foi necessária a implementação de duas classes:

\begin{tabular}{|l|l|}
\hline Classe & Descrição \\
\hline \hline PrintService & Implementa o serviço de impressão \\
\hline PrintServiceThread & Thread que atende a cada uma das requisições de impressão \\
\hline
\end{tabular}

Tabela 6.2: Classes do serviço de impressão.

A primeira classe é responsável por abrir o canal de comunicação, e a segunda por atender cada uma das requisições de impressão, redirecionando-as para a impressora.

É conveniente ressaltar que esse módulo não seria necessário em impressoras mais avançadas, pois a mesma poderia conter uma placa de rede e um software embutido, que aceitasse conexões em uma porta específica e atendesse requisições de impressão através de algum protocolo específico.

\subsubsection{Localização}

Como foi dito no capítulo 5, o sistema foi desenvolvido utilizando o Ekahau. Entretanto, a implementação foi feita de forma a tornar o sistema flexível quanto à tecnologia de localização utilizada. Criamos uma interface (LocationInterface) que define o esqueleto das classes que fornecem a localização do dispositivo móvel. Para utilizar um outro de sistema de localização, basta criar uma classe que implemente a LocationInterface.

No momento, implementamos duas opções de sistemas de localização encapsuladas nas classes ConstantLocation e EkahauLocation. A primeira implementação é mais simples, o usuário fornece manualmente a localização absoluta daquele instante. A segunda classe corresponde a um cliente do Ekahau, conforme mostrado no quadro 5.1, que obtém a localização da UM consultando o Ekahau Positioning Engine.

Além disso, definimos uma interface para as classes que contém a semântica de proximidade, ou seja, que decidem que servidor está mais próximo da unidade móvel. No momento, temos 
apenas uma implementação dessa interface: SimpleNearestLocation, cuja semântica é bem simples. Ela encontra o objeto (servidor) com a menor distância euclidiana ao ponto de origem (localização da UM) fornecido.

\begin{tabular}{|l|l|}
\hline Classe & Descrição \\
\hline \hline LocationInterface & Esqueleto das classes que fornecem a localização da UM \\
\hline ConstantLocation & Classe que fornece a localização (constante) de uma UM \\
\hline EkahauLocation & Fornece a localização de uma UM através do Ekahau \\
\hline Point & Representa a localização 3D da unidade móvel \\
\hline NearestLocation Interface & Interface das classes que contém a semântica de proximidade \\
\hline SimpleNearestLocation & Uma implementação simples de proximidade \\
\hline
\end{tabular}

Tabela 6.3: Classes do módulo de localização.

\subsubsection{SDS}

Foi necessário realizar algumas modificações nos sistemas de descoberta de serviços para que estes pudessem encontrar o servidor mais próximo ao cliente. As alterações principais são relativas à entidade que representa o repositório de serviços, pois foi necessário modificar o processo de seleção do serviço pedido e a forma da requisição para que o cliente informasse, de alguma maneira, a sua localização.

Além disso, foi necessário implementar, em cada um dos sistemas, o cliente e o servidor do nosso serviço de impressão, fazendo as adaptações necessárias conforme o arcabouço utilizado. Nas próximas seções mostraremos em detalhes as implementações realizadas em cada um dos sistemas.

SLP

A implementação do SLP utilizada é da Universidade de Columbia [49], feita em Java, que implementa a segunda versão do SLP e possui licença open source, podendo ser modificada e redistribuída conforme a necessidade.

Para uma melhor organização, modificamos a estrutura de pacotes da aplicação, a fim de agrupar classes utilizadas por uma mesma entidade. As classes que são utilizadas por mais de uma entidade foram colocadas no pacote util. 
Como foi visto na seção 3.1, o repositório de serviços do SLP, representado pelo directory agent, não escolhe o melhor serviço ao cliente, por isso foram feitas algumas modificações na implementação do mesmo. Além disso, o cliente do SLP precisou ser modificado para que este enviasse a sua localização atual. Para que isto fosse possível, foi modificada a especificação do SLP.

\begin{tabular}{|l|l|}
\hline Pacote & Descrição \\
\hline \hline ime.slp.da & Implementação do repositório de serviços \\
\hline ime.slp.sa & Provedor do serviço de impressão \\
\hline ime.slp.ua & Cliente do serviço no SLP \\
\hline ime.slp.util & Classes comuns, utilizadas por todos os pacotes \\
\hline
\end{tabular}

Tabela 6.4: Divisão de pacotes no subsistema SLP.

A seguir descreveremos todas as alterações e implementações realizadas no SLP, agrupadas pelo tipo.

\section{Especificação}

O sistema deve localizar o servidor mais próximo ao cliente. Para isso, o user agent precisa informar ao DA a sua localização no momento da requisição do serviço. Sendo assim, foi necessário alterar ligeiramente a especificação do SLP para contemplar a informação de localização do cliente.

Quando o cliente requisita um serviço, este envia uma mensagem SrvRqst ao directory agent com o tipo de serviço desejado, grupo do servidor, etc. Assim, incluímos um novo tipo de mensagem: SrvRqstWithLocation com functionID 13 (ver tabela 3.2), que contém os mesmos campos da mensagem SrvRqst mais um campo adicional User Location, que informa a localização atual da unidade móvel. Portanto, no momento da requisição de um serviço, no caso de impressão, o DA terá conhecimento da localização do usuário e poderá encontrar o servidor mais próximo ao UA.

A estrutura da nova mensagem criada é mostrada na figura 6.1. Podemos ver que a mensagem contém os mesmos campos da mensagem SrvRqst apenas sendo adicionado o campo User Location. Para incluir o novo tipo de mensagem na implementação do SLP utilizada, acrescentamos o novo functionID na classe que define as constantes (Const) do SLP e modificamos as classes responsáveis pela criação e análise das mensagens: slpMsgComposer e slpMsgParser, 
respectivamente (ver tabela 6.5), adicionando novos métodos que realizam a função de análise e montagem de mensagens SrvRqstWithLocation.

\begin{tabular}{|c|c|}
\hline Length of <PRList> & $<$ PRList $>$ string \\
\hline Length of <service-type> & $<$ service-type $>$ string \\
\hline Length of <scope-list> & <scope-list> string \\
\hline Length of predicate & predicate string \\
\hline Length of <SLP SPI > & $<$ SLP SPI > string \\
\hline Length of <User Location> & $<$ User Location> string \\
\hline
\end{tabular}

Figura 6.1: Estrutura da mensagem SrvRqstWithLocation.

\section{Service Agent}

Para disponibilizar o serviço de impressão no SLP implementamos um service agent, que localiza o directory agent da rede, publica o seu serviço, inicia o mesmo e espera conexões de clientes.

A publicação do serviço foi feita conforme a especificação do SLP (o processo é explicado na seção 3.1). Entretanto, para que seja possível a busca pelo servidor mais próximo ao cliente, deve existir algum mecanismo em que o SA possa informar a localização, geralmente fixa, da impressora.

Para solucionar esse problema, criamos um atributo padrão SrvLocation que conterá a localização do SA no momento do registro do serviço, e poderá ser utilizado pelo DA para decidir se o mesmo está ou não próximo ao cliente.

Após a publicação da URL do serviço, é tarefa do SA iniciar o serviço propriamente. Isto é feito através da instanciação da classe PrintService (ver seção 6.1.2) recebendo como parâmetro a respectiva porta do serviço (registrada no DA). Depois disso, o agente estará pronto a receber requisições na URL publicada. 


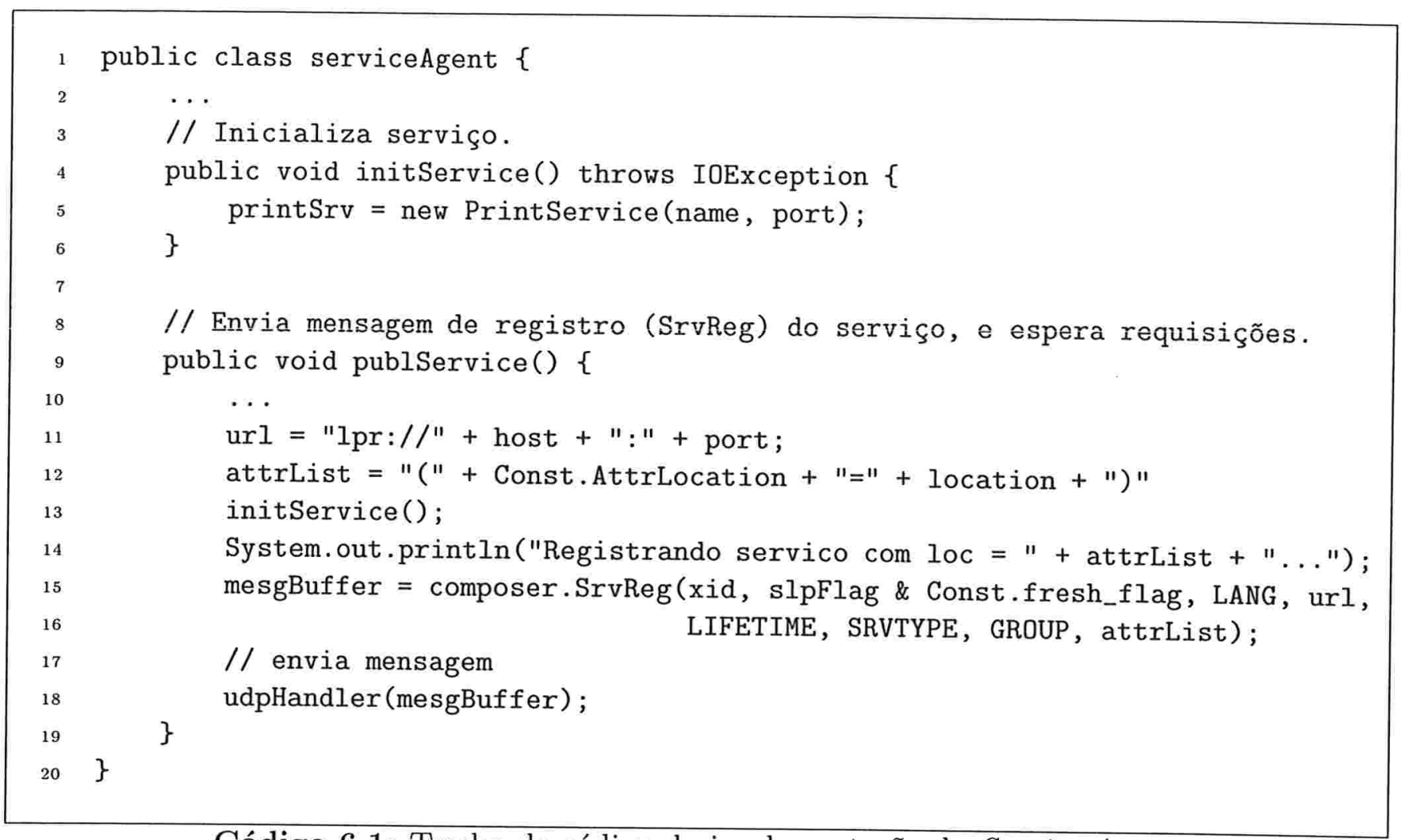

Código 6.1: Trecho de código da implementação do Service Agent.

\section{Directory Agent}

Modificamos o DA para receber mensagens do tipo SrvRqstWithLocation e, ao recebê-la, realizar uma busca na sua lista de serviços considerando a localização informada pelo usuário.

Para que o DA passasse a receber o novo tipo de mensagem, modificamos a classe daAction, adicionando mais uma ação executada no recebimento deste tipo de mensagem.

A ação padrão do elemento DA, ao receber uma mensagem SrvRqst, é chamar o métodogetMatchedURL da classe Database, responsável pela escolha dos servidores que atendem à requisição. Assim, tivemos que reescrever este método, adicionando um novo parâmetro userLocation que, após a busca dos serviços, escolhe o serviço mais próximo ao cliente, de acordo com a sua semântica de proximidade, representada pela classe NearestLocationInterface presente no módulo de localização (ver seção 6.1.3). Além disso, modificamos a classe que contém as ações do agente, criando um novo evento, ativado no recebimento de uma mensagem SrvRqstWithLocation, que chama o método getMatchedURL sobrecarregado com o parâmetro de localização. 


\section{User Agent}

Implementamos o cliente do serviço de impressão. O UA localiza o DA da rede, requisita o serviço informando a sua localização e, por fim, utiliza o serviço.

O processo de requisição do serviço é o mesmo da seção 3.1. A única diferença é o envio da mensagem SrvRqstWithLocation para informar a localização do cliente, ao invés da mensagem SrvRqst, conforme foi adiantado na seção de "Especificação".

Após a seleção do serviço, o cliente terá a informação da URL do servidor de impressão. O UA então, se conecta ao servidor na respectiva porta e inicia o protocolo de comunicação com o servidor. No nosso caso, o cliente envia o arquivo seriado a ser impresso, representado pelo objeto File, através do socket. O servidor, ao receber o arquivo, pode reconstruí-lo e enviá-lo para a impressora.

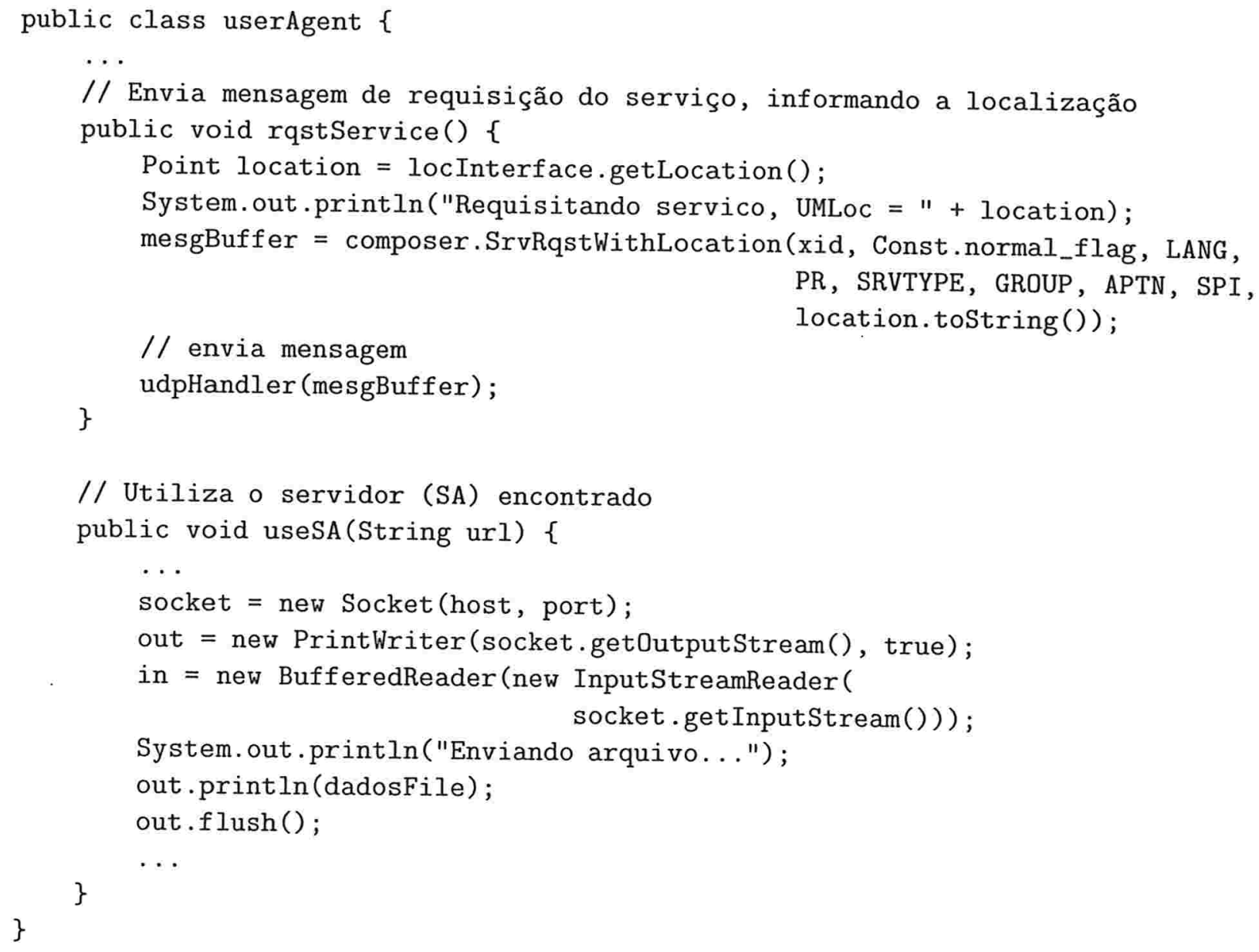

Código 6.2: Trecho de código da implementação do User Agent. 


\begin{tabular}{|r|l|}
\hline \multicolumn{1}{|l|}{ Classes } & Descrição \\
\hline \hline ime.slp.da & \\
\hline daAction & Implementação do directory agent \\
\hline Database & Classe responsável pela busca do serviço requisitado \\
\hline \hline ime.slp.sa & \\
\hline serviceAgent & Implementação do provedor do serviço \\
\hline serviceAgentAction & Define as ações do provedor de acordo com a mensagem recebida \\
\hline serviceAgentFindDa & Thread que localiza o DA da rede \\
\hline \hline ime.slp.ua & \\
\hline userAgent & Implementação do usuário do serviço \\
\hline userAgentAction & Define as ações do clientè de acordo com a mensagem recebida \\
\hline userAgentFindDa & Thread que localiza o DA da rede \\
\hline \hline ime.slp.util & \\
\hline Const & Define a constantes utilizadas no subsistema \\
\hline slpMsgParser & Recupera os campos de uma mensagem do SLP \\
\hline slpMsgComposer & Encapsula a criação de mensagens do SLP \\
\hline
\end{tabular}

Tabela 6.5: Principais classes do subsistema SLP.

Jini

O sistema em Jini foi feito conforme o exemplo apresentado na seção 3.2. Foi implementado o cliente, o provedor de serviço e o proxy, que se comunica com a implementação do serviço. A estrutura da aplicação foi organizada da seguinte forma:

\begin{tabular}{|l|l|}
\hline Pacote & Descrição \\
\hline \hline ime.jini.client & Implementação do cliente no Jini \\
\hline ime.jini.service & Implementação do provedor de serviço \\
\hline ime.jini.util & Classes comuns, utilizadas por todos os pacotes \\
\hline
\end{tabular}

Tabela 6.6: Divisão de pacotes no subsistema Jini.

Entretanto, para disponibilizar a nova funcionalidade de busca do servidor mais próximo de acordo com a localização do cliente, modificamos alguns procedimentos do Jini.

\section{Especificação}

Para que o sistema efetue a busca pelo servidor mais próximo ao cliente, é necessário que 
ele tenha conhecimento da localização do cliente. Assim, o cliente precisa informar ao LS a sua localização no momento da requisição do serviço.

Devido a isso, alteramos a especificação do Jini, criando uma nova classe denominada ServiceRegistrarWithLocation, que estende a classe ServiceRegistrar (que representa o Lookup Service no Jini), sobrecarregando o método lookup com um parâmetro adicional myLocation, que contém a localização do cliente. Assim, no momento em que o cliente requisitar o serviço (ver quadro 3.1), ele poderá fornecer a sua localização atual, através deste novo método.

\section{Service Provider}

Disponibilizamos o serviço de impressão no Jini, implementando o service provider, que localiza o LS da rede, publica e inicia seu serviço.

A publicação do serviço foi feita conforme o procedimento descrito na seção 3.2, com apenas uma modificação: o SP precisa informar a localização, geralmente fixa, da impressora. Para isto, foi criado um atributo de localização que descreve o serviço no Jini.

O atributo de localização foi implementado na classe AttrServiceLocation, que estende a classe AbstractEntry para que seja possível a sua inclusão no vetor de atributos que descrevem o serviço, representados no Jini pelo objeto Entry (veja o quadro 3.2 para um melhor entendimento). A classe contém um construtor que recebe a localização do servidor. Assim, o LS pode consultar o atributo de localização do servidor e decidir se o este está próximo ao cliente.

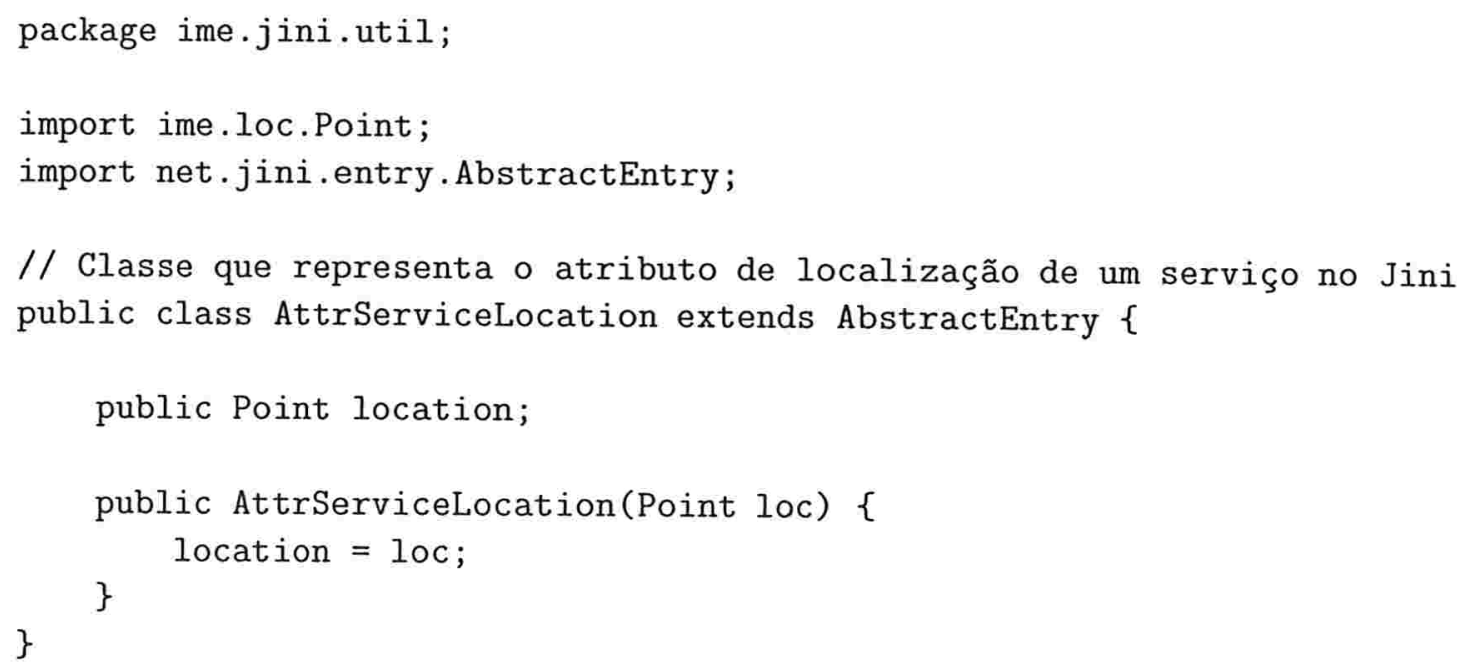

Código 6.3: Implementação da AttrServiceLocation. 
Além disso, conforme a especificação do Jini, é necessário definir a interface do serviço, representada pela classe ServiceInterface, que contém todos os métodos visíveis (públicos) ao cliente. No nosso caso, foram definidos dois métodos prints sobrecarregados, que são utilizados para impressão de um arquivo ou de um conjunto de caracteres especificado.

Em conjunto com a interface, foi criada a classe de proxy do serviço (ServiceProviderProxy) que implementa a interface. Nessa classe estão todos os parâmetros do servidor: endereço IP, porta, nome, etc., e o protocolo de comunicação com o servidor.

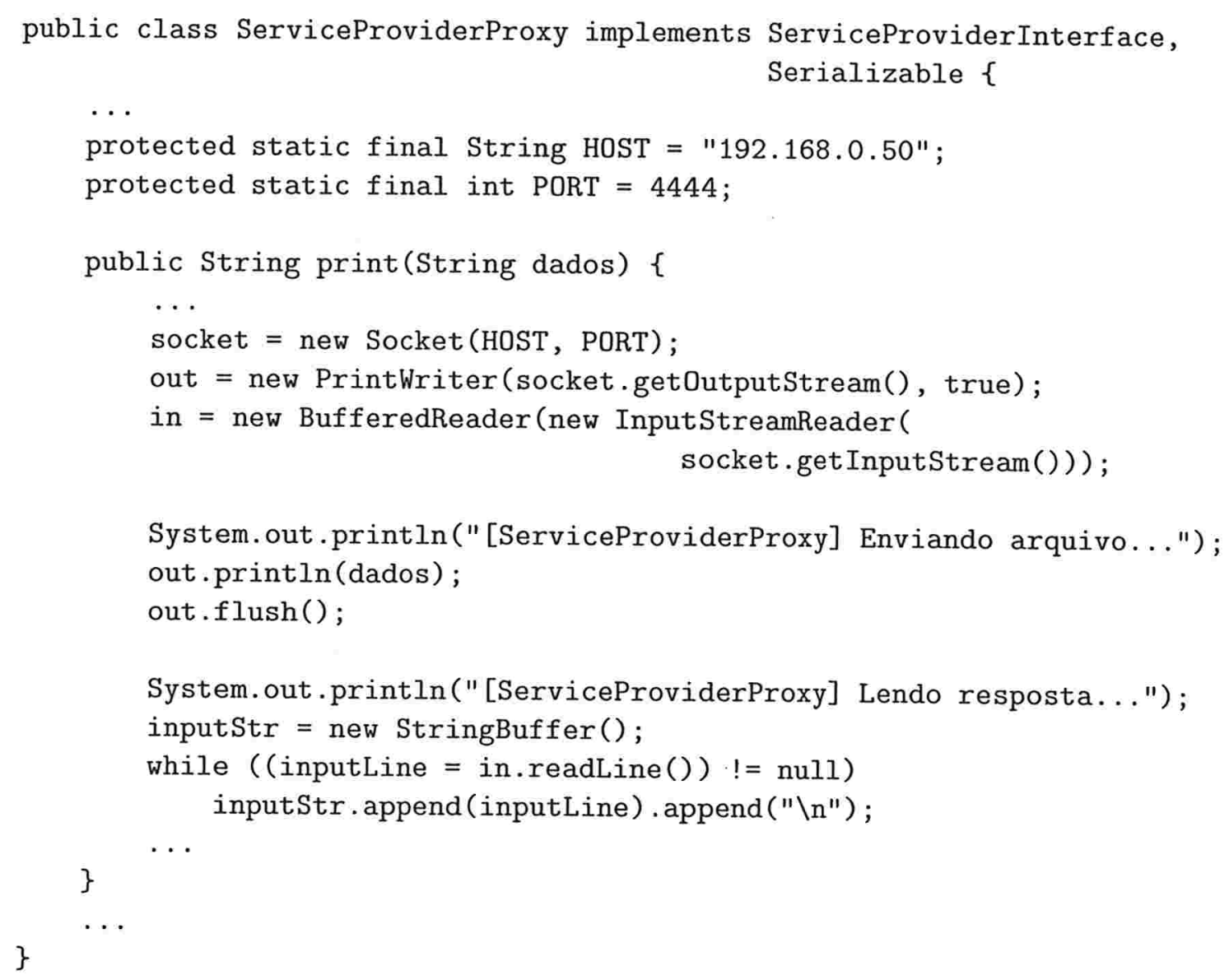

Código 6.4: Implementação do proxy do serviço.

Após a publicação da URL do serviço, o SP o inicia. De forma análoga ao sistema SLP, isto é feito através da instanciação da classe PrintService (ver seção 6.1.2) recebendo como parâmetro a porta e nome do serviço (definidos no ServiceProviderProxy). Depois disso, o servidor está pronto para receber requisições através do seu proxy. 


\section{Lookup Service}

O Lookup Service foi modificado para receber a localização do cliente e, de acordo com esta, encontrar o SP mais próximo a ele. Como foi dito anteriormente, estendemos a classe ServiceRegistrar (ver quadro 3.3) sobrecarregando o método lookup e acrescentando o parâmetro de localização do usuário.

Além disso, o método ficou responsável por encontrar o serviço mais próximo ao cliente, através da consulta do atributo de localização de cada servidor e, de acordo com a classe de semântica de proximidade, é retornado o objeto proxy do servidor escolhido.

\section{Client}

O cliente do serviço foi implementado de forma semelhante ao exemplo apresentado na seção 3.2. A única modificação necessária foi a alteração do objeto responsável pela procura do serviço. Ao invés do cliente instanciar a classe ServiceRegistrar, ele instancia a nova classe criada ServiceRegistrarWithLocation.

Em seguida, o método lookup é chamado informando a localização atual do cliente. O método devolve um objeto seriado ServiceProviderProxy, que é usado pelo cliente para utilizar efetivamente o serviço.

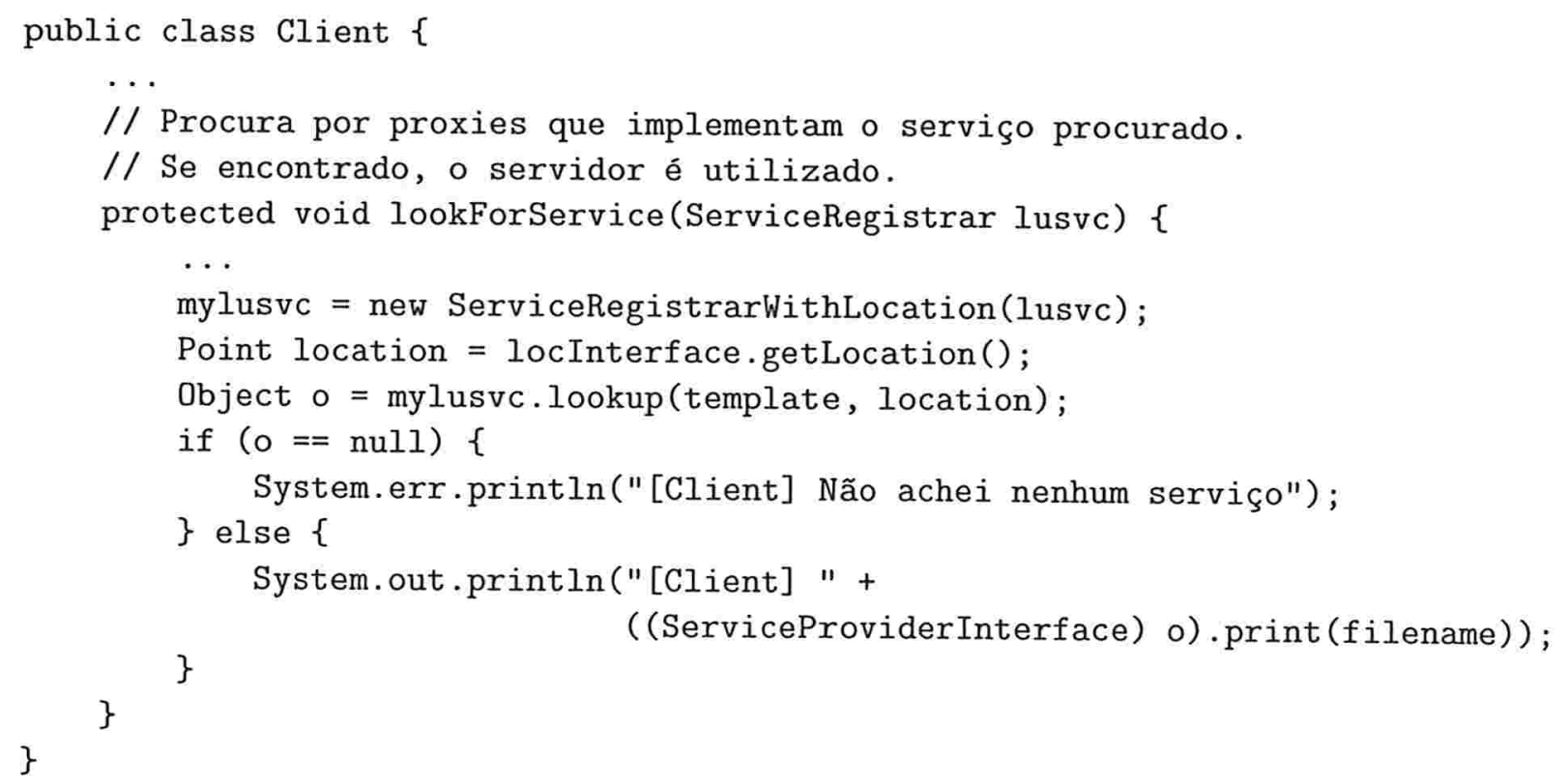

Código 6.5: Implementação do cliente no Jini. 


\begin{tabular}{|r|l|}
\hline \multicolumn{1}{|l|}{ Classes } & Descrição \\
\hline \hline ime.jini.client & \\
\hline ClientFindLS & Implementação do cliente no Jini \\
\hline ime.jini.service & Thread que localiza o LS da rede \\
\hline ServiceProvider & Implementação do provedor do serviço \\
\hline ServiceProviderFindLS & Thread que localiza o LS da rede \\
\hline ServiceProviderInterf́ace & Interface do serviço disponibilizado \\
\hline ServiceProviderProxy & Classe que representa o proxy do serviço no Jini \\
\hline \hline ime.jini.util & \\
\hline AttrServiceLocation & Representa o atributo de localização do serviço no Jini \\
\hline ServiceRegistrarWithLocation & Localiza o servidor mais próximo ao cliente \\
\hline
\end{tabular}

Tabela 6.7: Principais classes do subsistema Jini.

\subsubsection{Dispositivo Móvel}

Gostaríamos que a aplicação desenvolvida pudesse ser utilizada por usuários portando dispositivos móveis conectados a uma rede sem fio, aos quais chamamos de unidades móveis. Para isso, foi necessário fazer algumas adaptações na aplicação e desenvolver um cliente do sistema para pequenos dispositivos.

Inicialmente, definimos qual seria a arquitetura e linguagem de programação utilizada no desenvolvimento. Para manter a compatibilidade entre os módulos e aumentar o número de dispositivos compatíveis ao sistema, escolhemos a linguagem Java por sua alta portabilidade. Definimos ainda que o dispositivo móvel utilizado para testes seria um Palm m515 contendo uma placa sem fio (mais detalhes serão dados na seção de testes 6.3).

O aplicativo também deveria permitir que o usuário, utilizando uma interface gráfica, pudesse escolher os arquivos ou dados contidos no seu Palm a serem impressos, tais como catálogo de endereços, lista de tarefas, arquivos de documentos, etc.

\section{Tecnologia}

O protótipo começou a ser desenvolvido utilizando a arquitetura J2ME [27] da Sun Microsystems. Entretanto, no momento em que foi necessário implementar a recuperação dos dados da base nativa do Palm, tais como catálogo de endereços, lista de tarefas, etc., percebemos que isso 
não seria possível com a versão da API atual MIDP 1.0 [28], responsável por disponibilizar esse tipo de funcionalidade no J2ME.

O acesso ao banco de dados padrão do Palm só poderia ser feito na MIDP 2.0, que ainda está sendo desenvolvida, e por isso ainda não foi disponibilizada a máquina virtual (JVM) para Palm.

Sendo assim, foi feita uma pesquisa sobre outras soluções Java para PDAs, especialmente para o Palm. Dentre as tecnologias pesquisadas, escolhemos a arquitetura Waba [6], mais especificamente uma extensão da mesma, com algumas melhorias, chamada SuperWaba.

O principal motivo para a escolha foi a grande portabilidade do sistema, que contém máquinas virtuais portadas para muitos dispositivos móveis, até para GameBoy. Além disso, a API já contém algumas funcionalidades prontas para Palm e Ipaq, o que agilizou o desenvolvimento do sistema.

Uma das funcionalidades, específicas para o Palm, é o acesso transparente ao banco de dados nativo do PDA, o que possibilita a fácil recuperação dos dados do catálogo de endereços, lista de tarefas, etc. Por esses motivos escolhemos a arquitetura SuperWaba para desenvolver a versão móvel da nossa aplicação.

\section{Arquitetura}

Como foi dito anteriormente, o aplicativo não poderia dispor de muita capacidade de processamento e/ou memória devido às limitações de hardware do dispositivo móvel.

Assim, foi necessário realizar algumas adaptações no sistema. A principal delas foi retirar das UMs o trabalho de localização do gerenciador de serviços da rede e a subseqüente requisição do serviço, e criar um agente que ficasse responsável por esse trabalho. Esse novo agente seria executado em um computador fixo, com mais capacidade de processamento, e atuaria como um proxy das requisições das UMs. Assim, criamos um outro elemento no sistema chamado PrintClientProxy, que realiza a requisição do serviço desejado no SDS especificado.

O novo elemento é iniciado informando o sistema de localização de serviços que ele deve utilizar. Em seguida, o aplicativo abre um canal de comunicação em uma porta específica para esperar requisições. Quando ocorre alguma requisição, o cliente móvel envia os dados a serem impressos, e o proxy inicia uma instância do cliente no SDS correspondente: ime.slp.ua.userAgent 
ou ime.jini.client.Client, que realiza o trabalho de requisição e uso do serviço, conforme explicado nas seções anteriores.

Assim, a implementação da aplicação foi dividida nos seguintes pacotes:

\begin{tabular}{|l|l|}
\hline Pacote & Descrição \\
\hline \hline ime.palm & Classes responsáveis pela GUI da aplicação \\
\hline ime.palm.proxy & Implementação do proxy do SDS \\
\hline ime.palm.data & Permite a visualização dos dados do Palm \\
\hline
\end{tabular}

Tabela 6.8: Divisão de pacotes do cliente Palm.

\section{Acesso aos Dados}

Para disponibilizar ao usuário uma forma de escolha dos dados a serem impressos, definimos uma interface de dados que podem ser visualizados e impressos no aplicativo do Palm.

A interface Dados Interface define o esqueleto das classes que fornecem os dados de impressão à aplicação. Para adicionar um novo tipo de dados, basta criar uma classe que implemente esta interface. Atualmente temos as seguintes implementações: catálogo de endereços, arquivos e-doc, e-mails e lista de tarefas.

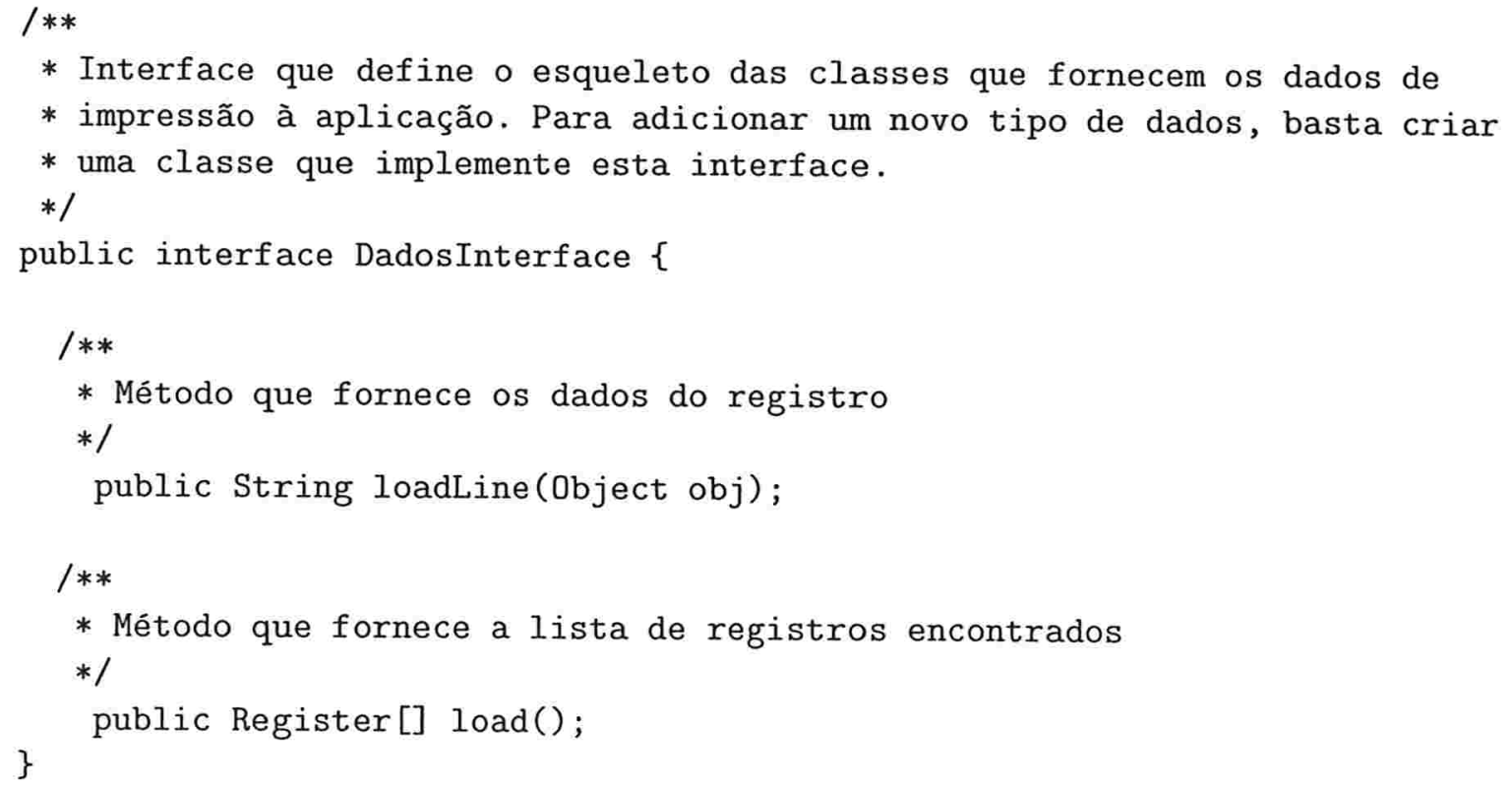

Código 6.6: Interface de dados do Palm. 


\begin{tabular}{|r|l|}
\hline \multicolumn{1}{|l|}{ Classes } & Descrição \\
\hline \hline ime.palm & \\
\hline RegintPalm & Classe principal do sistema \\
\hline ime.palm.proxy & Representa um registro de dados (ToDo, Email, etc) na GUI \\
\hline PrintClientProxy & Proxy do cliente no SDS \\
\hline PrintClientProxyThread & Thread que atende cada requisição feita ao proxy \\
\hline ProxySocket & Conexão ao proxy do sistema de localização de serviços \\
\hline \hline ime.palm.data & \\
\hline Dados Interface & Interface das classes que fornecem os dados de impressão \\
\hline AddressBook & Recupera os dados do catálogo de endereços \\
\hline FilesDoc & Visualização dos arquivos de tipo e-Doc do Palm \\
\hline MailList & Mostra e-mails da caixa de entrada \\
\hline ToDoList & Visualização da lista de tarefas \\
\hline
\end{tabular}

Tabela 6.9: Principais classes do cliente Palm.

\subsection{Exemplo de Uso}

No diagrama 6.2 está representada um exemplo de uso do protótipo, indicando as possíveis formas de inicialização do sistema, o processo desencadeado e as respectivas ações em cada módulo.

Inicialmente, temos as seguintes inicializações (representadas por um círculo preto):

- SDS: Neste módulo o Lookup Service ou Directory Agent são executados e esperam requisições de clientes ou servidores da rede. O Service Provider (ou SA) inicia o seu serviço, informando a porta e o nome do seu servidor ao módulo Print Service, que espera conexões na porta especificada. Em seguida, o SP registra o seu serviço no LS (ou DA) da rede, informando a sua localização física e a informação de acesso ao serviço (URL ou Service Proxy).

- Print Proxy: O módulo que representa o proxy do cliente móvel é iniciado informando o SDS a ser utilizado e a porta de espera das requisições.

- Cliente: O cliente do SDS pode ser iniciado manualmente ou através do Print Proxy, informando os dados a serem impressos a sua localização atual. 
- Cliente Palm: Este é o principal cliente do sistema e o ponto de início da simulação apresentada.

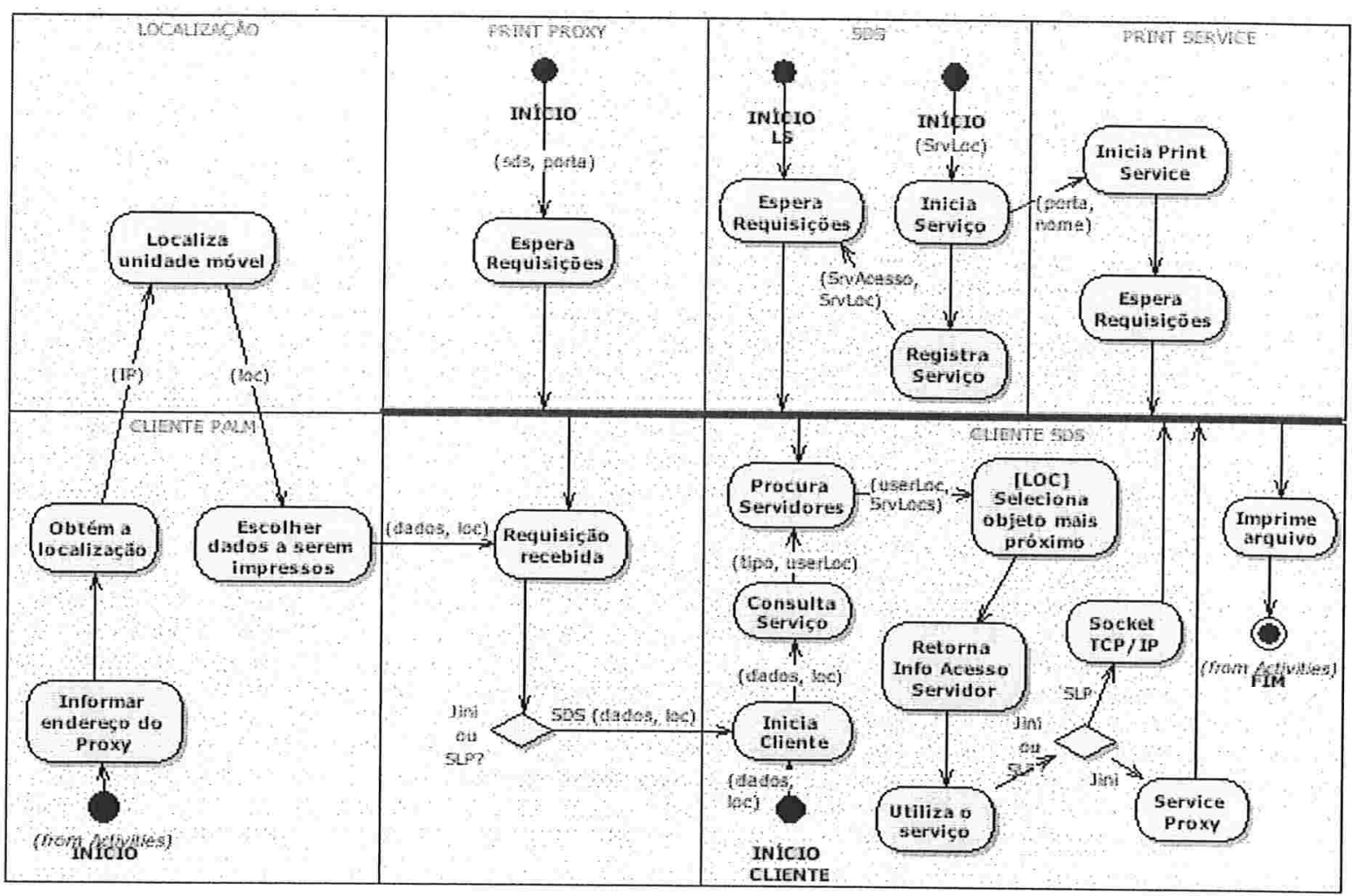

Figura 6.2: Diagrama de atividades do protótipo desenvolvido.

Realizadas as execuções descritas acima, o sistema está pronto para ser utilizando por um cliente. Vamos admitir que o cliente no nosso caso é a aplicação Palm para abrangermos o caso de uso mais geral.

O cliente móvel inicialmente fornece do endereço do Print Proxy que deseja utilizar e, em seguida, se comunica com o módulo de localização para obter (através do Ekahau) ou informar (manualmente) a sua localização.

Por último, o cliente escolhe através da GUI os dados a serem impressos e envia essas informações junto com a sua localização para o proxy especificado. O Print Proxy recebe a requisição e inicia o cliente do SDS (especificado durante a sua inicialização), repassando os dados recebidos.

O cliente do SDS, por sua vez, inicia o processo de consulta ao serviço de impressão se comunicando com o LS da rede, que recebe a requisição com a localização do usuário e procura dentre 
o seu repositório por serviços que atendam a mesma. Encontrados os servidores, o LS informa ao módulo de localização (LOC) um conjunto com as localizações dos servidores encontrados e a localização da UM, para que o mesmo decida qual é o servidor mais próximo ao cliente.

Escolhido o servidor, o LS retorna ao cliente a informação de acesso ao mesmo, que pode enfim utilizar o serviço, se comunicando com o Print Service através de um socket TCP/IP (SLP) ou do service proxy (Jini) e enviando os dados a serem impressos. O Print Service recebe a requisição e imprime os dados recebidos.

\subsection{Experimentos}

Nesta seção apresentamos o ambiente de desenvolvimento utilizado, descrevendo brevemente a forma de utilização do sistema e apresentando os resultados dos testes realizados no sistema. A implementação do protótipo pode ser encontrada em http://www.ime.usp.br/ lmap/prototipo/index.html.

\subsubsection{Ambiente de Desenvolvimento}

Um resumo do ambiente utilizado no desenvolvimento e testes é mostrado no quadro 6.10.

O desenvolvimento inicial do protótipo foi realizado em um PC com Linux, utilizando o emulador Palm OS Emulator v3.5 [24] para desenvolver o cliente Palm. O notebook foi utilizado nos testes com o módulo de localização, mais especificamente com o sistema Ekahau. Todos os elementos estão conectados através de uma rede local. O notebook e o palm utilizaram uma rede sem fio (padrão IEEE 802.11b) para se comunicarem com o servidor Linux. A estação (ERB) da rede sem fio e o servidor estavam conectados a uma mesma rede ethernet local.

\subsubsection{Utilização do Sistema}

Antes de apresentarmos os teste realizados, descrevemos brevemente a utilização dos módulos do sistema para um melhor entendimento do mesmo.

O sistema é composto por quatro módulos executados independentemente: 


\begin{tabular}{|l|l|}
\hline \multicolumn{1}{|c|}{ Módulo } & \multicolumn{1}{c|}{ Ambiente Utilizado } \\
\hline \hline \multicolumn{1}{|c|}{ Servidor } & \multicolumn{1}{c|}{} \\
\hline Sistema Operacional & Linux 2.4 Distribuição Debian 3.0 \\
\hline JDK & 1.3 .1 02 da Sun (build 1.3.1_02-b02, mixed mode) \\
\hline SLP & SLPv2 - RFC 2608 \\
\hline Jini & 1.1 - Sun Microsystems \\
\hline Placa de rede & 3Com 3c905C-TX \\
\hline Equipamento & Desktop Pentium III 800 Mhz, 512 Mb \\
\hline \multicolumn{1}{|c|}{ Cliente Móvel } & \\
\hline Sistema Operacional & Windows 2000 Professional \\
\hline JDK & 1.3.1_01 da Sun (build 1.3.1_01, mixed mode) \\
\hline Ekahau & 3.0 Positioning Engine \\
\hline Placa de rede & Orinoco - Lucent Silver compatível (sem fio) \\
\hline Equipamento & Notebook Pentium III 800 Mhz, 300 Mb \\
\hline \multicolumn{1}{|c|}{ Cliente Móvel } & \\
\hline Sistema Operacional & Palm OS v4.1 \\
\hline SuperWaba & 3.5 Vm \\
\hline Placa de rede & Xircom Wireless LAN for Palm \\
\hline Equipamento & Palm m515 - Motorola 33 Mhz, 16 Mb \\
\hline
\end{tabular}

Tabela 6.10: Ambiente de desenvolvimento.

\section{- Sistema de Localização de Serviços:}

Foram implementadas duas versões, uma utilizando o Jini e outra o SLP:

- SLP:

Para utilizar o SLP, é necessário iniciar os agentes DA, SA e UA:

* Directory Agent:

Uso: startDA

* Service Agent:

Uso: startSA $-D<$ name=value $>$

Propriedades disponíveis:

- name=<valor $>$ : Nome do servidor

- port=<valor $>$ : Porta do servidor

- location=<valor $\left.{ }^{1}\right\rangle$ : Localização física do servidor

\footnotetext{
${ }^{1}$ A localidade deve ser estar no formato de coordenadas: "( $x$ y $z$ )"
} 
* User Agent:

Uso: startUA $-\mathrm{D}\langle$ name=value $>$

Propriedades disponíveis:

- filename=<valor $\rangle \mid$ string=<valor $\rangle$ : Dados a serem impressos

- location=<valor | ekahau>: Sistema de localização de UMs utilizado

- Jini:

Para utilizar o Jini, é necessário iniciar os seguintes elementos:

* Lookup Service:

Uso: startLS <ip>: IP local

* Service Provider:

Uso: startSP <ip $>-D<$ name=value $>$

Propriedades disponíveis:

- location=<valor >: Localização física do servidor

* Client:

Uso: startClient $-\mathrm{D}\langle$ name=value $>$

Propriedades disponíveis:

- filename=<valor $\rangle \mid$ string=<valor $\rangle$ : Dados a serem impressos

- location=<valor | ekahau>: Sistema de localização de UMs utilizado

Além disso, é necessário iniciar o RMI Activation Daemon, para que seja possível a comunicação entre o LS e os outros elementos via RMI, e um servidor HTTP para cada SP, para que o cliente consiga fazer download do respectivo service proxy. Isso pode ser feito através dos scripts: startRMID, startLSHTTP e startSPHTTP.

\section{- Cliente Palm:}

Para utilizar o cliente móvel para Palm, é necessário iniciar o Print Client Proxy:

- Print Client Proxy:

Uso: startPrintClientProxy $-D<$ name=value $>$

Propriedades disponíveis:

- sds=slp|jini: SDS a ser utilizado

- port=<valor $>$ : Porta do proxy 
O módulo do sistema desenvolvido para o Palm pode ser executado em dois emuladores contidos no pacote do sistema ou no próprio dispositivo. Para utilizar o cliente no próprio Palm, é necessário instalar os aplicativos (.prc) e os arquivos de dados (.pdb) do diretório bin/palm/SuperWaba. Em seguida instale os arquivos da aplicação: PrintPalm.pdb e PrintPalm.prc.

Para utilizar o emulador Waba Applet Emulator ou Palm OS Emulator, basta executar o script execAppletEmu ou execPalmEmu, respectivamente.

\subsubsection{Experimentos Realizados}

Para validar o funcionamento do protótipo desenvolvido, realizamos inicialmente experimentos com o módulo de localização de serviços, em que o cliente fornecia manualmente a sua localização atual e posteriormente, foram efetuados experimentos com o sistema de localização de unidades móveis (Ekahau).

\section{Localização de Serviços}

Para testar os módulos do SDS foi implementado um servidor de impressão e o respectivo cliente em cada arquitetura, como descrito na subseção 6.1.4. Inicializamos alguns servidores com diferentes localizações físicas e realizamos simulações de clientes, em diferentes locais, requisitando o serviço de impressão, para verificar se o sistema escolheria o servidor mais próximo ao cliente.

Além do teste da escolha do servidor, foram realizados testes no módulo de impressão (PrintService) para assegurar que o arquivo estava sendo impresso corretamente. Outro teste interessante foi feito utilizando um Palm m515, conectado à rede sem fio através de uma placa Xircom Wireless LAN [13] e acessando o SDS através do PrintClientProxy, conforme explicado na subseção 6.1.5.

Os testes realizados tiveram sucesso, validando o módulo de localização de serviços. 


\section{Localização de UMs}

Para efetuar os testes de localização de unidades móveis, o Ekahau foi instalado em um notebook com Windows 2000 Professional e acoplado a uma placa de sem fio Lucent Silver PCMCIA.

Em seguida, seguimos o procedimento descrito na seção 5.5. Primeiramente foi realizada a calibragem inicial do sistema, utilizando um mapa representando o ambiente a ser rastreado.

Utilizando o aplicativo Ekahau Calibrator cadastramos os pontos de amostra a cada 10 metros em média. Em cada ponto de amostra coletado foi necessário girar lentamente o dispositivo (notebook) $360^{\circ} \mathrm{em}$ torno do seu eixo, para que o Ekahau possa inferir a direção da movimentação da UM. Os pontos de amostras coletados podem ser visualizados na figura 6.3. A linha entre os pontos de amostra é o caminho percorrido na coleta dos pontos.

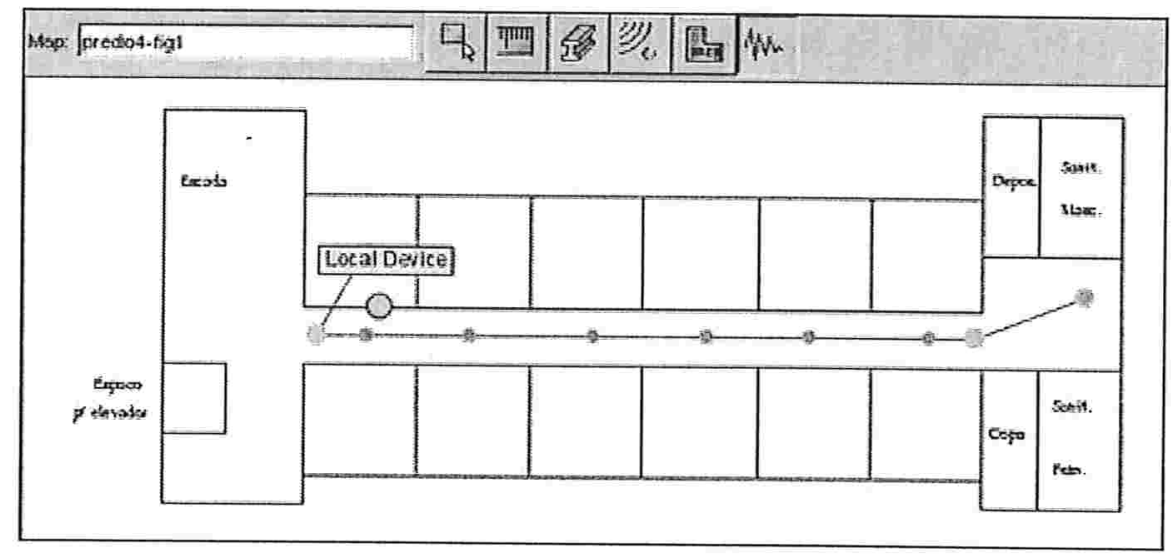

Figura 6.3: Coleta de pontos de amostra no Ekahau.

Feito isso, foi possível verificar a localização do próprio notebook no mapa, através do aplicativo Ekahau Manager, como mostra a figura 6.4, e através da API fornecida pelo sistema. O aplicativo mostra ainda a intensidade de sinal na área coberta. Verificamos que o resultado está correto pois quanto mais longe a unidade móvel está da antena mais fraca (mais escura) é a intensidade do sinal.

Outro teste interessante realizado foi a criação de áreas lógicas no mapa, a fim de verificar o seu funcionamento. Delimitamos no mapa 3 áreas: sala do Goldman, do Kon e corredor (região entre as salas). Através da API disponibilizada, conseguimos saber qual a área lógica em que é 
mais provável que a UM esteja.

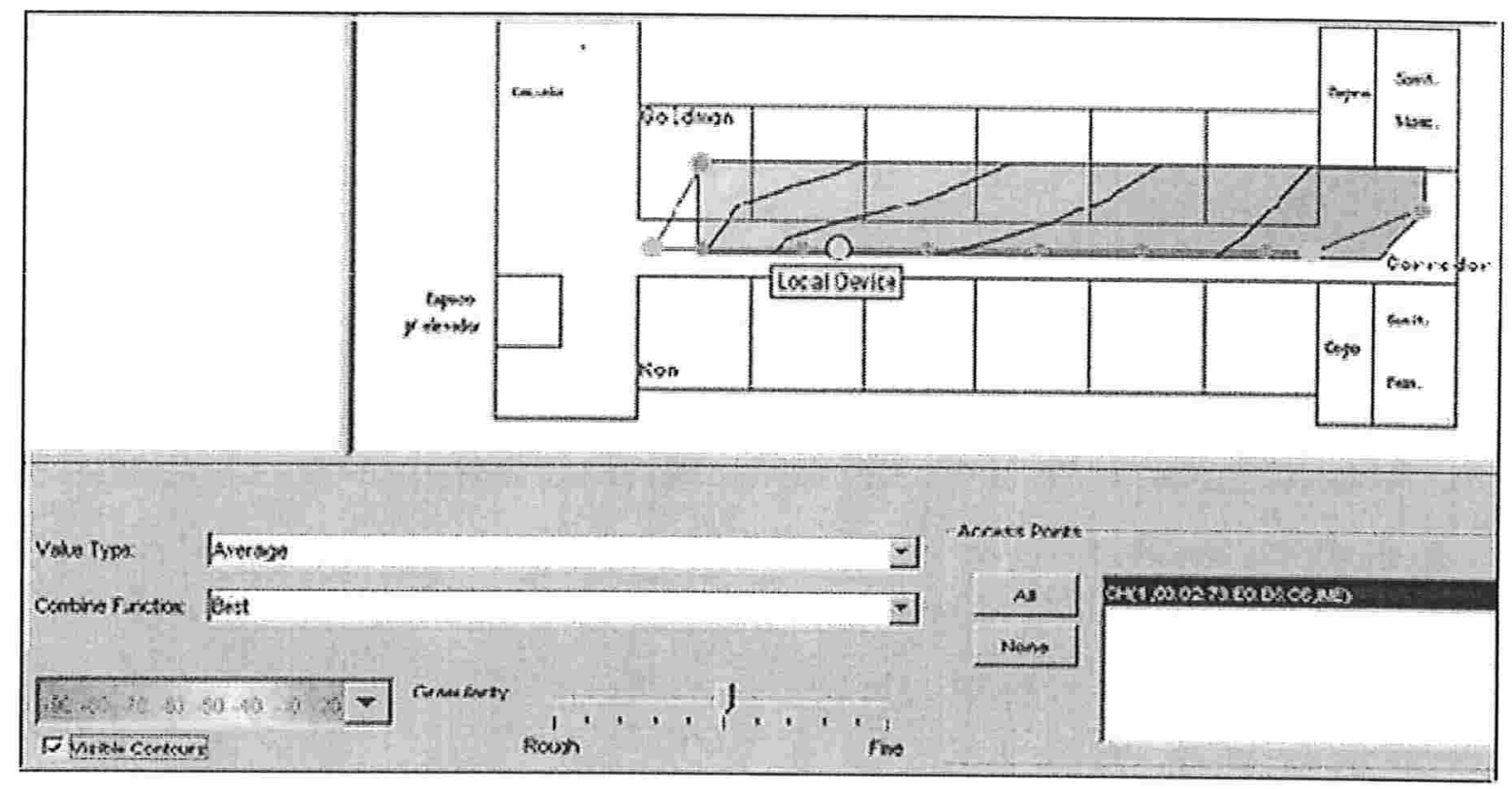

Figura 6.4: Localizando uma unidade móvel no Ekahau. 


\section{Capítulo 7}

\section{Considerações Finais}

O número de redes sem fio está crescendo rapidamente. Isso pode ser notado em aeroportos, hotéis ou prédios comerciais em que a sua utilização é cada vez mais comum. Com isso, surgem alguns problemas, como a localização e acesso aos serviços nessas redes. No capítulo 1 descrevemos, com algum detalhe, os problemas e possibilidades que a mobilidades dos elementos deste tipo de rede nos oferece. Mais especificamente, abordamos o problema de localizar e acessar o serviço de impressão mais próximo a uma unidade móvel. Como acessar o serviço? Como obter a localização da UM?

Para resolver o problema de localização e acesso ao serviço, descrevemos nos capítulos 2, 3 e 4, os sistemas de descoberta de serviço que provêem aos usuários móveis os serviços da rede sem qualquer intervenção administrativa, permitindo um acesso rápido e transparente aos recursos. Esses sistemas serão muito importantes nos futuros ambientes de rede, como em redes ad hoc [3] e redes sem fio, que demandam uma reorganização automática devido à grande mobilidade dos seus elementos.

Nesses tipos de ambientes, em que os usuários são móveis, é muito importante que as aplicações sejam construídas levando-se em consideração a localização, de forma que ela se adapte ao local em que a unidade móvel se encontra, comportando-se de maneira diferenciada de acordo com a posição do usuário. Mas, para isso, é necessário obter a informação de localização das UMs. No capítulo 5 descrevemos os principais sistemas de localização existentes, suas características, funcionamento e realizamos um breve comparação entre eles. Além disso, é descrito com mais detalhes o Ekahau Positioning Engine, sistema utilizado no protótipo desenvolvido. 
No capítulo 6, apresentamos uma solução para adaptar os SDSs ao ambiente de computação móvel, integrando-os aos sistemas de localização de UMs. A solução foi implementada utilizando dois SDSs distintos: SLP e Jini. O SLP é um protocolo simples, independente de sistema operacional, baseado em troca de mensagens texto, não contempla a forma de acesso ao serviço e demanda poucos recursos dos dispositivos. É indicado para a implementação de serviços simples. O Jini, por sua vez, é um sistema mais completo e flexível, devido a técnica de mobilidade de código utilizada ele permite ao cliente acesso transparente ao serviço. Entretanto, por ser um sistema mais sofisticado, ele demanda mais recursos, o tráfego de rede gerado em suas operações é cerca de 10 vezes maior que o gerado pelo SLP, como mostra o artigo [15].

A principal contribuição desse trabalho é a apresentação de uma solução para integrar os SDSs com sistemas de localização de UMs, transformando-os assim, em sistemas sensíveis à localização, que reagem de forma diferente conforme a localização da unidade móvel. Além disso, foi implementado um protótipo para validar esta solução, utilizando como exemplo o serviço de impressão, entretanto a solução se adequa a qualquer tipo de serviço. Acreditamos que isso incentivará e facilitará a criação de serviços sensíveis à localização, como o de impressão, ou o de um guia turístico virtual, entre outros.

A solução pode ser utilizada ainda em estabelecimentos públicos ou comerciais, que contenham uma rede sem fio, como museus, supermercados, aeroportos ou shoppings, onde, em alguns casos, já existem sistemas específicos [18]. Utilizando a arquitetura apresentada, poderia ser disponibilizado um sistema de fornecimento de serviços, tais como: serviço de informações sobre produtos (ou quadros) vendidos (ou apresentados) que estão próximos ao usuário, serviço de impressão, de rota ao produto procurado mais próximo, compra ou reserva online na loja mais próxima que vende o produto desejado, entre outros.

\subsection{Trabalho Futuro}

Apesar do protótipo ter atingido o seu objetivo inicial, ou seja, resolver o problema proposto, identificamos alguns ítens que podiam ser melhorados e novas funcionalidades que poderiam ser implementadas.

- Implementar novas semânticas de proximidade. Seria interessante desenvolver outras semânticas de proximidade, que considerem outros fatores para o critério de escolha 
do servidor mais próximo ao cliente. Um fator interessante, por exemplo, seria analisar a velocidade e a direção da movimentação da UM. Se a mesma estivesse se movimentando rapidamente, se afastando do servidor A (mais próximo a ela no momento da requisição) e se aproximando do servidor B, seria interessante se o SDS analisasse o arquivo a ser impresso, e se o mesmo fosse grande, ou seja, demorasse a ser impresso, ele escolhesse o servidor B para ser utilizado pela UM.

- Portar cliente móvel para outras plataformas. O cliente móvel foi desenvolvido para Palm utilizando a arquitetura Waba, cuja JVM (java virtual machine) foi portada para vários dispositivos. Esse foi o principal motivo para a sua utilização, entretanto são necessárias algumas alterações no módulo de escolha dos dados a serem impressos para cada plataforma.

- Serviços Restritos. Atualmente os serviços do SLP e do Jini não contemplam uma forma flexível de restrição ao acesso de determinado serviço. Poderia ser implementado um sistema de pagamento pelo serviço, em que o usuário precisasse pagar ou fazer uma assinatura para ter acesso ao serviço. Outra utilidade seria o pagamento do serviço conforme o seu uso, que poderia ser utilizado em serviços de busca. Por exemplo, uma pessoa em um shopping portando um dispositivo móvel, poderia procurar a loja mais próxima que vende determinado produto e pagaria por cada busca efetuada.

- Pontes entre os SDSs. O protótipo foi feito utilizando dois sistemas distintos de localização de serviços. Assim, poderia ser desenvolvido um agente intermediário, que atuasse como uma ponte (brigde) [29] entre os elementos do Jini e do SLP, permitindo que clientes SLP possam ter acesso aos servidores Jini e clientes Jini possam acessar servidores SLP. Com isso, teríamos uma integração transparente entre os elementos dos SDSs e uma base única dos serviços da rede. 


\section{Glossário}

API Application Programming Interface. Um conjunto de funções e sub-rotinas que auxiliam o desenvolvimento de um programa.

DA Directory Agent. Repositório de serviços do SLP.

DHCP Dynamic Host Configuration Protocol. Protocolo de organização e simplificação da administração de endereços IP de máquinas locais. Fornece dinamicamente um endereço IP a um novo elemento conectada a rede.

DNS Domain Name System. Método de nomeação para o endereçamento IP, converte o nome de um computador em uma rede IP no seu respectivo endereço IP e vice-versa.

ERB Estação Rádio Base. Estação de recepção e transmissão de sinais para uma rede sem fio, como a rede da telefonia celular.

GENA General Event Notification Architecture. Mecanismo de notificação de eventos, em que o cliente pode se registrar para receber eventos de um determinado elemento do sistema.

GPS Global Positioning System. Sistema de localização para ambientes externos, utiliza comunicação via rádio com cerca de 24 satélites para inferir a localização do dispositivo receptor.

HTTP Hypertext Transfer Protocol. Protocolo de comunicação de dados que possibilita a transferência de documentos na Web.

IANA Internet Assigned Number Authority. Mantido pelo Instituto de Ciências e Informação da Universidade do Sul da Califórnia, controla a distribuição de identicadores para serviços a serem fornecidos via Internet. 
IEEE Institute of Electrical and Eletronics Engineers. Entidade americana que cuida de padrões técnicos principalmente na área de redes.

IETF Internet Engineering Task Force. Comunidade internacional aberta de fabricantes, projetistas de rede, operadores e pesquisadores que desenvolve e monitora os padrões das redes de computadores, sua arquitetura e operação.

IP Internet Protocol. Padrão de endereçamento dos blocos de dados enviados através de uma rede de computadores, como a Internet.

LAN Local Area Network. Uma rede local onde os computadores são conectados a uma distância próxima, como um escritório de uma empresa.

LMP Link Manager Protocol. Responsável pela conexão física entre os dispositivos de uma rede Bluetooth

LS Lookup Service. Repositório de serviços do Jini.

PAN Personal Area Network. Rede pessoal sem fio com dimensão reduzida. Seu alcance limita-se a algumas dezenas de metros. Sua velocidade é relativamente baixa, na casa de 1 Mbps.

PDA Personal Digital Assistant. Dispositivo eletrônico móvel, cuja finalidade é servir como um assistente pessoal digital pessoal, tais como Palm, Ipaq, etc.

RFC Request for Comments. Documentos que especificam os principais protocolos utilizados nas redes de computadores.

RMI Remote Method Invocation. Tecnologia para programação distribuída que permite a um objeto rodando em uma máquina virtual Java invocar métodos em um objeto rodando em outra máquina virtual Java.

RSSI Recevied Signal Strength Signal. Indicação do nível de sinal recebido pelo dispositivo móvel.

SA Service Agent. Elemento que disponibiliza um serviço ao repositório de serviços do SLP. 
SDP Service Discovery Protocol. Protocolo para localização de serviços em redes Bluetooth. Seu desenvolvimento foi financiado por um consórcio de grandes empresas de telecomunicações.

SDS Sistemas de descoberta de serviços. Sistemas que provêem a localização dinâmica dos serviços disponíveis em uma rede. Alguns sistemas também oferecerem mecanismos para acesso transparente aos serviços mesmos.

SLM Salutation Manager. Elemento principal do SDS Salutation. É responsável por todas operações do sistema, inclusive intermediar o acesso do cliente ao serviço.

SLP Service Location Protocol. Sistema de localização de serviços desenvolvido pelo IETF para redes locais TCP/IP. O protocolo permite a busca e o registro de serviços, porém a forma de acesso aos mesmos não é contemplada.

SM Service Manager. Gerenciador dos serviços de uma rede.

SOAP Simple Object Access Protocol. Protocolo baseado em XML para troca de informação em um ambiente distribuído e descentralizado. Produz um envelope que define um framework para descrever qual é a mensagem e como processá-la, regras de decodificação para mostrar tipos de dados definidos pela aplicação, e uma convenção para representar RPC (Remote Procedure Call) e as respostas.

SP Service Provider. Elemento que disponibiliza um serviço ao repositório de serviços do Jini.

SSDP Simple Service Discovery Protocol. Protocolo de publicação e consulta dos serviços de uma rede.

TCP/IP O TCP é um protocolo de transmissão de dados em uma rede. Empacota os dados para a transmissão e remonta os dados recebidos. Normalmente, aparece associado ao IP.

UDP User Datagram Protocol. Um protocolo de transmissão de dados não confiável que não necessita de conexão entre o cliente e o destinatário da mensagem.

UM Unidade móvel. Usuário portando um dispositivo móvel, tais como Palm, Ipaq, etc., conectado a uma rede sem fio. 
UPNP Universal Plug and Play. Conjunto de protocolos para descoberta de serviços, desenvolvido por um consórcio de empresas liderado pela Microsoft.

URL Universal Resource Locator. Padrão que permite identificar e acessar um servidor na Internet.

UUID Universal Unique Identifier. Identificador único de um elemento em um sistema.

WAN Wide Area Network. Uma rede de comunicações com área ampla, ligando vários prédios de escritórios, por exemplo.

XML Extensible Markup Language. Meta-linguagem utilizada na definição de linguagens para estruturação de documentos. 


\section{Bibliografia}

[1] Infrared Data Association. Infrared Data Association Serial Infrared Physical Layer Specification. Technical report, Infrared Data Association, 2001. URL: <http://www.irda. org/standards/specifications . asp>.

[2] P. Bahl and V. N. Padmanabhan. Radar: An In-Bulding RF-based User Location and Tracking System. Microsoft Research, March 2000. URL: <http://research.microsoft.com/ ${ }^{\sim}$ bahl/MS_Projects/projects.html>.

[3] M. Barbeau. Service Discovery Protocols for Ad Hoc Networking. Carleton University Press, November 2000.

[4] M. Barbeau. Mobile, Distributed, and Pervasive computing. Carleton University Press, 2001.

[5] E. Guttman C. Perkins and J. Kempf. Service Templates and Service: Schemes. IETF Internet Engineering Task Force RFC 2165, June 1999.

[6] C. Catanzaro. An Introduction to Superwaba. Virginia Tech, March 2002. URL: <http://csgrad.cs.vt.edu/ccatanza/superWaba.html> - Últ. Acesso: 07/2003.

[7] A. Cervera. Developing Location Based Applications. Technical report, University of Copenhagen, 2003. URL: 〈http://positionserver.it-c.dk:8000>.

[8] Microsoft Corporation. Universal Plug and Play Device Architecture. Technical report, Microsoft Corporation, 2000. URL: <http://www .upnpa .org/resources/documents . asp> - Últ. Acesso: 04/2003. 
[9] Microsoft Corporation. Plug and Play Technology. Technical report, Microsoft Corporation, 2003. URL: <http://www.microsoft.com/whdc/hwdev/tech/PnP/default.mspx> - Últ. Acesso: $11 / 2003$.

[10] G. Kakivaya D. Box, D. Ehnebuske and D. Winer. Simple Object Access Protocol. W3C Note, May 2000.

[11] R. Droms. RFC 2131 - Dynamic Host Configuration Protocol. Bucknell University, March 1997.

[12] RFC Editor. The Request for Comments. Technical report, RFC Editor, 2002. URL: <http://www.rfc-editor.org> - Últ. Acesso: 04/2003.

[13] D. Gewirtz. Another Look at Xircom 802.11b Wireless LAN Module. Palm Power Magazine, pages 18-21, September 2001.

[14] Y. Y. Goland. Multicast and Unicast UDP HTTP Messages. Internet Engineering Task Force Draft, June 1999.

[15] J. Govea and M. Barbeau. Comparison of Bandwidth Usage: Service Location Protocol and Jini. Carleton University Press, 2000.

[16] D. Green. Trail: The Reflection API. Technical report, Sun Microsystems Inc., 2003. URL: <http://java.sun.com/docs/books/tutorial/reflect/> - Últ. Acesso: 05/2003.

[17] E. Guttman. Service Location Protocol: Automatic Discovery of IP Network Services. IEEE Internet Computing, August:71-80, 1999.

[18] Forbes Hawkins. Museum Victoria Collection Inventuary System. Technical report, Museum Victoria, Australia, March 2003.

[19] J. Hightower and G. Borriello. Location Sensing to Techniques. Technical report, University of Washignton, August 2001.

[20] J. Hightower and G. Borriello. Location Systems for Ubiquitous Computing. IEEE Computer, August:57-66, 2001.

[21] G. Richard III. Service Advertisement and Discovery: Enabling Universal Device Cooperation. IEEE Internet Computing, September/October:18-26, 2000. 
[22] Caldera Systems Inc. An Introduction to SLP. Whitepaper Caldera Systems, Inc., 2001. URL: 〈http://www. calderasystems. com> - Últ. Acesso: 05/2003.

[23] Ekahau Inc. Ekahau Positioning Engine. Technical report, Ekahau Inc., 2002. URL: <http://www. ekahau.com> - Últ. Acesso: 07/2003.

[24] Palm Inc. Palm Os Emulator Tutorial. Technical report, Palm Inc., 2002. URL: <http://www.palmos.com/dev/tools/emulator> - Últ. Acesso: 05/2003.

[25] Sun Microsystems Inc. Jini Architectural Overview. Technical report, Sun Microsystems Inc., 2001. URL: <http://www.sun.com/jini/> - Últ. Acesso: 06/2003.

[26] Sun Microsystems Inc. Jini Network Technology. Technical report, Sun Microsystems Inc., 2001. URL: 〈http://www.sun.com/jini> - Últ. Acesso: 06/2003.

[27] Sun Microsystems Inc. Java 2 Platform, Micro Edition. Technical report, Sun Microsystems Inc., 2003. URL: <http://java.sun.com/j2me/> - Últ. Acesso: 05/2003.

[28] Sun Microsystems Inc. Mobile Information Device Profile. Technical report, Sun Microsystems Inc., 2003. URL: <http://java.sun.com/products/midp/> - Últ. Acesso: 05/2003.

[29] S. Gundala J. Allard, V. Chinta and G. G. Richard III. Jini Meets UPnP: An Architecture for Jini/UPnP Interoperability. University of New Orleans, October 2000.

[30] S. Aggarwal J. Cohen and Y. Y. Goland. General Event Notification Architecture. IETF Internet Draft, September 2000.

[31] E. Guttman J. Veizades, C. Perkins and S. Kaplan. Service Location Protocol. IETF Internet Engineering Task Force RFC 2615, June 1997.

[32] D. L. Lough, T. K. Blankenship, and K. J. Krizman. A Short Tutorial on Wireless LANs and IEEE 802.11. Virginia University, June 2000.

[33] A. Loureiro and G. Mateus. Introdução à Computação Móvel. Universidade Federal de Minas Gerais - UFMG, 2000.

[34] S. Hodges M. Addlesee, R. Curwen and A. Hopper. Implementing a Sentient Computing System. IEEE Computer, August:50-56, 2001. 
[35] D. McCormack M. Barbeau, E. Hughes and F. Bordeleau. Service Recommendation using SLP. IEEE International Conference on Telecommunications (ICT), April 2001.

[36] R. E. McGrath. Discovery Protocols for Ubiquitous Computing. University of Illinois Press, April 2000.

[37] V. N. Padmanabhan P. Bahl and A. Balachandran. Enhancements to the Radar User Location and Tracking System. Technical report, Microsoft Research Technical Report, February 2000. URL: 〈http://research.microsoft.com/〜bahl/publications.aspx> Últ. Acesso: 08/2003.

[38] B. Pascoe. Salutation Lite Find and Bind Technologies for Mobile Devices. Salutation White Paper, June 1999.

[39] C. Perkins and E. Guttman. DHCP Options for Service Location Protocol. IETF - Internet Engineering Task Force RFC 2610, June 1999.

[40] C. Perkins and E. Guttman. Service Location Protocol, Version 2. IETF - Internet Engineering Task Force RFC 2608, June 1999.

[41] C. E. Perkins. Service Location Protocol for Mobile Users. Technical report, Sun Microsystems Inc. Press, 2000.

[42] L. M. A. Pinho and A. Goldman. Sistemas de Localização Dinâmica de Serviços em Ambientes de Computação Móvel. WCSF2003 - V Workshop de Computação sem Fio e Computação Móvel, October 2003. URL: <http://www. inatel.br/wcsf/> - Últ. Acesso: $11 / 2003$.

[43] Microsoft Research. Systems and Networking Projects. Microsoft Corporation, 2003. URL: 〈http://research.microsoft.com/sn/\#projects> - Últ. Acesso: 07/2003.

[44] C. Schwingenschlögl and A. Heigl. Development of a Service Discovery Architecture for the Bluetooh Radio System. University of Munich Press, 2000.

[45] J. Waldo. The Jini Architecture for Network-centric Computing. Communications of the ACM, 42(7):76-82, 1999.

[46] J. Waldo. Alive and Well: Jini Technology Today. IEEE Computer, June:107-111, 2000. 
[47] R. Want and B. Schilit. Expanding the Horizons of Location-Aware Computing. IEEE Computer, August:31-34, 2001.

[48] W. Liao Y. Tseng, S. Wu and C. ChaoY. Location Awareness in Ad Hoc Wireless Mobile Networks. IEEE Computer, June:46-52, 2001.

[49] W. Zhao and H. Schulzrinne. Service Location Protocol. Technical report, University of Columbia, September 2000. 